\section{Pacific Northwest}

National Laboratory

Operated by Battelle for the

U.S. Department of Energy

\title{
An Evaluation of DOE-EM Public Participation Programs
}

\author{
J. A. Bradbury \\ K. M. Branch \\ E. L. Malone
}

February 2003

Prepared for the U.S. Department of Energy under Contract DE-AC06-76RL01830 


\title{
STANDARD DISCLAIMER
}

This report was prepared as an account of work sponsored by an agency of the United States Government. Neither the United States Government nor any agency thereof, nor Battelle Memorial Institute, nor any of their employees, makes any warranty, express or implied, or assumes any le gal liability or responsibility for the accuracy, completeness, or usefulness of any information, apparatus, product, or process disclosed, or represents that its use would not infringe privately owned rights. Reference herein to any specific commercial product, process, or service by trade name, trademark, manufacturer, or otherwise does not necessarily constitute or imply its endorsement, recommendation, or favoring by the United States Government or any agency thereof, or Battelle Memorial Institute. The views and opinions of authors expressed herein do not necessarily state or reflect those of the United States Government or any agency thereof.

\author{
PACIFIC NORTHWEST NATIONAL LABORATORY \\ operated by \\ BATTELLE \\ for the \\ UNITED STATES DEPARTMENT OF ENERGY \\ under Contract DE-AC06-76RLO 1830
}


PNNL-14200

\section{An Evaluation of DOE-EM Public Participation Programs}

Judith A. Bradbury

Kristi M. Branch

Elizabeth L. Malone

Pacific Northwest National Laboratory

February 2003 
This report evaluates the scope and effectiveness of the public participation programs, including Site-Specific Advisory Boards (SSABs), at seven U.S. Department of Energy (DOE) sites: Fernald, Hanford, Los Alamos, Nevada, Oak Ridge, Paducah, and Savannah River. The primary purpose of the study is to assist both DOE Field and Headquarters managers in reviewing and understanding lessons learned over the past decade concerning public participation programs administered by the DOE Office of Environmental Management (EM).

The evaluation provides a snapshot of selected EM public participation programs at a particular point in time. It is based on interviews and site visits conducted between January and June 2002 - a time of change within the program. The study focuses on public participation programs that incorporate a variety of activities and address a wide range of individual site activities and decisions. It uses the Acceptability Diamond as an evaluative framework to answer questions about stakeholders' experiences with, and assessment of, DOE-EM's public participation programs. The Acceptability Diamond, which was developed by researchers from the Pacific Northwest National Laboratory in previous research, identifies four dimensions - substantive issues, decision-making process, relationships, and accountability - that determine the effectiveness of an agency's interactions with a local community. Essentially, a public participation program may be deemed effective to the extent that it provides for open disclosure and addresses all four acceptability dimensions in ways that are appropriate and effective for a particular community and situation. This framework provides a guide for agencies to (1) set objectives, (2) design public participation and oversight programs, and (3) set criteria for evaluating program effectiveness. In the current study, where the framework is used to assess program effectiveness, the focus is on stakeholders' perspectives of public participation: on the nature of DOE-EM's public disclosure and the four interrelated dimensions of DOE-EM's interactions with its neighboring communities. 


\section{EXECUTIVE SUMMARY}

This report evaluates the scope and effectiveness of the public participation programs, including Site-Specific Advisory Boards (SSABs), at seven U.S. Department of Energy (DOE) sites: Fernald, Hanford, Los Alamos, Nevada, Oak Ridge, Paducah, and Savannah River. The primary purpose of the study is to assist both DOE Field and Headquarters managers in reviewing and understanding lessons learned over the past decade concerning public participation programs administered by the DOE Office of Environmental Management (EM). Researchers from the Pacific Northwest National Laboratory (PNNL) prepared this report, which was reviewed by the EM Office of Intergovernmental and Public Accountability and the public participation coordinators at each of the sites.

\section{Approach}

The evaluation provides a snapshot of selected EM public participation programs at a particular point in time. It is based on interviews and site visits conducted between January and June 2002 - a time of change within the program. The study focuses on public participation programs that incorporate a variety of activities and address a wide range of individual site activities and decisions. It used the Acceptability Diamond, shown in Figure 1 in Section 1.3, as an evaluative framework to answer questions about stakeholders' experiences with, and assessment of, DOE-EM's public participation programs. The Acceptability Diamond, which was developed by PNNL in previous research, provides a guide for agencies to (1) set objectives, (2) design public participation and oversight programs, and (3) set criteria for evaluating program effectiveness. In the current study, where the framework is used as a means of assessing program effectiveness, the focus is on stakeholders' perspectives of public participation: on the nature of DOE-EM's public disclosure and the following four interrelated dimensions of DOE-EM's interactions with its neighboring communities:

- Substantive issues: What role did public participation play in enabling stakeholders to access and understand pertinent information, identify their interests and frame the issues, get their issues on DOE-EM's and the regulators' agendas, and protect the community's interests?

- The decision-making process: What role did public participation play in clarifying DOE-EM's and the regulators' decision- making processes and providing opportunities for stakeholders to influence DOE-EM's (and in some cases regulators') decisions?

- Relationships: What role did public participation play in creating a forum for effective exchange and relationship building, and in helping the participants define and achieve the desired relationships of mutual respect?

- Accountability: What role did public participation play in clarifying expectations about responsibilities and accountability and in establishing and enforcing accountabilities? Was sufficient information available to ensure transparency - to 
permit stakeholders to determine what has been done, by whom, when, and with what effect?

The study was designed to increase understanding and improve program effectiveness both through the research process (i.e., interactions between the researchers and the participants) and through the research results. To conduct the study, the PNNL team:

(1) Identified the evaluation framework and prepared a concept paper that examined the congruence between the framework and theoretical developments in the social science literature (see Appendix A);

(2) Collected and summarized information available in DOE documents and websites and conducted interviews with Field Office and SSAB representatives to refine the final scope of the study, including the specific sites to be included in the study and the key research questions to be addressed;

(3) Developed and implemented a site visit protocol that included observation of public involvement activities and informal discussions with a cross-section of stakeholders at the selected sites, as well as integration of results from across the phases (see Section 2); and

(4) Prepared summaries of the selected sites, based on publicly available documents (see Section 3).

Members of the study team visited the seven sites between January and June 2002, during which they observed public participation meetings, reviewed documentation, and conducted a series of interviews with persons knowledgeable about DOE programs and public participation. The PNNL team talked with persons representing different viewpoints in an effort to ensure a balanced report. In addition, the team conducted follow-on telephone interviews.

\section{Key Findings}

\section{Open Information Disclosure Is a Prerequisite for Effective Involvement}

- Disclosure is a necessary, though not sufficient, component of public participation. Disclosure of pertinent information underlies all four dimensions of the Acceptability Diamond. Without open information, stakeholders are unable to identify and frame the issues, provide useful input to decisions, believe that their contributions are respected and valued, and develop a basis for accountability.

- Because of the fundamental relationship between open information disclosure and the four dimensions of the Acceptability Diamond, any indication that DOE-EM is imposing new restrictions on the provision of information - or is intentionally refusing to release information that has been routinely provided in the past affects stakeholders' assessment of public participation on all dimensions. It is viewed by many stakeholders interviewed for the study as signaling that EM is not committed to public participation. 


\section{The Changing Context of the EM Program Is Raising Concerns that Warrant Attention}

In the early 1990's EM was a growing organization. Cleanup, and the development of more effective environmental technologies, reflected a new, positive mission for DOE. Staff and budget were growing. DOE-EM was initiating a vigorous public participation program to involve stakeholders in defining and addressing issues and was creating various venues and the means by which stakeholders could learn about DOE and provide community viewpoints about cleanup issues and site priorities. Policies for ensuring openness and public participation were developed at both EM Headquarters and the sites.

At the time of the study, the program's context was very different. The sense of embarking on a new mission was being replaced by an emphasis on completion, closure, and long-term stewardship. Cleanup was well underway at most sites; some were nearing closure. At these sites, stewardship issues were becoming increasingly important while identifying and reaching agreement on cleanup alternatives was becoming less important. Many sites were anticipating a significantly reduced role for DOE-EM, both at their site and within DOE. Further, although there was no formal change in public participation policy, many study respondents perceived that DOE-EM Headquarters was sending a variety of signals indicating that they were placing a lower priority on consultation with community stakeholders. Throughout these transitions, knowledgeable stakeholders continued to be interested in providing community inputs into DOE's decision-making process.

This changing context of the EM program has ramifications for the entire study, affecting both the context in which public participation is viewed and implemented and the conclusions of the study itself. In particular, the changing context poses some important policy issues for both EM and the broader DOE organization.

Every site now has informed and attentive stakeholders. They understand the technical issues and the regulatory and organizational context; they are knowledgeable about the pathways of influence. In large measure, they have struggled through the evolution of DOE-EM's approach to public participation with the site managers and support staff and are a valuable resource for the program. Their commitment is based on a belief that DOE-EM, as an organization, has committed to a policy of openness and consultation. However, many respondents question EM's current commitment - and more broadly, DOE's commitment - to public participation. They note that EM's collaborative approach to public participation has not been adopted by other DOE components and express concern about the future role of public participation at their site.

The discussions conducted for this evaluation reveal that, at the time of the study, many respondents view EM's commitment to public participation with uncertainty (at best), concern, and dismay on all four dimensions of the Acceptability Diamond. ${ }^{1}$ In their

\footnotetext{
${ }^{1}$ This finding does not apply to the Savannah River Site, which the PNNL team visited earlier than other sites and before discussion of the Performance Management Plan, management personnel changes, and the implications of the Top-to-Bottom Review.

Final Report, February 2003 
discussions, respondents raised specific concerns about: (1) their ability to obtain the information they need to identify their interests, frame issues, and get them on the agenda; (2) the nature of the decision-making process and their opportunity to have meaningful influence on decisions important to the community; (3) their standing with DOE-EM as stakeholders and their relationship with EM personnel; and (4) the absence of mechanisms to hold DOE accountable for its commitments.

This changing context poses some important policy questions for both EM and the broader DOE organization. Respondents highlighted three primary EM policy implications in their discussions:

- Recent EM Headquarters (HQ) actions appear to signal a significant change in approach that risks jettisoning the community relationships and credibility that EM has striven so hard to establish for the past 8-10 years. Respondents cited, in particular, lack of prior consultation on the Top-to-Bottom Review, on proposed accelerated cleanup plans, and on site budgetary priorities. They reported that the apparent change by the new EM-HQ management, in effect, encourages them to seek alternative avenues of influence and opposition over which EM does not have control and emphasized that determined opposition by stakeholders can stop EM from achieving its cleanup mission.

- EM-HQ actions have reawakened concern about the structure of the public participation process. Public participation sponsored solely by DOE makes it vulnerable to public concern that the public's independent voice could be threatened by an EM decision to withhold information, or limit or eliminate public participation activities such as the SSABs.

- One of the key issues highlighted by the study is the future role of public participation within DOE. Stakeholders have expectations that are likely to impact the broader DOE organization. Over the past decade, EM has been the primary source of public participation among DOE programs. What will be the role of the public as EM is reduced or exits, or as other DOE programs acquire responsibility for activities, such as long-term stewardship, that affect community well-being?

\section{All Four Dimensions of the Acceptability Diamond Are Important}

- The four dimensions of the Acceptability Diamond resonated with both stakeholders and EM and contractor staff interviewed for the study. There was widespread agreement that open information disclosure is fundamental to effective participation, that all four dimensions need to be addressed, and that public participation has an important role to play in each.

- Different people emphasized different dimensions of the diamond, depend ing on their background, interests, and experience - some emphasized relationships, others emphasized defining issues, influencing decisions, or accountability.

- The relative emphasis varied also according to the phase of the program at a site. For example, where the issues have been identified and site closure is becoming 
more of a near-term reality, accountability tends to receive more emphasis than the substantive aspects.

\section{A Mix of Public Participation Activities Is Needed}

- The "ideal" mix of participation activities depends upon site characteristics, the interests of various stakeholders, and the mix of short- and long-term issues. Long-term, intensive engagement processes (such as those represented by the SSABs) complement and enhance other public involvement and education activities. Multiple ways to engage citizens and provide information are needed at these sites.

- Most respondents reported that people value long-term mechanisms such as SSABs because they enable members of the public to understand the "big picture" and to follow the evolution of issues and decisions. Respondents also emphasized the need to provide additional opportunities for a broader cross-section of the public to become aware, informed, and involved.

- A key theme throughout the interviews was the difficulty of getting the public's attention and informed input. Many SSAB members take their responsibility toward the public very seriously - they view themselves as liaisons between the public and EM. Members try to increase awareness and involvement while also representing the community by identifying issues and values important to the community.

- Those persons who were interviewed see a broad participation program as evidence of openness, of a willingness to disclose information and to hear and consider the public's perspective. Respondents considered this openness and communication valuable to both EM and the community, even if only relatively few members of the public took advantage of opportunities provided.

\section{SSABs Have Played a Key Role in Building a Strong Public Participation Program}

- At all sites, regardless of their original formation and goals, the boards have become the focus of public participation and a principal (if not the primary) mechanism for providing information and opportunities for informed involvement. Constructive engagement in the 1990s has raised expectations about how DOE will interact with stakeholders regarding the EM program.

- The long-term, relatively intensive nature of the SSAB provides valuable ways to address the four dimensions of the Acceptability Diamond. Specifically, board members

> Become knowledgeable about "big picture" site issues

$>$ Are well equipped to provide informed input to decisions

> Have a forum and time to build effective working relationships with DOE staff and contractors 
> Have the requisite institutional memory to provide the basis for holding DOE accountable for past actions and ensuring that commitments to the community are kept.

- SSABs have helped educate a segment of the public about site issues, DOE, and the regulatory process, as well as enhancing constructive working relationships. SSABs have resulted in the establishment of a knowledgeable subset of members of the public who understand the DOE and regulatory context, and know how to give useful input and how to raise their concerns.

- At many sites, boards have become a resource for EM throughout the planning and decision-making process. Because of changes in DOE staff at the sites, the boards provide the institutional memory of important site issues.

- At a number of sites, the SSABs have played a critical role in reaching out to the broader community.

- Boards have also played a positive role in educating site staff about community priorities as well as the role and need for public participation in achieving the site's mission.

- EM staff and SSAB members who were interviewed view cross-site communication through SSAB Chairs' meetings, workshops, visits, and emails as a good way to exchange information, broaden participants' perspective on the range of issues and challenges facing the EM program, and help struggling public participation programs.

\section{Report Structure}

The report is organized into three sections and three appendices. Section 1 provides an introduction and overview. Section 2 presents and discusses the overall, cross-site evaluation findings and Section 3 presents brief summaries outlining characteristics of the seven study sites and their public participation programs. Appendix A reviews pertinent social science theories and their relationship to the evaluation framework used in this study. Appendix B presents EM's public participation policy and the public participation goals that guide DOE-EM programs, and Appendix C presents the discussion protocol used to guide discussions with members of the public and EM and contractor staff. 


\section{TABLE OF CONTENTS}

Abstract.................................................................................................................................... ii

Executive Summary .................................................................................................................... v

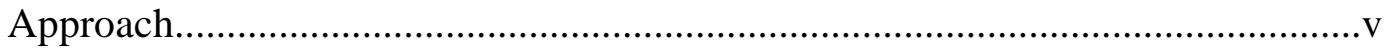

Key Findings ...........................................................................................vi

Open Information Disclosure Is a Prerequisite for Effective Involvement .....vi

The Changing Context of the EM Program Is Raising Concerns that Warrant

Attention ............................................................................................... vii

All Four Dimensions of the Acceptability Diamond Are Important ........... viii

A Mix of Public Participation Activities Is Needed ......................................ix

SSABs Have Played a Key Role in Building a Strong Public Participation

Program .......................................................................................

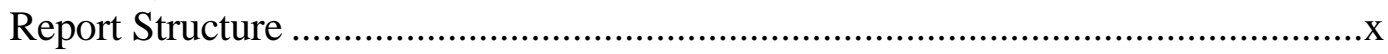

Table of Contents ..................................................................................................................... xi

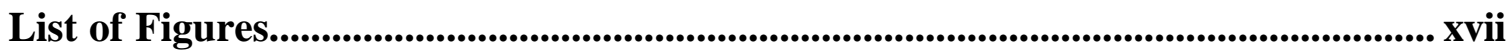

Foreword: Organization of the Report ............................................................................... xix

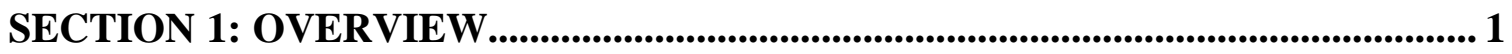

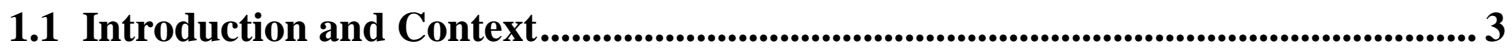

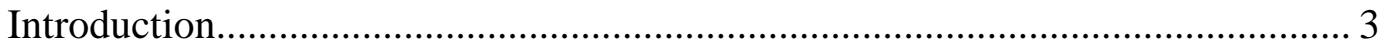

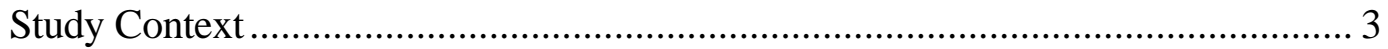

1.2 Approach ...................................................................................................................... 5

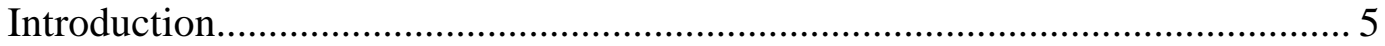

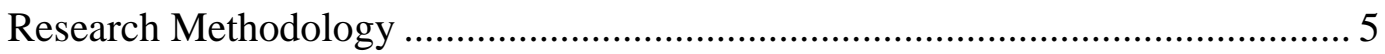

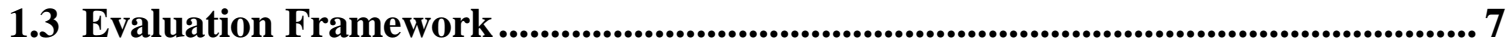

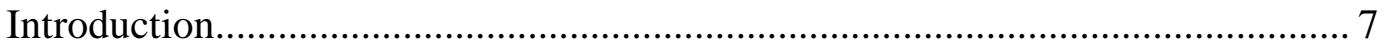

Origin and Description of the Framework ....................................................... 7

Figure 3.1 The Acceptability Diamond ......................................................... 9

Congruence of the Dimensions with Theoretical Literature ................................ 10

Applicability of the Framework to the Current Study ...................................... 10

Guidance for Agency Managers .......................................................... 10

Consistency with EM Public Participation Policy and Goals ..................... 11

Comprehensive Approach to Evaluation................................................. 11

Flexibility in Addressing Differing Site Contexts ...................................... 11

Congruence with Previous Work on the Process Aspects of Public

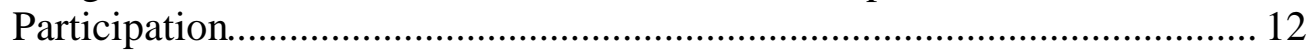




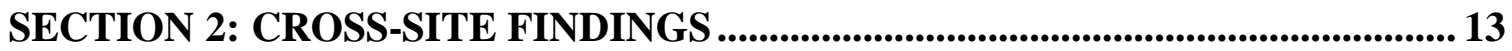

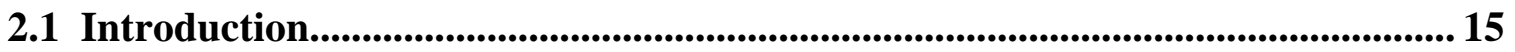

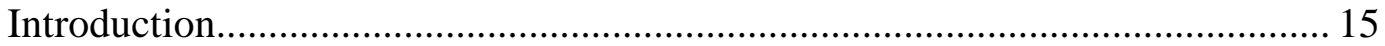

Application of the Acceptability Diamond Framework........................................ 16

2.2 Information Disclosure .................................................................................................... 17

Disclosure's Central Role in Public Participation ................................................ 17

The Sites' Channels of Information Distribution................................................ 18

Patterns of Distribution and Use................................................................ 18

Evaluations of Quality and Utility............................................................... 19

The Role of Public Participation Activities in Disclosure .................................... 20

2.3 Substantive Issues and DOE-EM Public Participation Programs ........................ 21

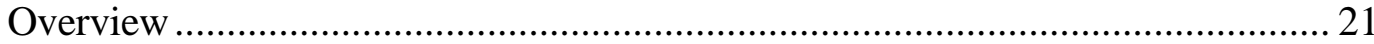

Understanding Information and the Issues ......................................................... 21

Overcoming Barriers of Technical and Regulatory Complexity..................... 21

Dealing with Fragmentation of Authority and Scope..................................... 23

Identifying and Framing Issues that Influence the Agenda .................................. 23

Forums for the Active Participants ............................................................ 24

Ways to Engage the Broad Public …………………................................. 25

Protecting Community Interests ..................................................................... 26

2.4 Decision Making and DOE-EM Public Participation Programs ........................... 29

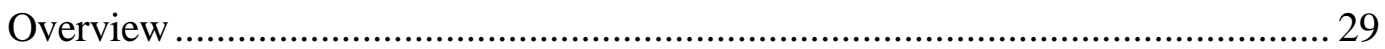

Clarifying the Decision-Making Process .......................................................... 29

Influencing Decisions ...................................................................................... 30

Influence Through Informal Communication and Early Input ....................... 31

Formal Input and Consensus Recommendations ............................................. 31

Access to the Decision Makers....................................................................... 32

2.5 Relationships and DOE-EM Public Participation Programs .................................. 35

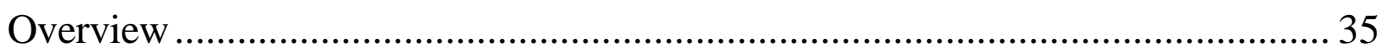

Dealing with History and Context to Create a Forum for Effective Exchange and

Relationship Building ............................................................................. 35

Factors that Help or Hinder Creation of a Forum.......................................... 35

Working within the Particular Community Contexts to Create an Effective

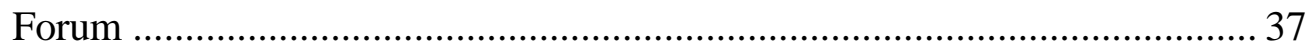

Defining and Achieving Mutually Beneficial Relationships ................................ 40

DOE-Community Relationships............................................................. 41

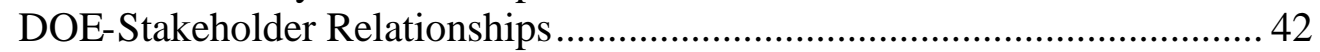

2.6 Accountability and DOE-EM Public Participation Programs ................................. 45

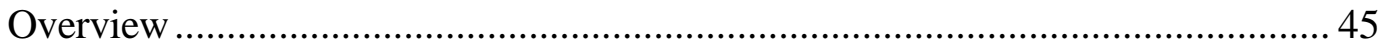

Clarifying Expectations about Responsibilities and Accountability: Differing

Views about Accountability........................................................................ 45

Establishing and Enforcing Accountabilities ....................................................... 46

Final Report, February $2003 \quad$ xii 
DOE: Accountability for Site Cleanup and the Public Participation Process 46

The Public: Accountability for Informed Participation............................... 47

The Regulators: Accountability for Regulation and Enforcement ............... 48

2.7 The Role of the SSABs...................................................................................................... 51

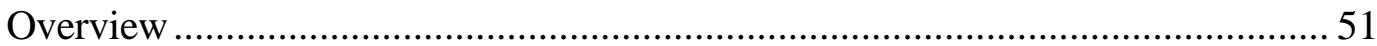

The Complementary Role of the SSABs ..................................................... 51

The Role of Non-SSAB Activities ........................................................... 51

Growth of the SSABs' Role ..................................................................... 52

The Role of the SSABs in Public Disclosure .............................................. 53

The Role of the SSABs in Addressing the Dimensions of the Acceptability

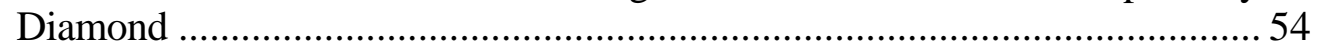

2.8 Summary and Conclusions ...................................................................................5 57

The Effectiveness of the Acceptability Diamond Framework............................57

The Essential Role of the Public and the SSABs............................................... 58

Performance on Information Disclosure and the Four Dimensions of the

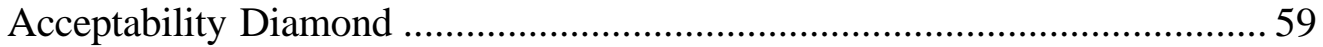

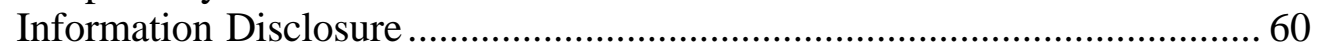

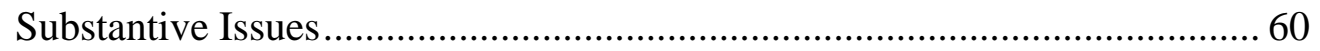

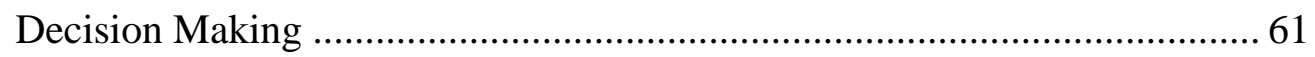

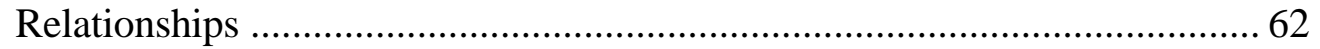

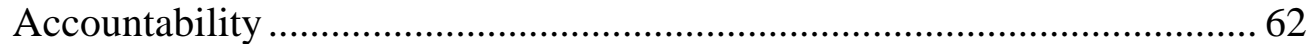

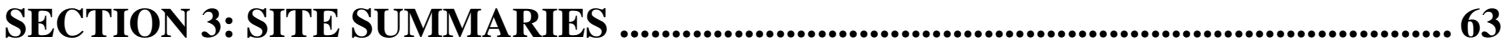

3.1 Introduction to the Site Summa ries ...........................................................................6 65

3.2 Fernald Environmental Management Project ............................................... 67

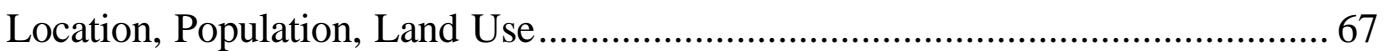

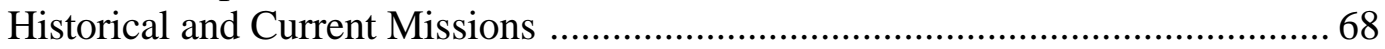

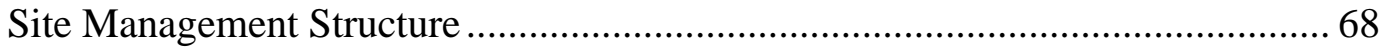

Cleanup and Waste Management Activities ..................................................... 69

Structure and Staffing of the EM Public Participation Program.......................... 69

EM Public Outreach and Participation Goals and Activities .............................. 70

Public Participation Goals ..................................................................... 70

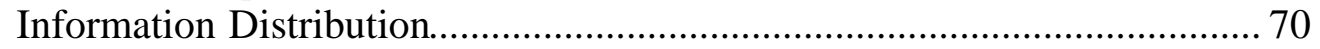

Non-SSAB Public Participation Activities................................................. 71

The Fernald Citizens' Advisory Board (FCAB) ....................................... 71

Key Public Participation Challenges and Status in Relation to the Acceptability

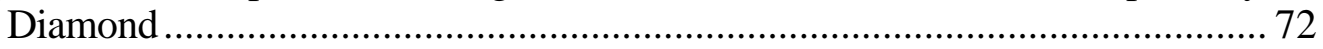

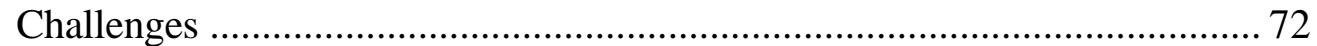

Status in Relation to the Acceptability Diamond .................................... 73

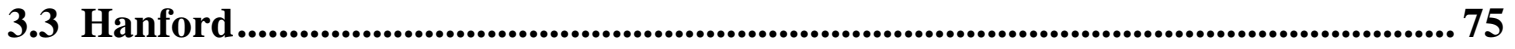

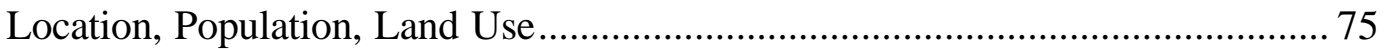

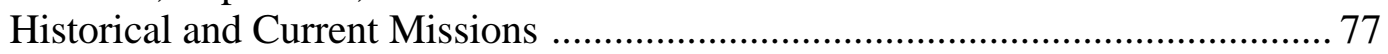

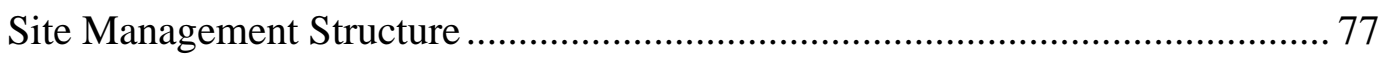

Cleanup and Waste Management Activities ....................................................... 77

Final Report, February $2003 \quad$ xiii 
Structure and Staffing of the EM Public Participation Program......................... 78

EM Public Participation Goals and Activities ................................................. 78

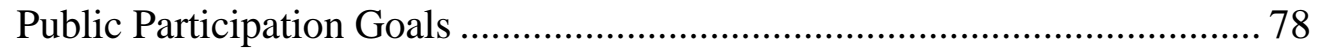

Information Distribution................................................................... 79

Non-SSAB Public Participation Activities................................................ 80

The Hanford Advisory Board .............................................................. 80

Key Public Participation Challenges and Status in Relation to the Acceptability

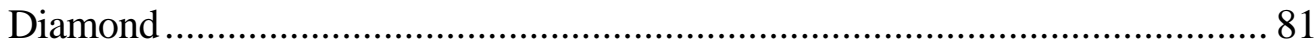

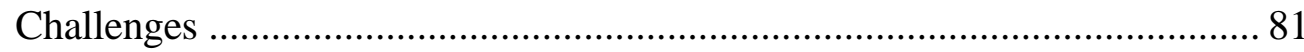

Status in Relation to the Acceptability Diamond ................................... 82

3.4 Los Alamos National Laboratory ...................................................................... 85

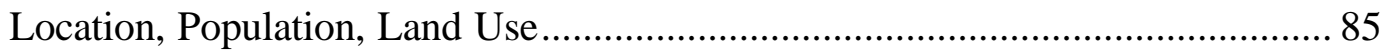

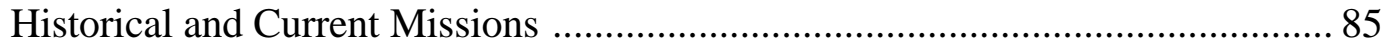

Site Management Structure .............................................................................. 86

Cleanup and Waste Management Activities ..................................................... 87

Structure and Staffing of the EM Public Participation Program.......................... 87

EM Public Outreach and Participation Goals and Activities ............................... 88

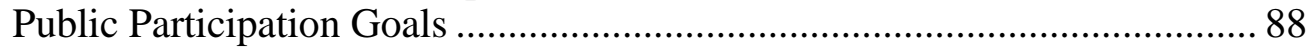

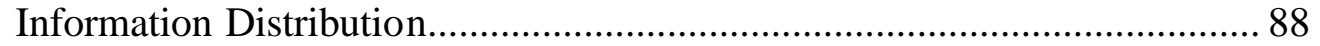

Non-SSAB Public Participation Activities................................................. 89

The Northern New Mexico Citizens' Advisory Board............................... 89

Key Public Participation Challenges and Status in Relation to the Acceptability

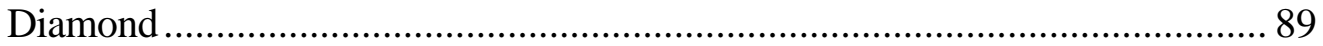

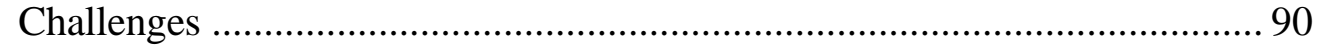

Status in Relation to the Acceptability Diamond ..................................... 90

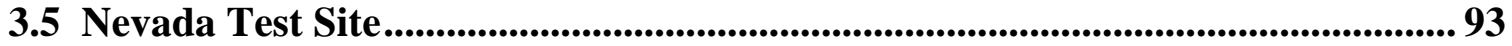

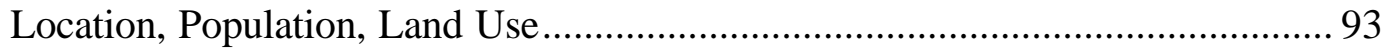

Historical and Current Missions ..................................................................... 93

Site Management Structure ............................................................................. 94

Cleanup and Waste Manage ment Activities ...................................................... 95

Structure and Staffing of the EM Public Participation Program.......................... 96

EM Public Outreach and Participation Goals and Activities .............................. 96

Public Participation Goals ......................................................................... 96

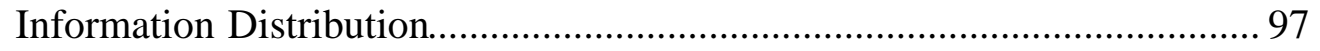

Non-SSAB Public Participation Activities................................................ 97

The Community Advisory Board for Nevada Test Site Programs (CAB) .... 97

Key Public Participation Challenges and Status in relation to the Acceptability

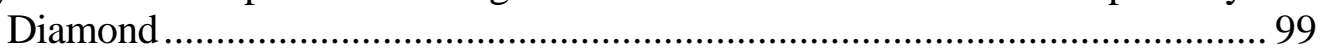

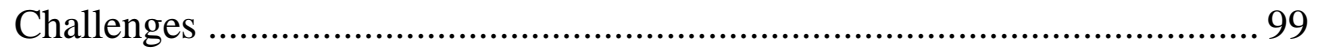

Status in Relation to the Acceptability Diamond .................................... 100

3.6 Oak Ridge Reservation....................................................................................................... 103

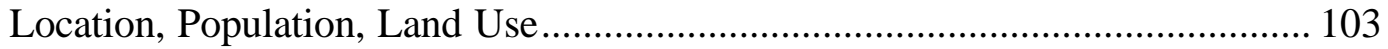

Historical and Current Missions ................................................................... 103

Site Management Structure ...................................................................... 104

Final Report, February $2003 \quad$ xiv 
Cleanup and Waste Management Activities ..................................................... 105

Structure and Staffing of the EM Public Participation Program.......................... 106

EM Public Outreach and Participation Goals and Activities .............................. 106

Public Participation Goals ...................................................................... 106

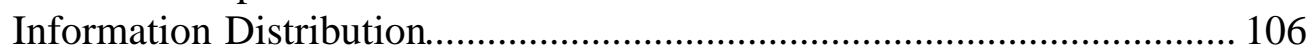

Non-SSAB Public Participation Activities.................................................... 107

The Oak Ridge Site-Specific Advisory Board (ORSSAB) .......................... 107

Key Public Participation Challenges and Status in Relation to the Acceptability

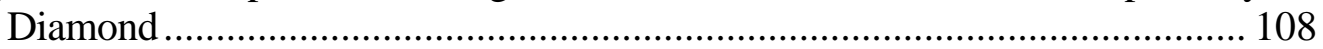

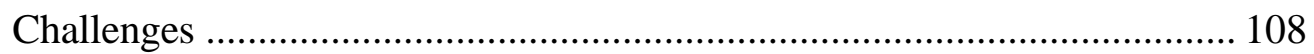

Status in Relation to the Acceptability Diamond .......................................... 109

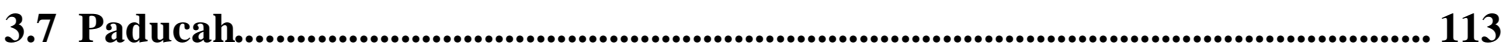

Location, Population, Land Use................................................................... 113

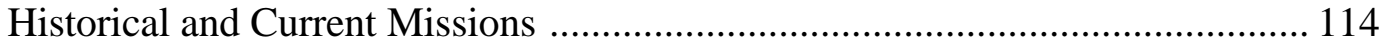

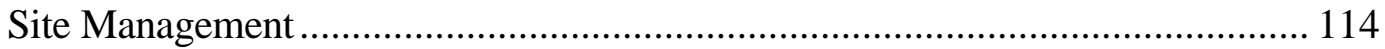

DOE Cleanup and Waste Management Operations .............................................. 115

Structure and Staffing of the EM Public Participation Program.......................... 116

EM Public Outreach and Participation Goals and Activities ............................... 116

Public Participation Goals .................................................................... 116

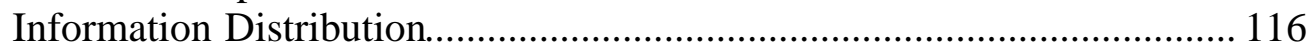

Non-SSAB Public Participation Activities................................................ 117

The Paducah Citizens' Advisory Board ……………….............................. 117

Key Public Participation Challenges and Status in Relation to the Acceptability

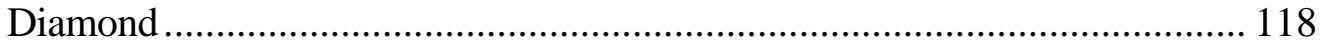

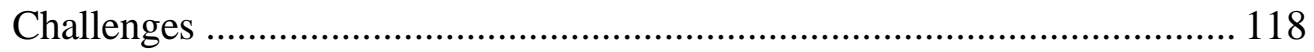

Status in Relation to the Acceptability Diamond ........................................... 119

3.8 Savannah River Site..................................................................................................... 121

Location, Population, Land Use..................................................................... 121

Historical and Current Missions ...................................................................... 121

Site Management Structure ………………............................................... 123

Cleanup and Waste Management Activities ......................................................... 123

Structure and Staffing of the EM Public Participation Program.......................... 123

EM Public Outreach and Participation Goals and Activities ................................ 124

Public Participation Goals .................................................................. 124

Information Distribution......................................................................... 124

Non-SSAB Public Participation Activities................................................ 124

The SRS Citizens' Advisory Board........................................................... 125

Key Public Participation Challenges and Status in Relation to the Acceptability

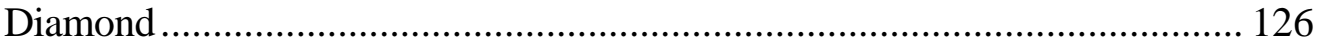

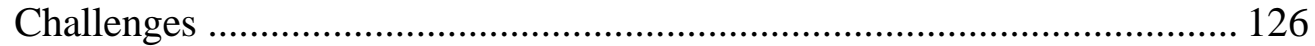

Status in Relation to the Acceptability Diamond ...................................... 126 


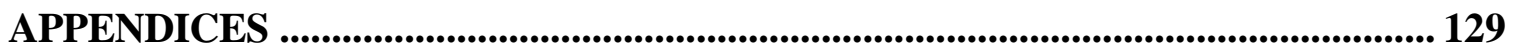

Appendix A: Theory Paper..................................................................................................... 131

Theoretical Basis for the Acceptability Diamond Framework ........................... 131

Public Participation Literature: Many Case Studies, Little Theory..................... 131

The Acceptability Diamond ............................................................................... 133

Figure A.1 The Acceptability Diamond ............................................................. 134

The Theory of the Public Sphere and Communicative Action............................. 135

The Public Sphere and the Acceptability Diamond .............................................. 138

Figure A.2. The Public Sphere, Where the Lifeworld Critiques the System. ... 139

Multi-Dimensional Public Participation Programs .............................................. 143

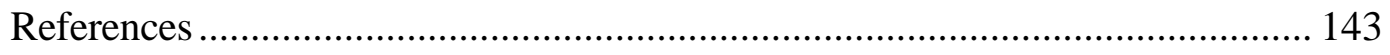

Appendix B: DOE-EM's Public Participation Policy ...................................................... 145

Appendix C: Field Visit Protocol................................................................................................ 149 


\section{LIST OF FIGURES}

Figure 3.1 The Acceptability Diamond ..................................................... 9 
Final Report, February 2003 


\section{FOREWORD: ORGANIZATION OF THE REPORT}

This report provides a framework for evaluating the scope and effectiveness of the public participation programs, including Site-Specific Advisory Boards (SSABs) at seven DOE sites: Fernald, Hanford, Los Alamos, Nevada, Oak Ridge, Paducah, and Savannah River. The primary purpose of the study is to assist both Field and Headquarters managers in reviewing and evaluating lessons learned over the past decade concerning DOE-EM's public participation programs. Researchers from the Pacific Northwest National Laboratory (PNNL) prepared this report, which was reviewed by the DOE-EM Office of Intergovernmental and Public Accountability and the public participation coordinators at each of the sites.

The focus of the study is on stakeholders' perspectives on public participation programs that incorporate a variety of activities and address a wide range of site activities and decisions. The report is organized into three sections and three appendices. Section 1 provides an introduction and overview. Section 2 presents and discusses overall, crosssite evaluation findings; and Section 3 presents brief summaries of the characteristics of the seven study sites and their public participation programs. Appendix A reviews pertinent social science theories and their relationship to the evaluation framework used in this study. Appendix B presents DOE-EM's public participation policy and the public participation goals that guide DOE-EM programs, and Appendix C presents the discussion protocol used to guide discussions with members of the public and EM and contractor staff.

The first section introduces the study in Chapter 1.1, which provides an overview of the study context. Chapter 1.2 discusses the study approach, and Chapter 1.3 outlines the framework for evaluating the public participation programs.

Section 2 presents the results of the fieldwork for the study in a discussion of cross-site findings. Chapter 2.1 introduces the cross-site analysis. Chapter 2.2 discusses the central role information disclosure plays in public participation. Chapter 2.3 describes how public participation helps communities and agencies to identify the most important issues and involve them in decision-making and management agenda. Chapter 2.4 describes study respondents' assessment of the clarity and openness to influence of the decisionmaking process. Chapter 2.5 discusses the role public participation plays in establishing the context for effective dialogue and learning and the central role a relationship of recognition and respect plays in facilitating communication and understanding. Chapter 2.6 addresses the role of public participation in contributing to DOE's accountability to their local communities. Chapter 2.7 discusses the role of the SSABs in complementing and expanding the effectiveness of other site public participation activities. The section concludes with an overall summary in Chapter 2.8.

Section 3 provides summaries for each of the seven sites included in the study. Each summary includes a description of the site drawn from publicly available information: location, population, and land use; historical and current site missions; site management 
structure; cleanup and waste management activities; structure and staffing of the EM public participation program; and EM public outreach and participation goals and activities. A final component of each summary identifies key challenges and summarizes the research team's assessment of the site's status in relation to the Acceptability Diamond, based on members' site visits and interviews. 


\section{SECTION 1: OVERVIEW}




\subsection{INTRODUCTION AND CONTEXT}

\section{Introduction}

This study focuses on a framework for evaluating the scope and effectiveness of public participation programs at DOE-EM sites. How can EM managers best evaluate the agency's experience over the past decade in incorporating community issues and viewpoints into its cleanup plans and programs? What lessons does EM's experience highlight for agency managers in designing and implementing public participation programs that will enhance their ability to work effectively with local communities in achieving their mission and protecting local environments and public health?

This first section of the report provides a framework for evaluating DOE-EM public programs across the seven sites selected for study. It includes three chapters. This chapter is an introductory overview of the context of the study. Chapter 1.2 discusses the study approach, and Chapter 1.3 outlines the framework used to evaluate the public participation programs.

\section{Study Context}

In the early 1990s, DOE-EM undertook a major new effort to involve community stakeholders in decisions that would affect them and their communities and interests. This effort grew out of several continuing public participation activities, along with the realization that community viewpoints were an essential part of complex cleanup plans and programs. Interest in, and support for, public participation programs were evident in Congress and in the Keystone Dialogue. ${ }^{2}$ Experiences with the processes initiated by the National Environmental Policy Act (NEPA), the Comprehensive Environmental Response, Compensation and Liability Act (CERCLA) (especially the requirement for Community Relations Plans), and the Federal Facility Compliance Act (FFCA) laid some of the groundwork, and the new, positive mission of cleaning up the sites led to an emphasis on involving members of the public.

Two key components of EM's emphasis on the value of public participation were the development of a formal public participation policy, goals, and objectives; and the establishment of local Site-Specific Advisory Boards (SSABs) at 12 DOE environmental remediation sites, at various times during the early and mid-1990s. These actions were a formal representation of a change in the way DOE was conducting its missions, adding consideration of community concerns and values to the Department's decision-making and management processes.

\footnotetext{
${ }^{2}$ Final Report of the Federal Facilities Environmental Restoration Dialogue Committee: Consensus Principles and Recommendations for Improving Federal Facilities Cleanup, April 1996, Keystone Center, Keystone, Colorado; Interim Report of the Federal Facilities Environmental Restoration Dialogue Committee: Consensus Principles and Recommendations for Improving Federal Facilities Cleanup, February 1993, Keystone Center, Keystone, Colorado.
} 
Because the SSABs represented a significant commitment by DOE-EM to change its relationships with community stakeholders, the Department has conducted several assessments of the advisory boards. These include two surveys that established a set of performance criteria jointly agreed to by EM and board representatives ${ }^{3}$ and a qualitative study of nine of the boards that identified and analyzed six factors affecting board performance (PNNL-12139, 1999). In addition, many of the SSABs conduct annual selfevaluations.

Public participation programs now are well integrated into site operations and SSABs continue to operate at nine DOE sites. However, the EM program context has changed since the early 1990s, and in particular since publication of the 1999 study. This changing program context influenced the current study, affecting both the context within which participants view and implement public participation, and the conclusions of the study itself. In the early 1990's both EM's staff and budget were growing, and cleanup was a new, positive mission for DOE. DOE-EM initiated a vigorous public participation program to involve stakeholders in defining and addressing issues and provided a range of means by which stakeholders could learn about DOE and provide community viewpoints. This contrasts with the current situation where the sense of embarking on a new mission has been replaced by a focus on completion, closure, and long-term stewardship. Cleanup is well underway at most sites; some are nearing closure. At these sites, stewardship issues are becoming increasingly important while identifying and reaching agreement on cleanup alternatives is becoming less important. Many sites are anticipating a significantly reduced role for DOE-EM, both at their site and within DOE. In addition, it has become clear that other components of DOE are not adopting EM's approach to public participation. This situation raises questions about long-term avenues for public involvement at sites moving toward closure and/or a significantly reduced DOE-EM role.

In addition to these changes, which have been occurring over a period of years, more immediate changes are also being experienced as the result of new EM Headquarters' initiatives. EM Headquarters released the Top-to-Bottom Review and initiated development of site Performance Management Plans that emphasized accelerated schedules and site closure while the PNNL researchers were conducting site visits. The evaluation thus reflects some of the uncertainty stakeholders expressed about the future role of public participation, both within EM and within the broader DOE organization, where traditionally EM has played a leadership role for other DOE programs.

\footnotetext{
${ }^{3}$ U.S. Department of Energy, Office of Environmental Management. 1996. Site Specific Advisory Board Initiative Evaluation Survey Results (2 vols). Prepared by Pacific Northwest National Laboratory for the U.S. Department of Energy, Office of Environmental Management. (DOE/EM-0311 and 0312); Bradbury, J., K. Branch, and M. Zalesny. 1997. Site Specific Advisory Board Initiative 1997 Evaluation Survey Results. Volume I, Summary Report and Volume II, Supplementary Appendix: Summary of Individual Site Results. Prepared by Pacific Northwest National Laboratory for the U.S. Department of Energy, Office of Environmental Management.
} 


\section{Introduction}

Building on previous studies and a further review of the literature, the PNNL team developed a research design and selected sites to participate in the study. The team selected for visits seven of the nine environmental remediation sites having a SSAB: ${ }^{4}$ Fernald, Hanford, Los Alamos, Nevada, Oak Rid ge, Paducah, and Savannah River. ${ }^{5}$

\section{Research Methodology}

The research team's objective was to design a study that increases understanding and improves program effectiveness through both the research process (i.e., interactions between the researchers and the participants in conducting the research) and the research results. The research was conducted in four phases:

- Phase I: The PNNL team identified the evaluation framework for the study and prepared a concept paper examining the congruence between the framework and theoretical developments in the social science literature.

- Phase II: The research team collected and summarized information available in DOE documents and websites and conducted a limited number of interviews with Field Office and SSAB representatives. This information was used to refine the final scope of the study, including specific sites to be included in the study and key research questions to be addressed.

- Phase III: The team prepared summaries of the selected sites, based on publicly available documents. The summaries were distributed to the DOE-EM site public participation contacts for review.

- Phase IV: The PNNL team developed and implemented a site visit protocol that included observation of public involvement activities and informal discussions with a cross-section of stakeholders. The team integrated results from across the phases into a final report.

The research team visited the seven sites between January and June 2002. During site visits, the team observed SSAB and other public participation meetings, reviewed documentation, and conducted a series of interviews with persons knowledgeable about DOE programs and public participation activities. The interviewers talked with persons representing different viewpoints in an effort to ensure a balanced report. They

\footnotetext{
${ }^{4}$ With the exception of Oak Ridge, most sites refer to their board as a Citizen Advisory Board (CAB), rather than a SSAB. The Hanford board is known as the Hanford Advisory Board (HAB).

${ }^{5}$ The Idaho and Rocky Flats sites were not included in this study because of on-going research by other organizations.
} 
conducted one- to two-hour interviews with SSAB chairs and members (including former members), other participants in the public participation programs of the site, and DOEEM and contractor staff with responsibilities pertaining to public participation programs. The face-to-face interviews were supplemented with telephone interviews with those involved in public participation programs who could not be scheduled during the site visit. Between 17 and 21 interviews were conducted at each site.

The research team conducted the interviews as informal discussions, following a general agenda of topics (a copy of the protocol is included in Appendix C); interviewers did not cover all topics with all interviewees. Participants were initially selected on the basis of their level of knowledge and involvement in EM programs and any special insights or particular perspectives they could provide rather than through a statistically representative sampling of the nearby population. Additional interviewees were selected by a "snowball" approach, i.e., by asking the initial interviewees for recommendations, with the specific objective of obtaining wide representation of community viewpoints. Because of the central role played by the SSABs in each site's public participation programs, many of the interviewees were current or ex-SSAB members, or regular participants in board meetings.

An issue for this study was to define the boundaries of the public participation program at each site. At some sites (for example, Los Alamos) the public participation programs, activities, and staff are organizationally separate from those of the public relations and community relations functions; at other sites (for example, Fernald) these functions are more integrated. Another difference among the sites relates to the advisory board as distinct from other activities; sometimes these activities are conducted separately, sometimes integrated. Where possible, the sites' own definitions of their public participation programs were used to define the scope of the study; relevant site public participation activities are described in each of the site summaries.

Evaluation of programs (such as the EM public participation program) that have qualitative goals is more appropriately achieved by applying comprehensive frameworks and criteria that permit cross-program comparison than by attempting to apply quantitative metrics. This study used as the evaluation framework the Acceptability Diamond, which was developed by PNNL in the course of work on public participation programs in the federal sector. As discussed in the following chapter, the Acceptability Diamond incorporates the goals articulated by DOE-EM while providing flexibility to evaluate the effectiveness of programs at sites that differ geographically, culturally, and demographically, as well as in terms of their histories and DOE missions. 


\subsection{Evaluation FrameWORK}

\section{Introduction}

The evaluation framework used for this study was the Acceptability Diamond, developed initially from a study of community viewpoints about U.S. Army plans to destroy chemical weapons stockpiles ${ }^{6}$ and refined in subsequent research on federal agencycommunity interactions. This section outlines the origin of the framework and describes its constituent dimensions, summarizes the congruence between the framework and other recent theoretical developments in the social science literature, and discusses its applicability in the current DOE-EM context.

\section{Origin and Description of the Framework}

The PNNL study of community views was initially focused on community residents' perceptions of the risks of alternatives for dealing with the stockpile of chemical weapons maintained by the U.S. Army. However, discussions with stakeholders revealed that people do not think about technology or risk in isolation. Indeed, very few people mentioned risk per se. Rather, the study confirmed the claims of the social science literature on risk that conflict is not only about risk but also about a number of broader sociocultural and scientific issues that have been hidden by the nearly exclusive focus on risk assessment and communication. In addition, PNNL researchers found evidence supporting claims that there are fundamental differences in both the ways that people frame issues and in people's views about how these risks should be managed.

At each chemical weapons storage site, the research team found differing views on the Army's plans. However, despite these differing views, residents' arguments were strikingly similar in structure - in the scope of concerns and the basic reasoning used to support, oppose, or express uncertainty about the Army's plans. Throughout, concerns about technology choice and technical performance were linked with other categories of concern. The research showed that the issues raised in the communities were both technical and non-technical. It highlighted the impossibility of trying to address issues of technology acceptability and technical performance without also addressing issues related to a community's ability to have its issues addressed, to agency credibility (including regulatory agencies' credibility), to past and anticipated agency treatment of and relationship with communities, to issues of the fairness and appropriateness of the decision-making process, and to concerns about the adequacy of institutional safeguards and protection. In the public's eyes, these community concerns are inextricably linked with technical issues. A major conclusion of the research was the need for the Army and indeed for agencies in general - to address all of these dimensions if they are to achieve their missions and work effectively with communities.

\footnotetext{
${ }^{6}$ Bradbury, J., Branch, K., Heerwagen, J., and Liebow, E. 1994. Community Viewpoints of the Chemical Stockpile Disposal Program. Report prepared by Battelle Pacific Northwest Laboratories, Washington, D.C.
} 
Specifically, public concerns incorporated four, interrelated themes or dimensions that PNNL researchers characterized as an Acceptability Diamond. Subsequent work by PNNL with other agencies, including DOE, confirmed that concerns frequently voiced by community members in other settings could similarly be grouped into these dimensions and that public disclosure (provision of information) plays a critical role in each dimension. Furthermore, the dimensions could serve as a guide to agency managers on the types of issues that they need to address in public participation activities, as well as providing a way to measure their effectiveness in addressing community issues and incorporating community views into agency programs.

The Acceptability Diamond has four dimensions:

- Substantive issues: What are the issues from both agency and public viewpoints? How was a remediation technology selected, the schedule established, and the program designed? Does the public have sufficient, timely information to enable them to identify the issues of importance to them? Are they able to get their issues on the agenda and have them addressed?

- The decision-making process: Is the decision-making process clear? Who is making the decision? What decision method is being used? Is it fair? What information is being used as the basis for a decision? Has the public been given a genuine opportunity to be involved in and influence the decision?

- Relationships: How do people feel that the agency has treated them? Has the agency demonstrated in previous actions that the well-being of the community is a factor in its decisions or that it will be a factor influencing future decisions? Responsiveness and openness in providing information are important contributors to good relationships. Such relationships give each party, including the public, "standing," i.e., members of the public are affirmed as individuals and treated with respect. With such standing, people expect that all participants will adhere to certain norms that are assumed to be valid, such as honesty and openness.

- Accountability: Does the agency take responsibility for disclosure of pertinent information and the results of its processes and decisions? Do the officials demonstrate by their behavior that they fulfill their commitments? Are there mechanisms to provide assurance that responsibilities and commitments are met? Keeping technical commitments is only part of accountability. Demonstrating commitment to the non-technical concerns of the public means that outcomes are not only technically effective but also promote community health, safety, economic stability, and well-being.

Figure 1 shows the four important dimensions of the Acceptability Diamond and highlights the central role played by public disclosure. Open information disclosure is a prerequisite for addressing all four dimensions. Without open information, stakeholders are unable to identify and frame the issues (substantive dimension); affect decisions (decision-making process); believe that their contributions are respected and valued and that DOE-EM is indeed operating in a credible, open, responsive manner (relationships); 
and be assured of transparency - to be able to determine what has been done, by whom, when, and with what effect (accountability).

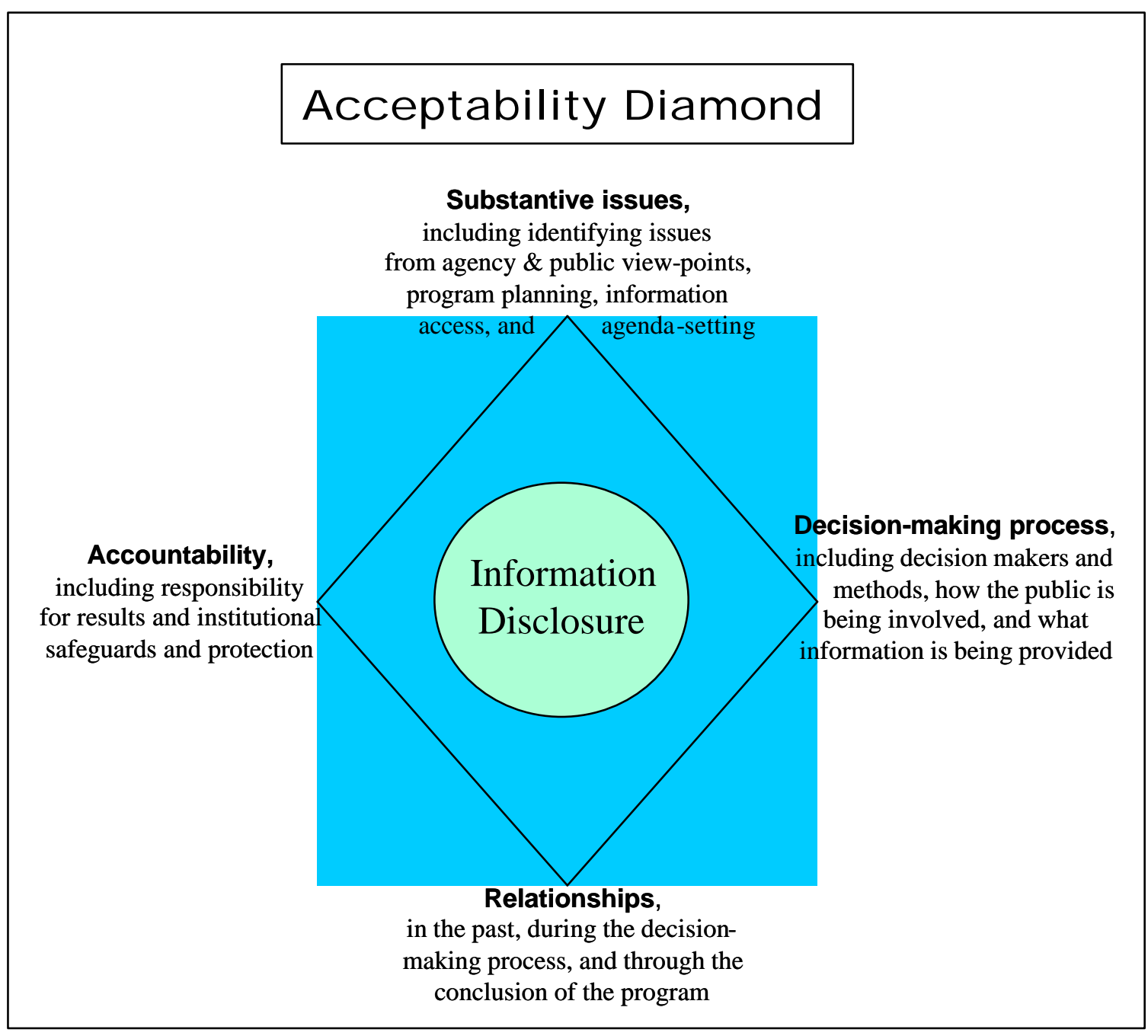

\section{Figure 3.1 The Acceptability Diamond}

A key feature of the Acceptability Diamond is its indivisibility. That is, people experience their interaction with an agency and with public participation programs as allof-a-piece, not as separate pieces, and the four dimensions are closely interrelated. No one facet can be successful without all the others. However, because the dimensions are related, there may be positive spillover from an emphasis on getting one dimension right. For example, establishing a policy of openness and responsiveness in providing information about substantive issues, and soliciting and using input from the public in setting priorities for addressing the issues may well enhance relationships, contribute to stakeholders' ability to provide informed input to decisions, and provide a basis for accountability. Demonstrating openness, providing information, and using inputs have been found to be features of effective programs in every dimension. 
The responsibility of public participation programs is to ensure that the four dimensions of the acceptability diamond are addressed in a manner and through processes that are effective and acceptable to stakeholders.

\section{Congruence of the Dimensions with Theoretical Literature}

Appendix A discusses the Acceptability Diamond framework's congruence with sociological theories related to relationships between public and private participants. The agreement of theory with the Acceptability Diamond indicates that the empirically derived framework can be effective in evaluating and designing DOE-EM's public participation programs. That is, EM may use the Acceptability Diamond to manage public participation programs on an ongoing and long-term basis. In sum, the concept of the Acceptability Diamond permits DOE-EM to (1) set objectives; (2) design public participation and oversight programs; and (3) set criteria for evaluating program effectiveness.

\section{Applicability of the Framework to the Current Study}

Several additional factors pointed to the value of using the Acceptability Diamond as the framework for evaluating the public participation programs of DOE sites:

- Its pertinence for providing guidance to federal agencies in working effectively with local communities;

- Its consistency with EM public participation policy and goals;

- Its provision of a comprehensive approach to evaluating the overall site public participation program (e.g., SSABs as well as other public meetings, interactions, and outreach activities);

- Its flexibility in addressing the differences in context between the DOE sites; and

- Its congruence with previous work on the process aspects of public participation.

\section{Guidance for Agency Managers}

One of the important values of the Acceptability Diamond lies in the guidance it provides program managers in designing and implementing a public participation program that will enhance their ability to work effectively with local communities. The research points to the need for program managers to adhere to open information policies and provide activities that address all dimensions of the acceptability diamond. Community members' issues and concerns are broad in scope, and failure to address them is likely to affect both the effectiveness of the public participation program and the agency's effectiveness in achieving its mission. In addition to serving as a guide, however, the Acceptability Diamond can help program managers evaluate whether they are addressing the full scope of issues and community needs. Essentially, a public participation program may be deemed effective to the extent that it provides for open disclosure and addresses all four acceptability dimensions in ways that are appropriate and effective for a particular community and situation. 


\section{Consistency with EM Public Participation Policy and Goals}

The dimensions highlighted by the diamond are entirely consistent with EM policy and goals. ${ }^{7}$ EM policy explicitly mentions decision- making and accountability, along with information disclosure and EM's intent to provide opportunities for the public to have their views heard. Relationship building is not explicitly mentioned in the policy; however, as discussed in Chapter 2.5, openness in providing information and the opportunities for interaction provided by public participation activities, in effect, address the relationship dimension.

As shown in Appendix B, EM defines public participation as "the process by which the views and concerns of the public are identified and incorporated into DOE's decisionmaking." The policy emphasizes EM's commitment to "conduct its programs in an open, responsive, and accountable manner" and to "create an open and accessible decisionmaking process that results in decisions that are technically and economically feasible, environmentally sound, health and safety conscious, address public concerns, and can be implemented." EM's stated policy is to "support an aggressive, substantive, EM-wide public participation program in which the public is provided with accurate, complete, and timely information and early, meaningful participation opportunities." Specific objectives include "providing a range of EM public participation opportunities tailored to meet the needs and interests of various segments of the public."

\section{Comprehensive Approach to Evaluation}

In pointing to the critical role of information and the four basic types of issues that need to be addressed, the Acceptability Diamond provides a means for evaluating the overall effectiveness of public participation at a site. This approach recognizes that different activities have different and complementary functions. The key question to be resolved is whether, in combination, the various information and participation activities - provision of information; formal, mandated public meetings; workshops and informal interactions; and SSAB and associated committee meetings - provide ways to meet community standards of acceptability regarding information disclosure, substantive issues, decisionmaking, relationships, and accountability.

\section{Flexibility in Addressing Differing Site Contexts}

As illustrated in the site summaries included in Section 3 of this report, wide variation exists among DOE sites. Differences exist in geographic location, demographic, social, and cultural characteristics, and in DOE missions and the historical relationships with each community. Using a broad framework permits meaningful evaluation and comparison among sites: as noted above, the key question is whether the individual programs provide mechanisms to address the four types of community concerns. The specific mechanism for how the concerns are addressed may vary, depending on the particular site; the question is whether mechanisms are in place and whether they complement one another.

\footnotetext{
${ }^{7}$ See Appendix B and http://www.em.doe.gov/public/empubpar.html for a complete list of goals.
} 


\section{Congruence with Previous Work on the Process Aspects of Public Participation}

The Acceptability Diamond confirms the findings of much of the empirical work describing how to implement effective public participation. Both emphasize the need for open, timely information that will enable stakeholders to identify issues from their perspective. Both also emp hasize

- Providing access to agenda setting (substantive dimension);

- Obtaining early participation that provides an opportunity to influence decisions;

- Establishing mechanisms and standards of interaction that emphasize respect, relationships, and team building; and

- Demonstrating accountability.

An agency or organization that attempts to address the four acceptability dimensions, in effect, will follow the precepts of this body of work. 


\section{SECTION 2: CROSS-SITE FINDINGS}




\subsection{INTRODUCTION}

\section{Introduction}

The seven sites on which this study focuses exhibit great differences in size and situation, but they also share a number of important features. DOE-EM has made a commitment to public participation at these sites, as exemplified by the establishment and continued support for the Site-Specific Advisory Boards (SSABs) and a variety of activities to inform and involve citizens. Furthermore, the sites' stakeholders have demonstrated their concern with potential and actual dangers from site materials and cleanup, and their willingness to contribute considerable time and effort to ensure the safety and well-being of their communities. At all seven sites, the advisory boards are seen as central to the public participation activities, although at several sites, significant alternative methods of public participation exist. At five of the seven sites, DOE-EM is the principal steward, or sponsor, of participation regarding EM site management. At Hanford, both the Washington State Department of Ecology and the Oregon Department of Energy sponsor Hanford-related public participation programs. ${ }^{8}$ At Oak Ridge, the DOE-sponsored program is supplemented by the Local Oversight Committee (LOC). ${ }^{9}$

The study team used the Acceptability Diamond as the framework for evaluating whether the participation programs were addressing the full scope of community issues related to DOE-EM cleanup plans and programs. This section discusses the various ways in which public participation programs at the different sites provide for public disclosure and address the four dimensions of the Acceptability Diamond: Substantive issues, Decisionmaking, Relationships, and Accountability. Discussions with stakeholders confirmed the interrelationship among the four dimensions of the Acceptability Diamond. Thus, for example, judgments about the acceptability of the decision-making process are affected not only by the attributes of the decision- making process itself, but also by judgments about the adequacy of

(1) DOE-EM's information disclosure;

(2) The public's ability to access and understand the information, identify their interests, and get their issues on the decision-making agenda;

(3) The mechanisms for ensuring that the decisions made and agreements reached will be implemented; and

(4) The nature of the relationships among DOE, the regulators, and the public.

\footnotetext{
${ }^{8}$ The Oregon Department of Energy sponsors a 20-person Oregon Hanford Waste Board to involve the public in Hanford issues.

${ }^{9}$ The Local Oversight Committee was established in 1991 as a consequence of the Tennessee Oversight Agreement between the State of Tennessee and DOE. In 1995, the LOC added a 17-20 member Citizen's Advisory Panel, which has met regularly since that time.
} 
This indivisibility, while complicating the description of each dimension, explains the importance of attending to all of these key aspects when designing and evaluating public participation programs.

\section{Application of the Acceptability Diamond Framework}

All four dimensions of the Acceptability Diamond resonated with the people with whom the research team talked during their site visits. However, as expected, different people emphasized different aspects, depending on their background, experience, and interests some emphasized relationships, others emphasized accountability or the ability to define issues. Environmental activists, for example, tended to emphasize accountability, while people with a technical background and site experience tended to emphasize the substantive issues. The relative emphasis varied also according to the program phase and context at each site. For example, at sites where issues have been identified and site closure is becoming more of a near-term reality, accountability tends to be given more emphasis than other aspects.

Following this introduction, Chapter 2.2 discusses the role of disclosure in providing the essential foundation for full public participation. In Chapters 2.3 through 2.6, each of the four dimensions is then discussed in turn - substantive issues, decision-making process, relationships, and accountability. Chapter 2.7 discusses the role of the SSABs in complementing and expanding the effectiveness of other public participation activities. Chapter 2.8 summarizes key findings, including the role of public participation activities in helping to ensure that the four dimensions are addressed. 


\section{Disclosure's Central Role in Public Participation}

A continuing theme throughout discussions with community members was the critical importance of their ability to access information that is timely, complete, and accurate. Open disclosure is of both substantive and symbolic significance. Information disclosure is a critical basis for public involvement; it is covered by both policy and regulations; and it is often the most obvious basis for tension between the Department and its stakeholders.

The extent and manner by which information is made available by DOE-EM and its contractors to the public and regulators has ramifications for all dimensions of the acceptability diamond, as discussed in the following chapters. It is a prerequisite for community members' ability both to understand and confirm EM's identification of the issues and to understand and identify issues of importance to themselves. It is a precondition for community involvement in, and ability to influence, the decision-making process. It is a key ingredient of respectful and communicative relationships and relationship building, and indicates that DOE-EM is indeed operating in a credible, open, responsive manner. And, finally, it forms the basis for accountability - without accurate information, the public cannot be confident that cleanup operations are actually implemented as planned and that their concerns are being truly addressed.

The need for open disclosure that enables the public to effectively participate is clearly stated in EM policy (Appendix B). This policy is reinforced by the legal requirement under CERCLA for establishment of a publicly available Administrative Record, as well as under NEPA requirements for public access, which state that "Federal agencies are required, to the fullest extent possible, to encourage and facilitate public participation in agency decisions that affect the quality of the human environment" (40 CFR 1500.2(d)); and "Agencies must also make diligent efforts to involve the public in preparing and implementing their NEPA procedures" (40 CFR 1506.6(a)).

However, not all information pertaining to site decisions is covered by these legal requirements, and DOE therefore retains discretion over what information is made available, and when it is disclosed. Stakeholders can challenge DOE's choices to withhold information by requesting information under the Freedom of Information Act (FOIA). The news media, particularly newspapers, have been influential in disclosing information about past or upcoming site activities at several sites, often after obtaining information via FOIA request. When this has revealed negative information that was apparently deliberately hidden from the public, as at Paducah, EM credibility, the integrity of its stewardship of the public participation process, and its relationships with the community have suffered severe setbacks.

The importance of information disclosure is widely recognized by the public. For example, one non-board member at Savannah River (where both board members and 
non-board environmental activists commented favorably on their ability to obtain information from DOE) noted that the biggest threat to DOE, generally, is a failure to disclose information and that the site's public participation program had done a good job in this regard.

Many of those interviewed for the study expressed alarm about EM-HQ's directive prohibiting the sites from releasing planning information and consulting with stakeholders in developing the Performance Management Plans concerning accelerated schedules for cleanup. These actions, they said, signaled to them that, although there had been no formal policy change, DOE-EM Headquarters was initiating a significant change from the collaborative approach that had been built over the previous decade through the public participation process.

\section{The Sites' Channels of Information Distribution}

\section{Patterns of Distribution and Use}

As shown in the site summaries, there may be multiple DOE programs and associated public participation programs, other than those sponsored by EM at any one site. Each site's participation programs have established a number of channels for informing the public. The public relations office is responsible for some channels, the public participation staff for others; responsibility is shared for still others. Typically, these channels include a public reading room (or more than one), a website, newsletters, fact sheets or other publications, and a toll-free telephone number. Advisory boards often have supplementary channels of information, particularly the assistance of support staff to help them identify and obtain information. Most sites have mailing lists for distributing information to stakeholders. At some sites, those responsible for different aspects of public participation have different and separate lists (for example, a list for NEPA activities).

Often these information channels are not used or only selectively used by actively involved stakeholders. Some stakeholders have their own channels and personal networks for obtaining information. For example, some members of "focus groups"10 at the Savannah River Site commented that, having formerly worked at the site, they know whom they should ask for specific information. Respondents at Hanford and Paducah described similar information-gathering strategies. In addition, many (though not all) SSAB members interviewed, reported that they rely on information packets prepared for each board or committee meeting and use the meetings as the primary opportunity for soliciting information in a detailed question-and-response process.

Nevertheless, in addition to meeting regulatory requirements and the needs of those who do regularly use them, the formal channels have great symbolic value in demonstrating DOE's openness to public participation. If reading rooms were to be closed, for instance,

\footnotetext{
${ }^{10}$ Focus groups are formed under the committees of the SSAB to study particular issues. People who are not on the advisory board but who have technical knowledge of and/or interest in a particular issue can serve on focus groups.
} 
the public would likely take this as a sign that DOE was becoming secretive and intending to withhold information.

\section{Evaluations of Quality and Utility}

Generally, interviewees gave low ratings to the qua lity and timeliness of materials in the public reading rooms, largely because the large volume and technical nature of much of the material make it difficult for the average person to use. In addition, some mentioned an inability to find specific or pertinent information or a lack of knowledge about the location of the reading rooms. The Fernald reading room (which was being considered for transfer at the time of the PNNL site visit) was praised for its easy accessibility and user-friendliness, as well as its allocation of shelf space for documents published by the Fernald Residents for Environmental Safety and Health (FRESH). Oak Ridge was in the process of opening a new building designed to house all publicly available documents under one roof. This had also recently been accomplished at Paducah. At Los Alamos, three advisory board staff, including a technical advisor, are now located in a new office in Santa Fe; the site's Environmental Restoration (ER) documents are occasionally placed in that location.

The quality of websites varied greatly from site to site. After the terrorist attacks of September 11, 2001, all DOE websites were taken down and "scrubbed" to remove sensitive information. At the time when PNNL conducted its initial and follow- up review of website content (January and July 2002) some, including the Los Alamos and Savannah River sites, had not been restored, although the advisory board websites were accessible. Others, such as the Fernald and Oak Ridge websites, are notable for a wealth of understandable, current information, while Hanford has a particular advantage in that an additional website is provided by its state regulatory agency. Still others were found to be either hard to access or outdated, such as the Nevada SSAB website and the general Los Alamos website.

All sites have EM mailing lists and many (particularly Fernald, Hanford, Oak Ridge, and Savannah River) publish regular, frequent information updates and calendars to notify the public of upcoming decisions and meetings and the availability of pertinent documents. Many respondents expressed their appreciation for this type of information - it was seen as very timely, succinct, and effective in giving a quick "heads-up" on upcoming events. NEPA issues and documents are managed separately at most sites, and information, including copies of documents, is distributed through a NEPA-specific mailing list.

At most sites, public educational and information activities are the responsibility of DOE, and EM is able to take advantage of these activities as a general informational service about the site. For example, the Savannah River Site provides extensive outreach and educational programs, through both DOE (e.g., the DOE Science Bowl and grants to local universities and colleges) and its contractor, the Westinghouse Savannah River Company, as well as through ecology programs funded through the Savannah River Ecology Laboratory and the Savannah River Archeological Research Program. 
Several sites, e.g., Oak Ridge and Hanford, reported that they are reducing or eliminating their EM-sponsored community educational activities because of funding shortages.

\section{The Role of Public Participation Activities in Disclosure}

Accurate, timely information is necessary for effective partic ipation. However, in addition to distribution mechanisms such as newsletters and websites, the public participation activities themselves serve as an important way to inform the public and demonstrate a willingness to disclose information in a timely manner. Frequently, such disclosure results in information that is more understandable and immediately useful to many members of the public. In part, this results from the process of preparing to meet with the public; in part, it results from the interaction process itself.

First, the various participation activities result in preparation of different kinds of materials tailored to different audiences, to supplement the formal requirements for document release. A number of persons whom the study team interviewed noted that preparing to meet with the public - in workshops, formal public meetings, board and committee meetings - influences the way in which DOE-EM staff think about and, subsequently, present the issues. One community member at the Savannah River Site, for example, particularly emphasized the value of public interaction in helping agency staff hear how their explanations sound to the public, as well as helping agency staff look at site issues in a practical, community-oriented way. Preparing to face the public encourages agency personnel to think of the types of questions that are likely to be asked, to think more broadly about the issues, and to focus the material accordingly. Different kinds of information are therefore assembled: less complex material for the less engaged public and detailed packages of information for SSAB board and committee meetings. (Board members, in particular, frequently emphasized the extensive information prepared for meetings - particularly the committee meetings.)

Second, the activities themselves frequently expand information disclosure and help the agency clarify its informational materials. Public participation activities promote inquiry and information requests from the public and, to the extent that they result in dialogue, they extend the information that is disclosed via response to comments and questions. Many interviewees reported that they view board and other public meetings as an opportunity for dialogue and detailed questioning of DOE to learn about issues. Further, stakeholder interactions typically expand the knowledge base of all, as the more knowledgeable stakeholders pass on their knowledge, provide a framework for understanding, and mentor less knowledgeable members. This process has expanded even further as the SSABs from different sites meet and exchange information of mutual interest. 


\subsection{SubStantive Issues AND DOE-EM Public PARTICIPATION PROGRAMS}

\section{Overview}

The framing, selection, and prioritization of issues to be addressed and decisions to be made have significant consequences for both site management and the affected communities. These activities are a key function of the scoping and public involvement requirements of NEPA and CERCLA, as well as of DOE-EM's public participation policy. The need to provide a forum for stakeholders to participate more effectively in identifying and prioritizing site issues and cleanup strategies was one of the motivations for establishing the SSABs. Getting the right issues on the agenda for decision making and for public participation - and framing them in ways that reflect the public's interests - are therefore fundamental to effective public participation. A key function of public participation programs is to ensure that stakeholders have the information and forums they need to identify and act effectively on their interests. The following chapter discusses the role, challenges, and respondents' assessments of the effectiveness of DOEEM's public participation programs in helping stakeholders to (1) access information and comprehend the technical, regulatory and organizational framework, and issues at the site that are important to their community and their interests; (2) get those issues on DOE and the regulators' agendas; and (3) ensure that the community's interests are protected.

\section{Understanding Information and the Issues}

\section{Overcoming Barriers of Technical and Regulatory Complexity}

Describing issues in a way that is understandable and relevant to the public and discerning the public or policy issues in highly technical matters have always been challenges at the DOE sites. This situation continues, as evidenced by responses from interviewees, who characterized the technical aspects as "daunting" and "a struggle." Understanding technical issues is cited as a huge problem for new and non-technical advisory board members and for the members of the larger public, who may not become involved in EM public participation programs, at least in part, because they do not understand how to grasp and address the technical issues.

An important problem frequently cited during discussions with members of the public was the complexity of the cleanup task. At larger sites, in particular, the sheer number of issues was frequently seen as overwhelming - requiring concerted, long-term commitment on the part of stakeholders to prepare themselves to participate effectively. It was generally agreed in site discussions that even where members of the public are most closely involved and DOE-EM is willing to provide information and technical assistance, as with the advisory boards, it takes considerable time and effort for citizens to become knowledgeable. Most agreed that about a year of regular engagement and hard work is needed for people new to DOE and site issues to reach a point where they 
understand the regulatory, organizational, and technical/substantive issues well enough to have command of the information.

The technical and regulatory complexity makes it difficult for the public to "see the big picture," and discern and prioritize key policy issues and individual tasks from the community's perspective. Respondents frequently identified the preparation required to participate effectively as a significant deterrent to broader involvement in all forms of public participation activities. Many emphasized that it is one of the most significant challenges community members face in feeling able to confidently identify the issues of importance to them and to influence the EM agenda. This is particularly true for participants who are neither retired (and hence have sufficient free time) nor deal with site issues in their everyday work (and hence are able to devote working time to understand the issues). It was cited as one of the reasons for the relatively high proportion of retirees among the most actively involved stakeholders. Careful scheduling and structuring of meetings; clear, well-formulated background and explanatory materials; and the availability of staff support and technical assistance were all identified as important ways that public participation programs could help stakeholders become effectively involved.

A number of persons commented that the less engaged members of the public often have difficulty seeing how the topics and activities described in public notices relate to their interests and concerns. They often need help translating the topics and activities into relevant issues - a function that is sometimes served by special interest groups, sometimes by regulators, and sometimes by public participation activities such as the advisory board or the working groups. Indeed, one of the benefits of groups such as the advisory boards is that they help non-board stakeholders realize that the topics or activities involve issues that are important to them and their community.

Respondents reported that the advisory boards and other actively involved stakeholders have struggled in a variety of ways with the need to be conversant with technical - and almost equally important - with regulatory and organizational matters in order to be effective in helping to identify and prioritize issues. At Hanford, this issue has been addressed by: (1) drawing members for the advisory board from organizations who nominate their own representatives; (2) expanding membership on the board through the use of alternates; and (3) implementing an issue management and committee structure that enables participants to focus on, and hence specialize in, a subset of the issues. Almost all the advisory boards included in the study have instituted some form of committee structure. Some have hired a technical advisor (Fernald, Nevada, and, more recently, Los Alamos). Others have drawn heavily on DOE and contractor staff and retired site workers to help in the detailed committee work (Savannah River, Los Alamos, Oak Ridge, and Paducah). However, respondents pointed out that too much reliance on former and current workers may make it difficult for non-technical members to have an appropriate voice in the issue-framing process, and may encourage newcomers and nontechnical members to be overly deferential to technical members. Furthermore, such a lack of balance in the issue-framing process defeats the objective of the SSAB Initiative to seek a diversity of community viewpoints. It also opens them to critics (as at Los 
Alamos, Oak Ridge, and Savannah River, for example) who allege that the board is captive, taking the framing of issues and technical information from DOE and contractors.

At Fernald, most board members who were interviewed emphasized the need for selfeducation and pointed to the high motivation of community members to "learn the lingo." While acknowledging that Fernald was a less complex site than some, these members noted the historical influence of a citizen lawsuit on their determination to learn about the potential effect of the site on the health and welfare of their families and community. They reported that, in the early days, the learning process of involved residents was assisted by community workshops conducted by the Environmental Protection Agency (EPA); by networking with other active, knowledgeable groups; and by mentoring from political representatives. Throughout, this learning has been enhanced by residents' own continued, critical, and persistent questioning of DOE and close scrutiny of site activities. At Nevada, the board has a technical advisor who helps identify issues and prepare board members to address them. He also holds workshops to provide this same service to residents of the community.

\section{Dealing with Fragmentation of Authority and Scope}

An additional problem for the public arises from the exclusion of salient community issues from the EM agenda. At sites where remediation is not the sole DOE mission, issues of broader national or more specific local interest, although beyond EM's scope of authority, may make it difficult for DOE-EM to get the issues they are concerned about on the stakeholders' agenda, on the one hand, and for the stakeholders to get the issues they are concerned about on the DOE agenda, on the other. For example, some of the most contentious issues at Los Alamos and the Savannah River Site are centered on the sites' production mission and overall management, while in Nevada, Yucca Mountain issues overshadow the cleanup agenda. At Oak Ridge, although weapons production issues are largely targeted at the NNSA, other key issues related to land use have been moved outside of the EM purview.

At all sites, health issues are addressed separately from environmental issues by the Centers for Disease Control (CDC) and other DOE programs. Respondents most often cited this separation of health from environmental issues as a cause for frustration: some understood the organizational rationale for this approach, while others questioned whether the apparently artificial separation of the issues was a deliberate strategy by DOE to constrain open discussion. For the latter persons, the inability to get health issues on the agenda was very closely linked to concerns about DOE-wide accountability and stakeholders' ability to protect their community's interests.

\section{Identifying and Framing Issues that Influence the Agenda}

The issues that are particularly salient for the broader public may influence DOE's agenda through non-board as well as board activities - for example, the general salience of water issues at Los Alamos has influenced the research agenda and ranking of priorities in the areas of groundwater and off-site contamination through runoff. 
Respondents emphasized the importance of scoping and public review meetings that are open and accessible to the broadest cross-section of the public in ensuring identification of key issues.

DOE-EM and its contractors identify and provide at least the initial framing of issues in many of the non-board public participation activities. However, grappling with the substantive issues dimension frequently becomes a primary task for the advisory boards, whose members are in a position to see the relationship among site activities and proposed cleanup strategies, and prioritize and frame the individual issues.

\section{Forums for the Active Participants}

The boards at all sites have played a major role in framing the issues and in agenda setting. Issue identification and agenda setting have been challenging for all boards, and particularly for those where boards have sought diversity in membership and include persons who have limited previous experience of the site and its activities. This issueidentification responsibility also continuously raises the caveat by board members that they are not substitutes for the broader public and that the SSABs are not substitutes for public involvement activities that provide opportunities for broader public input. Indeed, board members at a number of sites emphasized that the is sues they have come to identify through their intensive interactions may not be the issues of concern to other, less-engaged members of the public.

In some cases, the SSAB's role has been shared with other groups that play an active role in identifying and prioritizing issues. For example, at Oak Ridge the LOC also fulfills this function. At Fernald, FRESH ${ }^{11}$ also conducts meetings and pursues its own community/DOE agenda outside of board activities, as well as providing members who participate on the board. At Paducah and Hanford, activist groups (who also have representatives on the board), and, in the case of Hanford, the active involvement of the regulators, contribute to the process. In other cases, an active nucleus of former site workers who are either board members or participants in committees, as at Oak Ridge, or in focus groups, as at Savannah River, have formed a knowledgeable subset of stakeholders that can be drawn on in discussions and in mentoring less experienced participants.

Some communities and some boards have a significant cadre of members whose organizations compensate them for the time they spend on site issues and public participation (for example, representatives of local governmental organizations, site contractors, and some non-governmental organizations), thus enabling them to become knowledgeable about and focus on issues pertinent to the DOE site. Hanford, for example, benefits from having a large group of stakeholders who are highly knowledgeable about the issues, as well as able to devote a great deal of time to keep current, analyze site information, and attempt to influence the framing of issues and agenda of decision-making. Other communities and other boards have several active

\footnotetext{
${ }^{11}$ FRESH was established to advocate for the health and safety of neighboring citizens and has played a
} very active role in site activities. 
stakeholder groups whose members work to get issues on the agenda. At Fernald, the advisory board, FRESH, and union representatives have all been long-term, active participants: DOE staff attend and make presentations at FRESH monthly meetings. At Oak Ridge, the LOC, the city Environmental Quality Advisory Board, and individual residents likewise play an active role in getting community issues and priorities on the agenda.

The presence of a strong contingent of retired site employees also influences the nature of the active participants at some sites, particularly when a significant number of the retirees have spent their careers working on environmental monitoring, cleanup, and nuclear safety at the site. The focus groups at Savannah River, for example, include a large contingent of retirees who play a very active role in getting issues on the agenda, as well as serving as a peer group that can make a contribution independently of the board.

Some boards are now facing the loss of highly engaged, informed members through term limits. While term limits may be valuable for bringing in fresh ideas and viewpoints, some respondents expressed concern that these losses may nevertheless change the character of the boards and/or reduce the boards' effectiveness in serving their role as the community's "institutional memory." The former concern was mentioned by several respondents at Oak Ridge. The latter concern was voiced frequently by members of the Fernald board, whose members believe it is important to preserve continuity in board membership as the site faces closure: in this way, the community could ensure the continued involvement - and scrutiny - of members with a thorough understanding of site issues related to closure. At Hanford, a number of respondents mentioned the value derived from continuity of board membership. This continuity was seen as particularly important in the face of the recent changes in top-level EM staff at several sites, including Hanford, Oak Ridge, and Savannah River.

\section{Ways to Engage the Broad Public}

Boards are increasingly serving as "sponsors" of outreach activities designed to engage a broad cross section of the community. The Fernald board, for example, was a pioneer in informing and engaging community members to reach agreement on constructing a waste cell to store waste on site rather than shipping it to another site. The board continues to lead in educating and engaging the broader community on stewardship. At Paducah, the board began to play a more active role in the community following widespread media coverage, during 2000, of previously undisclosed issues of contamination; many members reported that the disclosures had increased awareness of their responsibility, as a board, to represent the community's interests.

Two effective mechanisms, developed in Oak Ridge and subsequently replicated by other boards, have enabled the boards to leverage their access to early information about issues and plans to engage the broader public. The first is a modification of the board committee structure to include non-board members as active participants in committee work. The second is the establishment of working groups of community members to address issues of particular interest. These working groups are sponsored by the SSAB and are composed of both board and non-board members who self-select to participate on 
the basis of interest. At some sites, a facilitator helps guide the discussions, and an outside technical expert provides technical advice. Once the working group has reached its conclusions and prepared its recommendations, the recommendations are brought to the board for its deliberation. The board can then choose to transmit the working group's recommendations, perhaps with modifications, as a formal SSAB recommendation to DOE-EM. ${ }^{12}$

\section{Protecting Community Interests}

Many respondents reported different ways that the public has tried to use participation activities to ensure that their issues are taken into account by DOE-EM and the regulators and to make the case for protection of community interests. Some emphasized the value of formal procedures for public comments and DOE response and of regulatory and legally binding agreements; others the value of multiple avenues and activities; others the value of board recommendations; and yet others, the value of informal opportunities for communication created or enhanced by previous public participation activities. More generally, a number of respondents emphasized the importance of the public participation process in helping EM and the community identify and emphasize areas of common interest - where community and EM interests intersect and create a common cause.

Formal comment/response procedures such as those associated with the NEPA process were taken as a "given" by most people who were interviewed. Environme ntal activists were especially likely to single them out for emphasis, viewing them as crucial for documenting community issues and EM responses. They view them as providing the primary mechanism for confirming whether or not the community's interests are considered, as well as constituting a legal basis for challenge.

At Hanford, in particular, respondents emphasized the importance of regulatory requirements and legally binding agreements in ensuring that the community's interests were taken into account in DOE decisions. The public's ability to call upon regulatory authority and, if necessary, to take legal action was widely acknowledged at all sites as an important "context setting" condition underlying the effectiveness of the more consultative and collaborative processes of public participation. For this reason, respondents frequently commented on the importance of effective regulators. Having regulators engaged in the public participation program was identified as an important asset at many sites. This was especially the case when the regulators' engagement resulted in a more effective working relationship between DOE-EM and the regulators on issues of importance to the community.

Most of those interviewed also emphasized the need for and value of multiple activities that provide opportunities for stakeholders with varying interests and needs to become informed and make their views known. This was most clearly articulated at Fernald, where DOE has consciously implemented a strategy of "multiple doors and windows."

\footnotetext{
${ }^{12}$ See, for example, the work of the Oak Ridge End Use Working Group and the Stewardship Working Group, which resulted in publication of The Oak Ridge Reservation Stakeholder Report on Stewardship, Volumes I (1998) and II ( 1999).
} 
At this site, interviewees overwhelmingly praised such an approach as necessary, including the potential for overlap and duplication (which tended to be viewed as useful). Some persons expressed concern that DOE may be moving toward a strategy of "onestop shopping" through the advisory boards, overlooking the need to reach out to, provide opportunities for, and take into account, the interests of less-involved citizens. At every site, respondents emphasized that the boards are not a substitute for the public. This concern was voiced at Hanford, where the board has been very specific about the need for involvement of and consultation with the broader public. Similarly, at Oak Ridge, several persons questioned the adequacy of the means DOE used in addressing possible health problems and residents' concerns about contamination in Scarboro, a predominately black community adjacent to the site. At Nevada, respondents expressed concern that mechanisms to inform and involve rural community residents are not adequate, despite efforts by the board to hold meetings in rural communities.

Where multiple avenues were lacking or ineffective (e.g., Nevada and Paducah), interviewees expressed concern that community interests were not being taken into account and that a combination of an inattentive public and an insufficiently aggressive public awareness and involvement effort was resulting in a civic failure. At all sites, board members reflected frustration about lack of general public interest and the difficulty - and their general lack of success - in establishing more effective communication with the broader public. As the boards and other active participants have struggled with the challenge of getting the attention of the public and raising public awareness, they report a greater appreciation for the difficulty - and the importance - of this task and the need for an active public in achieving effective public participation programs.

As discussed in the chapter on relationships, a common the me in a number of responses was the value of informal communication and interaction for ensuring that community interests were conveyed to managers and decision-makers. Personal relationships were often identified as important in facilitating the informal communications that led to both greater understanding of one another's interests and more timely intervention in the issue framing and alternative development process. Many persons pointed to the role of public participation activities in providing for informal contacts and opportunities for the community's wishes to be recognized and incorporated into alternatives early in the formulation process.

However, it was apparent from the discussions that, at many sites, tension between community interests and DOE's mission continues to exist. Even where site staff members are seen as being very open and responsive to the community's interests, this sense of tension appears to have increased. The increase was attributed to recent indications that decisions are being made by EM Headquarters and that site managers' influence (and thus, public influence) is limited. Consequently, tension is heightened by concern that public participation may not protect community interests. Many respondents noted that the effectiveness of public participation depends on the public's attentiveness and active role in identifying, communicating, and advocating for its interests, and that this was best accomplished by being informed and using multiple means and many 
voices. They emphasized that there were limits to the contribution public participation could make in ensuring protection of community interests, both because EM generally controlled the public participation process and because, if it chose, EM could just ignore public input. These issues are addressed in greater detail in the discussion of accountability in Chapter 2.6. 


\subsection{Decision Making and DOE-EM Public PARTICIPATION PROGRAMS}

\section{Overview}

Stakeholders care about the transparency, quality, and accessibility of DOE 's decisionmaking process. An important function of public participation is to improve this process. It should ensure that all interested stakeholders are aware of the decisions being considered and know who is responsible for what aspects of the decision-making process. It should also ensure that stakeholders have access to the information they need to determine their interest in the process and develop opinions about alternatives, as well as to have the ability to influence the process by making their interests, preferences, and arguments known to the analysts and decision makers before decisions are made.

At all of the sites studied, respondents reported that they have a better understanding of the decision-making process and the basis for DOE decisions, and that they have had some influence on EM's decisions as a consequence of the public participation process. ${ }^{13}$ This was especially the case for those who have worked through the advisory boards. Many believe that EM site officials are sincere in their receptivity to stakeholder input and have become responsive to requests for information and explanation, although at some sites, respondents appear to be less confident of the durability and impact of these changes. At each site, however, there is concern over indications that key decisions are being made more and more at EM Headquarters, without the full benefit of community viewpoints. A related concern is that site managers are being discouraged from seeking stakeholder input, in part by the imposition of decision/management schedules that do not allow effective participation.

This chapter discusses respondents' comments on ways in which public participation has contributed to clarifying the decision-making process and creating opportunities for stakeholders to comment on and influence decision-making.

\section{Clarifying the Decision-Making Process}

At almost all sites, the people with whom we spoke commented on the difficulty of understanding what the decision- making process is - specifically, what decisions are being made, who is making the decision (the site, Headquarters, Congress), and how stakeholders can affect it. Many of those we interviewed said that they did not understand DOE's decision-making process. Some speculated that this was as much a consequence of a confused and volatile decision-making process as it was DOE's inability or unwillingness to explain the process. Nevertheless, most respondents did agree that, at a minimum, public participation activities had resulted in a better understanding of what decisions were being made and of the site decision process. They reported that EM site staff were doing a better job than in the past of explaining the basis

${ }^{13}$ Others emphasize that they have had more impact through litigation. 
for the agency's decisions and of explaining specific decisions, even though they also often said that they did not have a clear understanding of the overall decision-making process. At Hanford, recognizing the complexity created by the large number of decisions to be made, an effort is underway to inventory and map them in a way that helps all parties understand what they are, how they are related, and how stakeholders can be involved.

Several respondents pointed out how public participation activities had improved their understanding of DOE-EM's decision-making process. Most freque ntly mentioned was their use of the public participation process to question DOE persistently, which helped illuminate the many aspects of the decision process that needed to be taken into account. Some, as at Savannah River, for example, pointed to the role of the public in "making sure all of the right pieces are in place." Others also noted that the process of preparing to interact with the public, in effect prompted agency staff to clarify for themselves the decision process - the need to explain the "who, what, why" to the public required agency officials to develop a clear understanding of their own.

Many of those interviewed, however, also noted that local public participation is thwarted if site managers' decision- making processes are pre-empted by decisions made at Headquarters without site consultation. They expressed frustration that after working hard to reach agreement at the site level, decisions could simply "disappear into a black hole" in Headquarters. A frequent complaint was that the situation has deteriorated over the year preceding the study and that stakeholders are confused about decision-making responsibilities. One person at Hanford, for example, pointed to a disconnect between the reality that they perceived and official statements:

The decision process is absolutely not clear. Two years ago, it was, but now it is even more squishy than it was.... Now, we are confused about how we as a board can be responsive when the site/field offices report that they are strapped in what they can say to us, for example about the budget, yet at the same time, we hear public statements from EM Headquarters that this is a Field Office responsibility.

\section{Influencing Decisions}

A common theme evident throughout the interviews was the importance of an active, attentive public pressuring DOE-EM to address the community's needs related to substantive issues, decision-making, and accountability. Generally, those interviewed felt that the participation processes provided at the sites did "quite a good job" of creating opportunities for interested parties to participate, and that the opportunities were open to all. They reported a variety of different ways they used those opportunities to increase their influence on decisions. Overall, however, respondents reported mixed results concerning their success in influencing important DOE-EM decisions. 


\section{Influence Through Informal Communication and Early Input}

Respondents frequently noted the important role that indirect and informal - off-line discussions between agency staff and members of the public play in decision-making. They reported that such discussions were especially useful when they occurred at an early stage when signals about the other parties' views could influence the nature and range of the alternatives being considered and indicate areas of particular importance and difference (or agreement). Frequently, public participation activities and personal relationships between EM staff and members of the community have created the opportunity for such informal discussions. The advisory boards were viewed as important mechanisms for providing early input and obtaining feedback on how public input was, or was not, used.

In part because of their impact on informal communication and early input, barriers of language and cultural differences were seen as obstacles, and were emphasized as particularly important for residents of communities neighboring the Los Alamos site. Distance from the locus of participation activity was seen as a significant deterrent to equal opportunity for participation and influence by residents of the rural communities around the Nevada Test Site, both by the rural residents we interviewed as well as those living in Las Vegas. This factor was also identified as giving an implicit advantage to residents at Fernald, and also residents living near the Savannah River Site or in the TriCities at Hanford - who were not only more likely to have these informal relationships, but were also in a position to use them with greater frequency than those who lived further away.

Several persons highlighted the value of the SSABs in providing opportunities for early input that allows stakeholders to shape the framing of decisions, as well as being a mechanism for obtaining feedback. Fernald advisory board members particularly commended site DOE staff for their flexibility in providing information in draft format for them to review. Over time, most boards included in the study have succeeded in gaining access to information at earlier stages of its development and are provided "heads-up" alerts about upcoming issues, decisions, and schedules. Access to such information is widely viewed as a key indicator of both the nature of the relationship between DOE-EM and the board (and other stakeholders) and essential for effective participation.

\section{Formal Input and Consensus Recommendations}

Advisory board members who were interviewed were especially likely to emphasize the value and influence of consensus recommendations from a body specifically established to provide input from a diversity of community viewpoints. They reported that the boards' recommendations were influential because EM was obliged to acknowledge them, take them into account, and provide a response indicating how they had been implemented or an explanation of why they had not. None of the board members interviewed reported that the boards' advice was being ignored, even if it was not always implemented. However, some noted that the boards' recommendations did not carry 
legal authority and questioned whether they were resulting in significant change in the way DOE carried out its business.

Some respondents, as at Paducah, emphasized the importance of asking questions in a public forum so that the broader community could become aware of DOE decisions and their implications. At Hanford, one respondent commented that the actions and recommendations of the board were reported in the media and that such media visibility played an important role in ensuring that DOE-EM responded to questions from the public. At Fernald, many respondents attributed their influence to persistent questioning and close scrutiny of DOE actions. Some, for example, pointed to "beating on DOE" and constant follow-up on cleanup actions. One person noted that "We watched the way they built the waste cell - we get frequent updates, we go out and look at it." At Savannah River, several persons emphasized the value of their site staff's rigorous tracking of board recommendations and EM responses.

Some respondents at Nevada and Los Alamos expressed more limited satisfaction with their influence. In part, this can be attributed to the specific context of site activities. In Nevada, board members generally believe that they have good access to local site decision makers and that these decision makers have been responsive to the board's requests and recommendations. However, there is a feeling that the board has had limited impact and that this, in part, is attributable to the absence of strong community expression of interest and the overriding dominance of Yucca Mountain activities. In addition, state regulators have not played a very active role in the public participation program and, because Nevada is regulated by the Resource Conservation and Recovery Act (RCRA) and not by CERCLA, the regulatory requirements for public participation are less demanding. At Los Alamos, the newly reconstituted board and a variety of supporting activities are positive developments, though too recent to permit reliable evaluation.

\section{Access to the Decision Makers}

At all sites with the exception of Savannah River, ${ }^{14}$ however, study respondents expressed concern about the declining influence of site personnel in decision making. They believe that it is increasingly clear that EM is making decisions at Headquarters and that their own, direct influence is also declining. However, as part of their comments about the importance of being able to access the "real" decision makers, respondents at a number of sites noted that there were multiple organizational avenues for them to influence DOE site decisions and that they were prepared to use these alternatives if the EM-sponsored participation process proved ineffective.

Many respondents expressed particular concern about lack of prior consultation on the Top-to-Bottom Review or on their site's Performance Management Plan, as well as lack of opportunity to provide early input on budget priorities, as in previous years. Their comments indicated that early access to information and prior consultation on important decisions are widely viewed as essential to an effective public participation program, as

\footnotetext{
${ }^{14}$ The PNNL team visited Savannah River earlier than other sites and before discussion of the Performance Management Plan, management personnel changes, and the implications of the Top-to-Bottom Review.
} 
well as serving as important indicators of the nature of the relationship with stakeholders. This is why some stakeholders responded to the recent decision to cancel the scheduled review process on the Fiscal Year 2004 budget with such alarm and criticism. These actions were widely seen as an indication that DOE-EM was fundamentally, and unilaterally, changing its decision-making process and its relationship with the boards and its stakeholders - on the decisions most critical to site cleanup and fulfillment of established schedules and commitments. As stated by one person at Hanford, recent DOE-EM actions reflect "a sea change in terms of stakeholder input and access: from having some influence on Headquarters to do the right thing, we are now focused on trying to prevent Headquarters from doing the wrong thing."

Respondents at Paducah generally agreed that the public participation program, supported by greater openness on the part of local DOE officials since 2000, had increased the public's ability to participate effectively. However, they expressed a high degree of concern that events occurring just prior to the study demonstrated how quickly such progress can be reversed, given DOE's ability to control the disclosure and public participation process. They pointed, in particular, to the failure of EM Headquarters to provide a senior-level briefing to the board on the Top-to-Bottom Review (as was done at other sites). They also emphasized management changes ${ }^{15}$ and the Core team ${ }^{16}$ shutdown as indicators of their own lack of influence.

At Hanford, respondents reported mixed reactions. There was concern about the Top-toBottom Review (characterized by one person as "a disaster") and almost universal criticism of the breakdown of the process for rolling out and obtaining input from stakeholders on the site's budget priorities. The recent "C3T" effort, where the top managers of DOE, EPA, and Washington Department of Ecology meet regularly to try to work out issues and identify ways to expedite cleanup, received mixed reviews. While applauded as responsive to stakeholders' long-standing exhortations for the agencies to work more closely together, it is also regarded with skepticism concerning decision making separated from the public process.

15 Management at Paducah has recently been consolidated at the Headquarters level.

16 The Core group included representatives from DOE, state and federal regulators. 


\subsection{Relationships and DOE-EM Public PARTICIPATION PROGRAMS}

\section{Overview}

In processes that involve people, relationships always matter: people have both needs and expectations from relationships, no matter how personal or impersonal they are. How DOE treats stakeholders and how stakeholders treat DOE - and one another - affect judgments about likely future behavior, the potential for constructive dialogue and learning, ability to influence decisions, and consequently, willingness to work toward shared solutions. All of the other dimensions of the Acceptability Diamond imply the requirement for good relationships, which are needed for open communication, for shared agenda-setting and decision-making processes, and for ensuring accountability.

A key function of the public participation program is to create the public space where meaningful communication can take place and relationships of mutual recognition and respect can develop. Constructive, deliberate, and honest interaction on matters of importance conveys recognition and respect for the interests and rights of the participants. Responsiveness and openness in providing information and in considering recommendations encourage reciprocity and promote understanding. In a virtuous circle, such interaction builds relationships that facilitate effective dialogue and learning while expanding networks and channels of communication.

DOE's relationships with nearby communities were established many years before EM initiated its public participation programs. In its efforts to create a forum that would promote constructive dialogue and build good relationships, EM was necessarily dealing with the legacy of relationships between DOE and affected communities. Changing a relationship originally constrained by secrecy to one based on openness and communication has posed a challenge for all DOE-EM programs. This chapter first outlines the continuing challenge at each of the seven sites included in the study. A second subsection discusses respondents' views of the attributes of a good relationship both between the community and DOE and, at a more personal level, between DOE site staff and active stakeholders. It includes respondents' assessments of the role the site's public participation program plays in creating a public space and interactions that build relationships of mutual recognition and respect, and in so doing, facilitate effective dialogue and learning.

\section{Dealing with History and Context to Create a Forum for Effective Exchange and Relationship Building}

\section{Factors that Help or Hinder Creation of a Forum}

Creating a forum for effective dialogue has entailed changing the nature of DOE-EM's interactions with its stakeholders and altering former community relationships - a major 
task that has posed a challenge for all sites. EM public participation programs have had to work hard to create a receptive public space in which segments of the community that have felt alienated, un-represented, or excluded can come together and overcome historical hostilities sufficiently to listen and talk constructively - and begin to rebuild relationships. This has been particularly challenging at sites that have a continuing production mission (e.g., Los Alamos, Savannah River, and Oak Ridge) or a community emphasis on production (e.g., Paducah) rather than cleanup. At these sites, where EM constitutes only one among several DOE programs, EM staff may have limited authority to control interactions and address issues of concern to the community.

Respondents in all communities, although more in some than others, viewed DOE's contribution to the economy as providing a foundation for a good relationship. They cited, in particular, DOE's role as a "good corporate citizen" in providing benefits such as jobs and income. ${ }^{17}$ However, it was often noted that these benefits were tempered by the adverse consequences of economic dependence and future disruption when DOE employment declined. Respondents also identified several factors that hindered development of an effective forum and good relationships:

- Conflict over the appropriate scope of stakeholder involvement. This has been most pronounced at sites with ongoing, non-EM missions and most detrimental to DOE-community relationships when there seem to be no alternative ways to talk about issues beyond the scope of the EM public involvement program. If not resolved, these conflicts can prevent constructive dialogue on any topic; ${ }^{18}$

- Dishonesty about, or failure to disclose, pertinent information;

- Apathy on the part of the public. Effective engagement requires interested and energetic stakeholders who are prepared to do the work necessary to become informed on the issues of importance to their community;

\footnotetext{
${ }^{17}$ Mention of DOE as a good corporate citizen and the source of income and jobs was sometimes followed by expressions of concern that recent changes indicated that DOE was now most interested in moving away.

${ }^{18}$ Los Alamos provides an example of this problem. The effectiveness of the participation effort of the Los Alamos Environmental Restoration Program - and its relationship with community members - is constrained by the boundaries the program set in excluding issues concerning site and facility management that are of community concern. Resentment about the disbanding of the original advisory board, precipitated largely by disputes over scope, still exists, although the board has now been reconstituted and vigorous efforts are being made by the local DOE-EM officials to establish technical support, open information, and good working relationships. Issues of scope are creating tensions with stakeholders at Oak Ridge, even though almost without exception, respondents praised EM as being the most proactive DOE program and commended its responsiveness and commitment to providing opportunities for involvement. Conflict over scope has not been a primary issue at Hanford, or at Fernald. Clarification of scope, and maintaining the established boundaries, has been a significant distraction at Nevada. It has become more pertinent recently as issues about the relationship between the Nevada Test Site and the Yucca Mountain groundwater modeling efforts and data have affected immediate decisions. At Paducah, the boundary between issues associated with site operations and site cleanup have created confusion and dispute, if not outright conflict.
} 
- Intractable disagreements among key stakeholders. Constructive dialogue can also be blocked if stakeholders hold such different perspectives and perceptions of interest that they do not treat one another with recognition and respect.

In addition, respondents identified citizen-initiated lawsuits as an important factor that influenced interactions and the quality of relationships between DOE and the community. On the one hand, litigation was identified as creating the conditions that led to establishment of the forum for dialogue and learning, as occurred at Fernald. On the other, ongoing lawsuits at Paducah, Hanford, and Oak Ridge were seen by both DOE and the litigants as inhibiting the open exchange of information, though some of the suits were brought specifically to force the disclosure of information.

\section{Working within the Particular Community Contexts to Create an Effective Forum}

Each of the seven sites faced particular challenges that DOE-EM had to overcome to establish a forum to deal effectively with the history and context of the site. The following site-by-site description summarizes these challenges.

- Los Alamos: In attempting to overcome its history of secrecy and pronounced differences in culture and worldview to create a forum for exchange and relationship building, Los Alamos, in particular, has had to face several difficulties. The cleanup program is "an Environmental Restoration Program in a Defense Program's world" - a relatively small program at a large site, whose credibility and importance is further jeopardized by a declining budget. The site's ongoing national mission involving nuclear weapons creates continued demand for information control and secrecy at the same time that it evokes national and local opposition. The site's location amidst Hispanic and Pueblo communities creates ongoing cross-cultural tensions and communication challenges. Large differences in education and income between laboratory employees ("Labbies") and others, particularly minority groups, led several respondents to note that: (1) the Laboratory has a reputation of being arrogant and of running its own show with little public participation; and (2) the surrounding communities feel ambivalent about the economic dominance and technical expertise of the Laboratory. The Environmental Restoration (ER) office is widely acknowledged as the only office at Los Alamos that provides meaningful opportunities for public participation. However, ER activities are regulated by RCRA, not CERCLA, meaning that the public participation requirements in general are less comprehensive than at some other sites.

- Savannah River is also a continuing production site, where interactions and relationships have been influenced by the importance of the site to the area's economy. This has made people disinclined to criticize or even to question site operations, although somewhat more skepticism and outspokenness is evident downriver and further from the site. Relationships and forums for interaction have also been shaped by the site's large area of economic and environmental influence and by the demographic characteristics of surrounding communities. EM managers have recognized and worked to overcome potential difficulties in 
establishing a forum for building good relations hips with stakeholders and adjacent communities. EM managers have focused much of their public participation effort on the advisory board and on developing good relationships between board members and DOE site and contractor staff, making responsiveness to all stakeholders a high priority. This strategy, with only a few exceptions, was praised as successful and contributing to constructive relationships. Opponents of the site's non-EM missions have chosen not to participate as board members, although they use board meetings to keep updated on site activities. The site has also addressed the demographic characteristics of its communities by demonstrating support for minority members and organizations and, from its inception, establishing and adhering to strict SSAB membership rules to preserve diversity of race and background. These rules are generally recognized as consistent with the site's commitment to minority involvement. $^{19}$

- At Oak Ridge, public participation activities are fragmented among different DOE Programs. In addition to EM, the National Nuclear Security Administration (NNSA) and the Office of Science/Oak Ridge National Laboratory each conduct separate, if limited, public participation activities. The focus of opposition to DOE's weapons-related activities has centered on NNSA rather than on EM. Many interviewees expressed concern about factors outside of EM control that affect the program's relationships with the broader community. These include DOE staff rotation, which limits site autonomy and disrupts relationships; and changing contractual relationships, which have resulted in "multiplication of contractors" and "churning of workers through the system" which, they report, has shown little concern for the worker's welfare. Although the advisory board is basically supportive of DOE, members are aware that some key issues (land use, health) have been designated as outside of EM's purview and thus outside the board's sphere of influence. The Top-to-Bottom Review and development of the Performance Management Plan also brought home to board members the limited power of site, as compared with EM Headquarters staff. Most respondents distinguished very carefully between relationships with the EM site staff (which they characterized as good) and those with EM Headquarters (characterized as problematic). Many expressed concern that the new EM-HQ Management was signaling a lack of commitment to public participation in general and continuation of the SSAB Initiative, in particular. They reported that this perceived lack of commitment creates tension in their relationship with both site and EM-HQ personnel.

- Paducah is designated as an environmental restoration site, whose DOE role is separate from that of the now-privatized U.S. Enrichment Corporation. However, the economic importance of the plant to the regional economy and the resulting focus of local officials - and DOE - on continuing production and next generation operations blurs the distinction between Paducah and sites that have a continuing

${ }^{19}$ However, other opinions were expressed: (1) the rules about environmental activists have been bent to accommodate some applicants; and (2) the rules limit the ability of the board to appoint motivated, technically knowledgeable people. 
DOE mission. Respondents reported that the city's managers and opinion leaders have made it clear to the community that they view any expression of concern or opposition - or any negative reports in the news media - as a threat to the proindustry image of the community and its chance to attract new industry, including the next generation uranium enrichment plant. A constant theme among respondents was the apparent apathy of community leaders and the general public toward health and environmental issues associated with former production activities. A strong pro-environment, pro-health constituency, centered primarily on the advisory board, gained strength in 2000 , following media revelations of DOE's cover-up of contamination. Most respondents indicated that the relationship between DOE-EM and the community and between DOE-EM and the board had become better since the arrival of a new Paducah Site Manager in the Spring of 2000, in part because they felt he "always tells us what he can."

However, polarization of community viewpoints persists. In addition, respondents interpreted the failure of the EM Headquarters manager to visit the site to discuss the EM Top-to-Bottom Review, and the direct prohibition on site staff from providing information to the board or site regulators, as unfavorable indicators of EM's commitment to public participation and the community's welfare.

- As sites that are focused entirely on cleanup, Fernald and Hanford have avoided the problem of opposition to the site's mission or dispute over scope of the EM participation program that has prevented many sites from establishing an effective forum for interaction and adversely affected relationships. These sites, however, continue to face their own challenges in relationship building. ${ }^{20}$

Having lost the lawsuit and experienced intense community controversy during the 1980s, DOE Fernald undertook a variety of activities specifically designed to respond to public concerns, address controversy, and deal with media visibility. The site instituted the "Envoy Program," aimed at establishing and maintaining constructive community relationships; and initiated monthly updates and public question-and-answer periods with project officials concerning current and planned activities. Respondents at both Fernald and Hanford frequently mentioned the value of having many avenues for participation and the benefits of the good working relationships with local DOE site staff and contractors that resulted from this changed approach. DOE-EM's public participation program emphasized, and study respondents echoed, that key ingredients of their relationships were: (1) open information policies; (2) collaboration among parties with different interests to meet a common goal of cleanup; (3) willingness to acknowledge and listen to others' views; and (4) respect (rather than trust). As one Fernald respondent stated, "We don't hate them any more. There is respect. We were able to see that we are all individuals, people." Their philosophy, which was based on the belief

\footnotetext{
${ }^{20}$ Efforts to identify new missions for facilities and staff at Hanford (such as the Fast Flux Test Facility (FTF)) have created tension - but largely between stakeholders on opposite sides of the issue. When DOE decided not to take on these new missions, the "pro-Hanford, pro-nuclear facility" stakeholders expressed greater frustration with the opposition that pressed for this outcome than with DOE.
} 
that "There can never be 100 percent trust," appeared to be one of "trust but verify," i.e., a stance of being on guard and knowledgeable.

Hanford respondents emphasized that the existence of a strong, legally binding agreement concerning site cleanup - and the active involvement of the site regulators (EPA and the Washington State Department of Ecology) - are critical to substantive stakeholder involvement in particular, and making progress at the site in general. The presence of the regulators has improved the dynamic and balance of the interactions, as compared to dealing with DOE alone. Respondents view multiple sponsorship of public participation programs as reducing dependency on DOE and contributing to relationships built on knowledge and mutual respect. However, they reported that relationships have been strained at Hanford and Fernald, as at other sites, by recent EM Headquarters actions, and concern is very evident that relationships built over a period of years and based on collaboration are being eroded. There is a sense among some respondents at Hanford that DOE's commitment to rigorous cleanup of the site may be wavering, while at both Hanford and Fernald, there is concern that the current EM management does not value public participation and that the situation is regressing to Decide-Announce-Defend (or, even, as one person phrased it, "without bothering to defend").

- The Nevada site has its own set of challenges. The distance between DOE offices in Las Vegas and the Test Site, and the distances between the affected rural communities hinder communication and development of relationships. Furthermore, Yucca Mountain issues, although outside the purview of the Test Site's public participation programs, overshadow concerns about cleanup and impinge on local government interactions with DOE and the board. In these circumstances, all interactions occur through the advisory board, which has responded by increasing the proportion of board members from rural areas, holding more meetings in rural communities, and focusing on issues of greatest concern to rural stakeholders. This has had the beneficial consequence of creating a forum for interaction with rural residents and building some links among Las Vegas residents and rural community residents. Most board members interviewed believe that the site manager is dealing with the board in a genuine manner. They reported that board activities have fostered personal relationships between local DOE-EM staff and board members, enabling constructive dialogues to occur. However, for the most part, respondents indicated that, aside from the actively involved stakeholders, DOE-EM is virtually invisible to the community.

\section{Defining and Achieving Mutually Beneficial Relationships}

As discussed above, all sites have faced challenges in building good relationships that foster constructive dialogue and mutual learning. The parties to a relationship may be defined as institutions (e.g., DOE-EM) or groups (e.g., the public), but such relationships rest on person-to-person interaction and relationships. Inevitably, more actively engaged stakeholders and EM staff will have more of a stake in the relationships that are developed in public participation programs. Personal knowledge anchors the more 
abstract relationships defined by policies. This sub-section discusses the viewpoints expressed in interviews with community members on: (1) what constitutes a good relationship between DOE-EM and both the overall community and actively engaged stakeholders; and (2) the role played by public participation programs in helping to achieve good relationships.

\section{DOE-Community Relationships}

As the central party in stakeholder relationships and steward of the public participation process, DOE is the subject of considerable scrutiny and concern. Respondents tended to describe the community's relationship with DOE and the regulators primarily in functional rather than personal terms, frequently reflecting an assessment of the impact DOE's presence is having on the community. For example, DOE's contribution to the local economy through the provision of jobs was mentioned by a number of respondents as a defining attribute of the relationship at Savannah River, Hanford, Paducah, and Oak Ridge.

At sites with multiple DOE programs, respondents often noted that the community had a different relationship with EM than with the other DOE programs. They frequently reported that EM was the only part of DOE that engaged the public with a public participation program of any importance. At some sites, most notably Los Alamos, respondents distinguished between DOE and the Laboratory or its contractors.

A number of respondents said that DOE was viewed as a good corporate citizen who had been a good neighbor, providing benefits such as jobs and income. This was sometimes followed by expressions of concern that DOE-EM now appeared most interested in moving away - "abandoning the community," "separating themselves from the community," and "breaking faith with the community." DOE's strong influence in the community and its power to affect community well-being were sometimes seen as translating into a good relationship and sometimes into resentment and unease over the inequality of power. Good relationships were described as "cooperative," "open," "reservoir of trust," and "benevolent dictator." Bad relationships were described as "foreign," "DOE acts like a monolith," "DOE behaves like an arrogant parent," DOE "[puts] their mission before the interests of the community," and "The relationship between DOE and the community is non-existent."

The terms "mutual," "respectful," "open," "responsive," and "collaborative" were used to define a good relationship between DOE and the community. Respondents saw the personal characteristics and behavior of the site manager as influential in creating a good relationship with the community. Being treated with respect was frequently identified as a key element in community-DOE relationships. A number of respondents indicated that the community wanted to be treated with respect rather than with hostility, and they wanted assurance that DOE "knew the community folks" and "had a sense of what the local people were thinking about." They emphasized the importance of sufficient contact that "DOE and the community got to the point where they understood one another's viewpoints." Direct, frequent, interactions strengthened the community's ability to "trust that DOE will have their interests at heart." Lack of direct contact - and the consequent 
sense of "not being known" by DOE managers were identified as a source of unease. As one of the rural residents in Nevada commented: "DOE doesn't know the local players and the community doesn't feel represented." Open communication was often identified as central to good relationships, with access to information by the community an important outcome of a good relationship with DOE.

Continuity of personnel was also identified as a determinant of good relationship, with high staff turnover - "worse than musical chairs" - adversely affecting the quality of DOE-community relationships. This is one of the reasons given for the concern and dismay a number of respondents expressed about the number of changes in management at the sites. In addition to negating the knowledge of the community gained through continuity of personnel, respondents were concerned that the recent shuffling of people and managers around the complex was a mechanism by which DOE was seeking to avoid accountability.

One respondent commented that, at the practical level, DOE-EM's public participation programs were not influential in shaping DOE's relationship with the community largely because they did not reach a sufficient proportion of the community. Nevertheless, others indicated that DOE-EM's policy and process of providing opportunities for participation had the effect of changing DOE's behavior, which, when combined with the change in relationship with actively engaged stakeholders, did alter the community's perception of DOE and the agency's relationship to the community.

\section{DOE-Stakeholder Relationships}

As a consequence of their frequent interactions, specifically through board and committee meetings, actively involved stakeholders have had the opportunity to build familiarity and personal relationships with the EM manager and a number of DOE and contractor staff. When speaking about the relationship between DOE-EM and themselves and other actively involved stakeholders, respondents often spoke in more personal terms. For example, in characterizing good relationships between active stakeholders and site management, and staff "open," "responsive," "honest," "credible," "attentive," "helpful," "first-name-basis," were the most frequent descriptors after "respect" and "recognition." In discussion with the PNNL research team, active respondents identified a number of factors that helped achieve constructive relationships. In general, public participation was seen as providing the impetus for these factors and the forum in which interactions could occur.

Among the factors respondents identified as most important in establishing good personal relationships were:

- Opportunities and forums for working together on shared problems, and a willingness to listen as well as to explain. A high degree of interaction and firsthand or personal knowledge between DOE-EM and stakeholders was facilitated by continuity of personnel and stakeholders;

- Recognition of the legitimacy of the rights, interests, and differing perspectives of the respective parties; 
- Consistent demonstration of respect, openness, honesty, and responsiveness attributes frequently identified as difficult for DOE and Laboratory staff (LANL staff, for example, were often considered to be arrogant, disrespectful, aloof, and deceptive), as well as for stakeholders to achieve, but which were essential to the establishment of credibility; ${ }^{21}$

- Opportunity for, and commitment by, stakeholders to become informed and knowledgeable.

As a number of respondents emphasized, an important aspect of relationships is affirmation of the existence, rights, interests, and viewpoints of the parties involved. They identified achievement of mutual recognition and respect as a desired goal and effective public participation processes as facilitating progress toward that goal particularly the frequent and relatively intensive interactions associated with the SSABs, focus groups, working groups, and committees.

With some exceptions, actively engaged respondents indicated that they had succeeded in establishing that they, and the public in general, had: (1) legitimate interests in decisions concerning site management and environmental restoration; (2) a right to information and to input on upcoming decisions, budgets, and plans; and (3) views that were salient to site (and EM Headquarters) managers. This was widely considered one of the important positive outcomes of the hours they had spent working with EM on common problems, and was frequently associated with the development of mutual respect and understanding, considered to be key attributes of a good relationship. "These people are here to listen, to talk with us and have some sense of some of the feelings we have," one actively engaged stakeholder said.

Respondents viewed increased opportunities for interaction and communication as essential for establishing mutual respect and recognition among participants. They characterized advisory board and other participation processes as "excellent" for building relationships. Respondents said, "As you work together...you start building relationships and trust" and "The more fragmented DOE and the contractors are, the more relationships you need to build and deal with to ensure continuity." A number emphasized that as a consequences of these working relationships, board and committee members developed an extensive network of informal relationships that enabled them to obtain additional information, and to seek explanations and advice. However, some respondents cautioned that public participation, including the advisory board, was limited in its ability to affect overall DOE-community relationships because the number of people who could be directly contacted was small compared to the overall population.

In general, good relationships between actively engaged stakeholders (such as board members) and EM staff were considered an advantage, though some respondents expressed ambivalence. One person specifically stated reservations about the value of

\footnotetext{
${ }^{21}$ Respondents noted that once this credibility was jeopardized, as by the processes for the Top-to-Bottom Review and Performance Management Plan development, stakeholders would view every statement and action by DOE with suspicion, wondering whether they were efforts to "pull the wool over their eyes."
} 
personal relationships, indicating that it was not desirable to have highly personal relationships, "with their expectation of personal 'favors," because this interferes with the goal of achieving "good, rational decisions in public participation activities." Others commented that "some people think the relationship [between DOE-EM and the board] is too close and is seen by the public as jeopardizing the objectivity of the board." Others expressed concern about the need to maintain a balance between trust and vigilance. Given these attributes, some respondents revealed a keen recognition that their relationships with EM and site staff were tenuous and vulnerable to impact from external factors. 


\subsection{ACCOUNTABILITY AND DOE-EM PUBLIC PARTICIPATION PROGRAMS}

\section{Overview}

Accountability is a complex concept, implying a system of agreed-upon responsibilities and commitments, transparency, and enforcement. Although respondents hold different views about DOE's accountability to a community, a perceived lack of accountability can lead to distrust, opposition, and/or the imposition of overly conservative requirements all of which reduce the effectiveness and efficiency of site cleanup and program management.

Public participation plays a complex role in achieving accountability. One element of accountability is agreed-upon responsibilities and commitments. DOE-EM's policies articulate the agency's responsibilities to communities and regulators; DOE-EM's decision- making process leads to specific commitments. A second element is transparency and the availability of sufficient information to determine what has been done, by whom, when, and with what effect. As discussed earlier, public disclosure and public participation play a crucial role in both ensuring that this information is available and comprehensible, and that stakeholders have someone to go to if there are problems in obtaining information. A third element of accountability is enforcement - mechanisms to ensure that there are consequences for failing to fulfill agreed-upon responsibilities.

Public participation clearly has a role in clarifying and building these commitments and in facilitating communication that permits DOE to report back to stakeholders and enables stakeholders to press for enforcement mechanisms. The following chapter discusses the differing views about accountability found among respondents at the seven study sites and outlines comments about the role of participation programs in contributing to accountability and in serving the mechanisms that provide accountability.

\section{Clarifying Expectations about Responsibilities and Accountability: Differing Views about Accountability}

For many respondents, the topic of accountability evoked strong emotions and constituted a key component - and indeed, a key test - of whether a public participation program was effective. A few, however, noted that DOE is accountable to (and, indeed, should be accountable to) its national missions and not to a particular community. A common theme throughout many interviews was the difficulty of differentiating between EM's and the broader DOE's accountability. A number of interviewees emphasized that accountability required DOE to be open in providing information and the public to be actively engaged in site issues: knowledge of the history of site activities enables the public to hold DOE responsible and verify that the agency has indeed fulfilled its commitments and responsibilities. 
Some respondents at Los Alamos and Savannah River downplayed the importance of DOE's accountability to the local community. At Los Alamos, for example, one person emphasized that the Laboratory has a national mission and that accountability is built into the U.S. system of representative democracy - and hence does not require additional mechanisms such as public participation. For this person, responsibilities are established and accountability is provided through Congress and the Administration, with oversight by regulatory agencies whose decisions are open for public review. A member of the public at the Savannah River site similarly emphasized constitutional accountability. More common, however, was the viewpoint expressed by a Fernald respondent that "we are all taxpayers" and need to make DOE accountable for its activities with respect to the communities that host and surround DOE facilities.

Accountability tended to be given greater emphasis by environmental activists at all sites, and by most members at sites at which closure is salient. The increasing salience of stewardship has brought to the forefront a number of accountability issues. Which agency will be responsible for ensuring environmental and community health and safety after site closure? Will adequate budgetary arrangements be made? As discussed below, respondents at these sites emphasized the role of public participation in obtaining answers to these and other pressing questions.

\section{Establishing and Enforcing Accountabilities}

\section{DOE: Accountability for Site Cleanup and the Public Participation Process}

Respondents frequently found it difficult to differentiate between EM's accountability and the accountability of the broader DOE organization. This theme was evident throughout the interviews, although the specifics varied according to site context. What is the nature of EM's accountability when new waste continues to be produced by other DOE site programs, as at Savannah River, Oak Ridge, and Los Alamos, or when there is no opportunity for involvement in operational decisions and ways for them to be more environmentally sound (a concern expressed at Los Alamos, which is a RCRA site)? What is the nature of EM accountability at Paducah for potential impacts from production at a now-privatized, former DOE facility? How can stakeholders in Nevada effectively address the issues of groundwater contamination from both the Test Site and Yucca Mountain when the programs insist that the analyses be kept completely separate? How can environmental and health issues be addressed holistically - and is the separation of organizational responsibility a DOE strategy to avoid accountability?

Respondents consistently expressed concern that EM's commitment to public participation and its accountability to local communities are diminishing. In the words of one participant, "We are seeing that the impact of public participation depends on the orientation and receptivity of decision makers and whether they care about communities." There is concern that DOE will use its control of the participation process in negative ways. For example, some respondents expressed concern that DOE-EM is indicating that it will be forthcoming at sites and for stakeholders that support its process and plans while withholding information and restricting participation opportunities at sites and for 
stakeholders that challenge the agency. Most respondents reported that, currently, they do not see anyone in a position to ensure that past commitments regarding public participation are honored. Some are very concerned that the past decade of increased EM efforts to demonstrate responsiveness and the honoring of commitments is apparently being eroded. They believe that, should this occur, dialogue will be replaced with stakeholder opposition, including litigation, that will seriously retard EM's ability to implement its programs.

\section{The Public: Accountability for Informed Participation}

The importance of accountability and of mechanisms that ensure accountability was highlighted by respondents at Hanford, Oak Ridge, and Fernald, where site stewardship issues related to privatization and closure are salient. These issues are likely to be given greater emphasis at other sites in the future as they move toward closure. At both Fernald and Oak Ridge, the advisory boards have played a leading role in alerting and educating their communities about issues of stewardship. Board members who were interviewed emphasized their important role in the past and expressed concern about the need for a continued role in identifying issues and ensuring community safety, following closure. They also emphasized the value of public participation in developing the public's institutional memory, which they viewed as an invaluable safeguard in ensuring DOE's long-term accountability to their community.

Many of those interviewed during the study emphasized the importance of public participation in ensuring DOE accountability to their community. For most, a primary role of public participation - and particularly the SSABs - is to provide a means for ensuring that DOE keeps its commitments to the community. Many viewed the advisory boards and other on-going public participation activities as a way that stakeholders could "hold DOE's feet to the fire" and call the agency on the issues. However, it was generally recognized that public participation alone was insufficient to ensure accountability or resolution of internal organizational issues - particularly when DOE is the sponsor of public participation at most sites.

As with identifying issues, Fernald respondents emphasized the importance of open information from DOE and an active, informed public in ensuring accountability. This was also raised as an important consideration at Hanford and Paducah - although, at the latter site, the absence of an active public was frequently mentioned as a concern. Nevertheless, SSAB meetings were emphasized by one board member at Paducah as a principal mechanism for raising community awareness and documenting DOE's responses to questions from the public.

Respondents noted that continuity of DOE (and contractor) personnel reduces the turnover that enables newcomers to claim ignorance of commitments made by their predecessors. Respondents at Fernald, for example, commented on the benefit continuity had provided them. ${ }^{22}$ Respondents at other sites viewed the recent "staff churning" that

\footnotetext{
${ }^{22}$ Although staff continuity existed at Nevada, respondents at that site mentioned it less frequently as an advantage in terms of accountability.
} 
has accompanied the Top-to-Bottom Review as a strategy to reduce accountability, in part by preventing key site personnel from establishing long-term relationships with community residents.

EM guidance that DOE respond to the advisory boards' recommendations is seen as important. ${ }^{23}$ Respondents also generally appreciate that in the U.S. political process, accountability comes first from legally binding contracts and requirements and second from a vigilant public that is prepared, through a variety of means, to apply pressure on decision makers. At Fernald, the ongoing public involvement activities are seen as keeping people knowledgeable and engaged - and thereby enhancing accountability. Respondents at Fernald, and other sites, frequently identified a united community, attentive to their interests, as the most effective - and most essential - mechanism for achieving accountability.

\section{The Regulators: Accountability for Regulation and Enforcement}

Depending on site context, respondents gave differing degrees of emphasis to the role of regulators in providing accountability. With the exception of Hanford (where the regulators play an active role), very few interviewees spontaneously mentioned regulators as providers of accountability. However, when specifically asked about the regulators' role, most acknowledged that this contributed to DOE accountability, although there was variation in the degree to which this was judged to be important.

At Hanford, most respondents viewed the regulators as essential to ensuring accountability. Hanford is noteworthy for the very active participation of its regulators, who also sponsor public participation activities, assist with the recruitment and submission for EM-HQ approval of new SSAB members, and take very seriously their role in heeding and responding to board recommendations. Regulators at Hanford are also unique among the sites in having a strong local presence, with an eight-person EPA local office to address Hanford issues, as well as active participation by regulators from both Oregon and Washington States. Although separation of the site into two DOE structures (DOE-Richland and the Office of River Protection, the latter reporting directly to Headquarters) has complicated accountability, the close participation of the regulators is seen as a principal mechanism for closing the accountability loop. The existence of a binding, legal agreement - The Tri-Party Agreement - with specific cleanup commitments and schedules, and a State Attorney General who has made clear the State's intention to enforce the agreement, were cited by many of those interviewed as critical mechanisms for providing accountability.

At Savannah River, Fernald, and Hanford, several interviewees noted that the board had played an important role in pressing EM and the regulators to work more effectively together. However, this does not appear to have occurred at all sites. At Oak Ridge, for

${ }^{23}$ DOE Operations, Field, and Area Offices are responsible for replying to site-specific recommendations (with a copy to the Director of the EM Office of Intergovernmental and Public Accountability), while EM Headquarters replies to Board recommendations about national or cross-site issues (see EM Site-Specific Advisory Board (SSAB) Guidance, December 2000, available at http://www.em.doe.gov/public/ssab/guidance.html). 
example, most respondents reported that the regulators were not well represented and are seen as neither fully engaged nor powerful in moving site issues forward with the board. At Los Alamos, regulators were named as a good source of information, although several factors were identified as limiting their role in providing accountability. These included: lack of compliance agreements, the limited power of the State, other pressing priorities for environmental regulators, and questions about the extent of regulator access to the site. DOE and the Laboratory were generally seen as so powerful and independent that "the idea of DOE being accountable is so strange in these parts that you have to stop and think about it." At Paducah, respondents do not view either their site regulators or public participation programs as effective routes to accountability. This viewpoint has been strengthened by the apparent consolidation of power at EM Headquarters and its recent shutdown of interactions among core team members (EPA, DOE, state regulators). ${ }^{24}$ Instead, board members and other stakeholders express reliance on media coverage, use of insider knowledge, and persistence of lawsuits as means of pressing for accountability. In Nevada, although seen as working closely with DOE, regulators play a limited role in public involvement: the site is regulated under RCRA, rather than CERCLA and by the State rather than EPA; EPA is not included as an ex-officio member of the Advisory Board; and state politics are overshadowed by Yucca Mountain issues.

\footnotetext{
${ }^{24}$ Regulators may be starting to play a more important role following the recent impasse between DOE and the regulators; however, these developments are still too new to permit definitive evaluation.
} 


\subsection{THE ROLE OF THE SSABS}

\section{Overview}

A key research question that this study examined is the role of the SSABs vis-à-vis other public participation activities at each site. To what extent are the SSABs and more traditional public participation activities complementary? What is the value of the boards (which represent a significant DOE financial and staff commitment) to an overall public participation program?

Discussions with stakeholders at the sites included in the study revealed clearly that the SSABs are best viewed as playing a role complementary role to other activities - yet adding a particular value, overall, in building a strong public participation program. The SSABs at these sites play an important role in public disclosure and in facilitating EM's effectiveness in addressing the four Acceptability Diamond dimensions of substantive issues, decision making, relationships, and accountability. Despite differing origins, the boards at all seven sites have now become the hubs of public participation activities. They often serve as the base around which informational materials are developed and distributed, and as a primary communication mechanism for stakeholders - both on and off the board, and actively or peripherally engaged. At a number of sites, this prominent role has created some concern that EM is relying too heavily, and sometimes inappropriately, on the boards to represent the public. However, the boards themselves have initiated and supported activities that engage the broader public and assisted EM in designing additional outreach and participation activities. In addition, cross-site interactions among the SSABs have contributed to the development of a broad perspective on common issues.

\section{The Complementary Role of the SSABs}

\section{The Role of Non-SSAB Activities}

All of the sites selected for study offer opportunities for public participation in cleanup issues, consistent with EM policy of "providing a range of public participation opportunities tailored to meet the needs and interests of various segments of the public." This includes some combination of formal public meetings; information exchange mechanisms; workshops; and other meetings such as focus groups, and non-DOEsponsored public participation activities, as well as the SSABs. The various non-SSAB, more "traditional" public participation activities serve several important functions. In addition to fulfilling legal mandates (NEPA, CERLA, RCRA), they are designed to reach the general public, addressing different perspectives and information needs, with activities tailored to a particular cultural context. Participation opportunities not sponsored by DOE (e.g., activities of the LOC in Oak Ridge, FRESH at Fernald, and the states' and interest groups' activities at Hanford) augment those of EM and add the particular value of diversifying sponsorship of communication and public involvement. 
In general, members of the public whom the study team interviewed emphasized the need for a variety of participation activities to meet the varying needs of both DOE and stakeholders. Traditional public participation program activities such as public meetings, workshops, and newsletters are seen as evidence of openness and willingness to disclose information and hear the public's perspective. A number of respondents emphasized that this was very important, even if only relatively few took advantage of the opportunities provided.

However, there was general agreement among respondents that, on their own, these activities do not provide the level and continuity of involvement that enables the average member of the public to (1) identify and frame issues from the public perspective; (2) become sufficiently knowledgeable about the complexity of issues to provide informed input and influence the decision process; (3) build constructive agency/public relationships; and (4) hold DOE accountable for safeguarding the community's welfare.

\section{Growth of the SSABs' Role}

The public participation context in which the SSABs were originally formed varied by site. At some sites, such as Los Alamos, Nevada, Paducah, and Savannah River, the boards initially constituted the major, if not sole, site participation mechanism established as part of DOE-EM's efforts to involve stakeholders in the early 1990s. At other sites (Fernald, Hanford, and Oak Ridge) various other participatory mechanisms were well established and the boards were thus one of several ways for the public to be informed and involved in site activities. At Fernald, in particular, the site strategy was one of providing "many doors and windows" for public participation; the advisory board was only one component of an extensive public participation program. The intent was to develop an informed public that could provide input, address issues on which DOE staff believed they needed community assistance, and help build a credible community relationship with DOE.

Despite their differing origins, over the ten-year period since the first boards were established $^{25}$ the SSABs have increasingly served as the focal point for public participation at all of the sites included in this study, with the possible exception of Los Alamos (where non-SSAB focus groups play an important role in the EM program). To quote one public participation coordinator, who commented on the increasingly important role played by the SSABs, "the public voted with its feet" to concentrate their participation on the activities linked to the boards, focusing on the boards as the most desirable and influential of the public participation programs. Over the past several years, in response to this trend, all of the boards have devoted additional time and effort to develop ways to broaden community participation. The boards are increasingly

\footnotetext{
25 The boards, established under the Federal Advisory Committee Act (FACA), were formed at different times. SSABs were initially established at five pilot sites in late 1992 and early 1993 (Fernald, Hanford, Savannah River, Idaho, Rocky Flats). The Oak Ridge and Paducah boards were among the last to be established in 1995 and 1996, respectively. The Los Alamos board was originally established in 1995 and operated until 1997 before being disbanded; the board was restructured and regular public meetings were resumed in 1998.
} 
teaming with DOE-EM to sponsor activities that, although initiated by the board, draw in other members of the community.

\section{The Role of the SSABs in Public Disclosure}

One of the factors contributing to the SSABs' emergence as a focal point for public participation is the role they play in public disclosure. Most interviewees reported that EM site staff have become more open in providing information and answering questions posed by board members and participants in SSAB committee meetings. They believe that over time, relationships have become more collaborative, resulting in an atmosphere that encourages informal, open interchange between SSAB members and EM. However, respondents also reported that they believe EM Headquarters has tried to reverse this trend of openness over the past year.

Frequently also, EM staff have developed timely, succinct updates on site activities, either on their own initiative as they have tried to prepare for effective SSAB meetings and committee meetings, or in response to stakeholder (and particularly SSAB) suggestions. However, respondents also emphasized the importance - and ability - of board members (and other highly active stakeholders) to cultivate multiple means of accessing information. They pursue multiple means because of the direct value obtained from having diverse sources of information, and because their demonstrated ability to obtain information from alternative channels encourages DOE and its contractors to be more forthcoming with information themselves.

The SSAB's role in public disclosure was highlighted by a non-SSAB member at the Savannah River Site. Though generally critical of DOE, his comment confirmed the opinion expressed by others that the biggest threat to DOE, generally, is a failure to disclose information and that the site's public participation program had done a good job in increasing disclosure:

It is only through the long-term activities that we can keep a hand le on being informed - without this, there is not enough time built into the NEPA process for the public to find out what is happening and have enough time left for meaningful comments. Ninety percent of what the CAB (Citizen Advisory Board) does is irrelevant but the important thing is that $\mathrm{CAB}$ meetings provide a way for us to get information and bring critical issues to someone's attention.

Similar views were expressed at Los Alamos, where the board is recognized as a particularly effective venue for obtaining information about programs and building relationships with the scientists doing the work.

A key theme throughout the interviews at all of the sites was the difficulty of getting the attention and informed input of the broader public. The SSABs themselves have played a critical role in reaching out to the broader community. All SSABs included in the study encourage community members to participate in committee meetings, in an attempt to draw on the community's experience and to deepen discussion of particular topics of 
interest. In a limited way, the focus groups at Savannah River draw on local knowledge to provide independent commentary. Each of the SSABs has established its own web page to provide access to site activities and issues as well as SSAB activities, and most have a committee that is responsible for outreach to the broader community. The Oak Ridge SSAB, which includes two high schoolaged members, also has a particularly active committee that is engaged in outreach with the schools.

Respondents emphasized that many SSAB members take seriously their responsibility to the public; they view themselves as brokers between the public and DOE, and try to increase awareness and involvement while also representing the community by identifying issues and values important to the community. At Paducah, a SSAB member expressed the view that the measure of the board's effectiveness is its ability to increase public awareness and that the public forum provided by the CAB meetings - which are videotaped - provides the primary opportunity to do this. At Hanford, the Hanford Advisory Board's (HAB) public involvement committee has developed guidance for evaluating the public participation program, and presses the Tri-Parties to increase their efforts to involve the broader public.

\section{The Role of the SSABs in Addressing the Dimensions of the Acceptability Diamond}

At most sites, the SSABs provide a reservoir of committed, knowledgeable community members who are an important source of the institutional memory about DOE site activities and agreements. To quote one member of the public at Fernald: "We defined what public participation is." Some stakeholders have been involved as SSAB members since inception of the boards (e.g., Fernald, Hanford and Paducah); others are ex-SSAB members or ex-workers who continue to be associated with the SSAB committees and related activities (Oak Ridge and Savannah River). Many have become involved in cross-SSAB meetings and have learned from the experience of other sites. These persons have a comprehensive knowledge of site issues: many have devoted an enormous amount of volunteered time to understand DOE's organization and the regulatory process, as well as the technical issues at their sites, and to help in the framing and resolution of site issues. They play a key role in public disclosure and in bringing to EM's attention and maintaining its focus on issues related to all four dimensions of the Acceptability Diamond.

Respondents reported that the long-term, relatively intense nature of the SSAB offers several advantages. Specifically, members:

- Become knowledgeable about the "big picture" site issues;

- Are better equipped to provide informed input to decisions;

- Have a forum and time to build effective working relationships with DOE-EM staff and contractors;

- Have the requisite institutional memory for holding DOE accountable for past actions and ensuring commitments to the community are kept. 
Where seen by members of the broader community as representing the community's interest and protecting its welfare, SSABs are particularly able to provide added value to DOE. Respondents at some sites expressed concern, however, that because EM Headquarters is the sponsor of the boards and has final approval power over the selection of board members, the Boards are biased toward DOE - or at least influenced by the power DOE exerts over their continued existence. This has been a particular issue at Los Alamos, but the concern is widely voiced.

The value of SSAB members' comprehensive understanding is clearly demonstrated in their ability to address substantive issues. As discussed in Section 2.3, a common theme in the interviews was the daunting, and even overwhelming task, of understanding technical issues and the organizational and regulatory context. SSAB respondents frequently mentioned the value added by their ability to see the connections among the multitude of decisions to be made and to ascertain the policy implications of technically framed decisions. They emphasized that board members, because of the time and effort they expend studying and discussing site issues, are more knowledgeable and better equipped than many other members of the public to grapple with the complexity of the site and to identify and prioritize individual issues and decisions from a community perspective. The boards at all sites included in the study have played a major role in contributing to an understanding of the issues and to bringing community values and, frequently, a common-sense perspective, to agenda setting and ranking issues in order of priority. Although this role may be shared with other stakeholder groups, the boards frequently act as the official and authoritative focal point for this process and serve as the primary mechanism for conducting the public debate. At Oak Ridge, for example, LOC respondents reported that they worked through the public forum provided by the SSAB to get their issues recognized and on the agenda. At Fernald, FRESH and the advisory board both play active roles in speaking for the community, but the board has acted as the official communicator in framing issues and educating the community on issues related to the waste cell and stewardship. At Nevada, board meetings are the primary forum for public disclosure and involvement regarding the test site.

The knowledge that SSAB members develop over time, as well as their seat at the table where decisions are discussed in their formative stages, also enables them to influence the decision-making process. SSAB members may be more likely to recognize the issues involved in the specific decision under consideration as well as having a broad understanding of how that decision fits into the overall site context. In part, this is because their involvement in a series of decisions over time and the greater ease with which they can interact with and question DOE and contractor staff enhance their ability to clarify what the decision process is and how decisions are made. This familiarity and ease of exchange, however, raise a recurring concern voiced by respondents at all sites. At a minimum, persistent questioning from informed SSAB members encourages EM management to spell out the basis for site decisions. But the concern, expressed by both board members and others, is that the boards will become an elite clique, more oriented toward internal discussions than toward the broader public. In addition, there is concern that the ease of accessing the board and the difficulty of effectively informing and 
providing involvement opportunities for the broader public, may lead DOE to reduce other components of the participation program.

Long-term interactions through the SSABs have been essential in developing effective working relationships between DOE-EM and the public. Public participation programs were initiated in the 1990's, following an era of secrecy and community distrust, and in some cases, legal action and bitter controversy. At all sites, the SSABs have enabled stakeholders to get to know one another - to know one another personally, as individuals whose viewpoints are understood and whose opinions have standing. The boards provide time and opportunity, through frequent and continued interactions, to develop a basis for mutual respect: for DOE-EM to build a demonstrable record of openness, responsiveness, and consideration of the community's welfare in site decisions on the one hand, and for community members to demonstrate, on the other hand, that they are informed and can add value (e.g., through saving time and money) to decisions. This process has been particularly valuable for sites such as Fernald, where high levels of concern about potential threats to community health, accompanied by litigation and high media visibility, had prevented productive discussion between the public and DOE. At the study sites, with only few exceptions, participants affirmed the value of the SSABs in building effective working relationships - even though they expressed the need to maintain distance or vigilance. Respondents also recognized that the efforts of EM site staff to build such relationships may be constrained by factors outside their control.

Finally, the long-term involvement and knowledge of the SSABs also help address concerns about accountability. Because of their longevity, which may outlast that of DOE-EM site staff, SSABs are in a position to keep watch over EM's activities including commitments - over time. Significantly, for example, the Fernald and Oak Ridge SSABs have taken the initiative on issues associated with stewardship, raising questions about the mechanisms to ensure accountability for the community's long-term welfare after site closure and EM departure. The SSABs also play an important role in relation to the regulators who are officially responsible for DOE oversight. This role is fulfilled directly through discussions at board meetings, as well as through the relationships established with regulators through their interactions on the board. In some cases (as at Savannah River and Hanford), interviewees report that the SSABs have played a leading role in pressing DOE-EM and the regulators to work together effectively. In others (as at Paducah and Hanford) advisory board members have taken an active role in identifying and calling the attention of regulators to issues that require oversight. 


\subsection{SUMmaRY AND CONCLUSIONS}

The findings presented in this report are based on research into stakeholders' perspectives on DOE-EM's public participation programs. The research was conducted at seven DOE sites, between January and July 2002: Fernald, Hanford, Los Alamos, Nevada, Oak Ridge, Paducah, and Savannah River. The study occurred during a period of significant change in the management of the EM program. Consequently, the findings reflect the uncertainty and anxiety expressed by study respondents about the meaning of management changes for the future role of public participation within EM - and more broadly, across DOE programs.

The EM public participation programs at the seven sites in the study incorporate a variety of activities and address a wide range of site activities and decisions. The study used the Acceptability Diamond as an evaluative framework to answer the following questions about the role public participation, and particularly the SSABs, plays in information disclosure and in the four interrelated dimensions of a federal agency's interactions with its neighboring communities and stakeholders:

- Substantive issues: What role does public participation play in enabling stakeholders to access and understand pertinent information, identify their interests and frame the issues, get their issues on DOE and the regulators' agendas, and protect the community's interests?

- The decision-making process: What role does public participation play in clarifying DOE-EM's and the regulators' decision-making processes and providing opportunities for stakeholders to influence DOE's (and in some cases regulators') decisions?

- Relationships: What role does public participation play in creating a forum for effective exchange and relationship building, and in helping the participants define and achieve constructive relationships?

- Accountability: What role does public participation play in clarifying expectations about responsibilities and accountability, and in establishing and enforcing accountabilities? Was sufficient information available for stakeholders to determine what has been done, by whom, when, and with what effect?

\section{The Effectiveness of the Acceptability Diamond Framework}

The study found that the Acceptability Diamond framework worked well. It made sense to those being interviewed - both members of the public and EM and contractor staff and was effective in providing a framework for discussing the role and effectiveness of the public participation program that was meaningful to both participants and sponsors. The framework provided a means of assessing the effectiveness of the sites' public participation programs from the perspective of participants, as well as providing guidance to managers. An important finding was that at each site, different people emphasized different dimensions of the diamond as most important. 
In addition, discussions with stakeholders underscored the essential role of open disclosure of information. Open disclosure is a prerequisite for effective public participation. It underlies all four of the dimensions of acceptability. It is a prerequisite for community members' ability both to understand and confirm EM's identification of the issues and to understand and identify issues of importance to themselves (the substantive dimension). It is also a prerequisite for community involvement in, and ability to influence, the decision-making process. It is a key ingredient of respectful relationships and relationship building and indicates that EM is indeed operating in a credible, open, responsive manner. And, finally, it forms the basis for accountability without accurate information and the means to follow up on decisions and commitments, the public cannot be confident that cleanup operations are actually implemented as planned and that their concerns are truly being addressed. Issues about timely and thorough disclosure continue to cause concern and disrupt relationships at a number of sites, particularly Paducah. Providing information in a format and style that makes it accessible and useful to the public was identified as a continuing challenge at all sites.

\section{The Essential Role of the Public and the SSABs}

The discussions also emphasized the essential role of the public. Without an attentive public that exhibits concern about site issues, participation mechanisms are ineffective. The public at a number of sites faces considerable obstacles in acting on their interests: long distances between locations, the time and effort required to gain sufficient understanding of complex site issues, and the time and effort required to follow a problem through from identification to resolution - which often takes years. In addition, contamination at some sites (for example, Nevada) cannot be seen or felt and it can take years before the consequences are known. This increases the challenge of getting the public's attention.

Almost without exception, the stakeholders whom we interviewed emphasized the need for a variety of public participation activities that provide opportunities for a broad crosssection of the public to become informed and involved. People have different interests and issues and prefer different levels of participation: an effective participation program provides a variety of activities that address varying needs, including fulfillment of regulatory mandates. Respondents believe that providing multiple avenues for information exchange and engagement is important and worthwhile even if only a few members of the public take advantage of the opportunities provided. Offering a variety of activities has symbolic as well as substantive value and is seen as evidence of EM's continuing openness and willingness to hear the public's perspective.

Respondents emphasized that the SSABs are best viewed as playing a complementary role to other avenues of communication and participation. The boards have played, and continue to play, a key role in building strong public participation programs. At all the sites studied, the boards have become the centerpiece of public participation - the primary mechanism for providing information and opportunities for input. They are seen as facilitating and enhancing public disclosure and as an important forum through which 
non-SSAB members can provide input. At a number of sites, the boards' committees have been modified to enable and encourage participation by non-board members, although some problems about scheduling and announcing committee meetings were noted. Most boards allow members of the public attending the meeting to participate actively. Many board members are very conscious of their responsibility to the public and view themselves as brokers between DOE and the public. They try to increase awareness and involvement, while also representing the community by identifying issues and values important to the community. Each board has developed its own outreach - all have web pages and newsletters, and several have committees that focus on reaching the public. Nevertheless, at all sites, success in reaching the broader public was considered limited, at best.

The long-term nature of the SSABs plays an important role in facilitating DOE-EM's effectiveness in addressing the four dimensions of the Acceptability Diamond. At many sites, boards have become an informed and experienced resource for EM throughout the planning and decision-making process. Furthermore, cross-site communication through SSAB Chairs' meetings and workshops, emails, and visits has contributed to a broadening of perspectives on the issues and challenges facing the EM program, as well as providing a valuable mechanism to help struggling programs. In addition to reaching out to their broader communities, the boards have educated site personnel about community priorities, as well as the role and need for pubic participation.

Overall, the SSAB Initiative has established a knowledgeable subset of members of the public. These citizens understand the DOE and regulatory context, are knowledgeable about cross-site issues and perspectives, and know how to raise their concerns and give useful input. Further, expectations have been raised about how DOE will interact with stakeholders regarding the EM Program. As discussed below, many persons interviewed by the research team expressed concern about recent EM Headquarters actions and questioned what this meant for the future direction of site management and EM management's continued commitment to public participation.

\section{Performance on Information Disclosure and the Four Dimensions of the Acceptability Diamond}

The study provides a basis for evaluating the performance of DOE-EM and its public participation program in meeting community needs in terms of the dimensions of the Acceptability Diamond. As stated above, it took place during a period of significant change in the management of the EM program. Consequently, the findings reflect the uncertainty and anxiety expressed by respondents about the meaning of management changes for the future role of public participation within EM - and more broadly, across DOE programs.

Study respondents expressed particular concern about DOE-EM Headquarters' decisions to modify their information disclosure practices, as evidenced by the lack of stakeholder involvement in the planning and formulation of significant documents such as the Top-toBottom Review and site Performance Management Plans. This apparent modification of 
approach had a cascading effect on each of the other dimensions of the Acceptability Diamond. It serves, also, to illustrate the central role information disclosure plays in public participation and the signal effect it has for stakeholders.

\section{Information Disclosure}

Since the establishment of the EM public participation program, respondents at most sites reported that substantial progress had been made in consistent and timely disclosure of accurate information about DOE-EM plans, activities, and site conditions pertinent to the community and of interest to stakeholders. They recognized that this progress resulted from a commitment to disclosure at both DOE Headquarters and the field offices, and at most sites gave DOE-EM high marks for the changes they had made. The establishment of multiple channels for information dissemination, including the Site Specific Advisory Boards, was widely noted as contributing to this progress. Study respondents at all sites emphasized the importance of an attentive and critical media and vigilance by interest groups and the general public to the actual disclosure of information. They believe that such attentiveness also contributes to public confidence in the disclosure process.

While acknowledging the effort being made by the boards, interest groups, and the public in this regard, respondents believed that both the media and the citizenry could, and needed to, do better. Revelations by newspapers of information about site conditions and activities that had not been disclosed by DOE, most dramatically at Paducah, were seen as evidence of a need for continued attention to, emphasis on, and improvement in disclosure processes within DOE. Study respondents also emphasized the need for greater effort to provide materials and activities that helped the public deal with the volume and complexity of information. Though improved, most did not consider existing materials and avenues to be maximally effective.

Events occurring at the time of the field research conducted for the study raised concerns among respondents that the progress made during the 1990s was being reversed. Many believed that decisions were being made by DOE-EM Headquarters to withhold rather than share information with the public, denying stakeholders access to planning information that had previously been shared with them. Many respondents expressed concern that, although there had been no formal policy change, this signaled a fundamental change in DOE-EM's commitment to openness, disclosure, and consultation, as well as the value EM Management placeson stakeholders' contributions.

\section{Substantive Issues}

Respondents generally reported that the public participation programs at their sites had increased the ability of the public to identify their interests and issues and to get those issues on the site's agenda. High-engagement activities such as the advisory boards, committees, and working groups were recognized as providing particularly effective opportunities for stakeholder involvement, since they allow stakeholders to participate in the framing of issues and agendas for research and implementation. However, the success of such efforts was judged differently at different sites. Activities that brought non-technical and technically knowledgeable members of the public together were seen 
as an important way to overcome barriers to participation created by the technical and regulatory complexity of the issues. In general, these activities were considered most useful when special attention was given to education and collaborative discussion.

Many respondents commended site technical staffs for their efforts to provide explanations, present their materials more effectively, and to include stakeholders in the problem definition and issue framing process. They noted that the active participation of regulators in these high-engagement activities contributed to their effectiveness, in part because it helped address the problems created by fragmentation of authority over siterelated issues. However, none of the respondents thought that the problem of effective outreach to the public had been solved.

Concern was expressed about the large majority of the affected public that remained unaware and uninvolved. Respondents at multiple sites also expressed concern and frustration that issues of long-term stewardship were not being placed on the agenda quickly enough. The decision by DOE-EM Headquarters to conduct the Top-to-Bottom Review, to prepare the accelerated cleanup plans, and to formulate their FY04 budget request with much less stakeholder consultation than in previous years was seen as a significant setback in the effectiveness of the public participation program. Respondents reported that they believed EM was changing the agenda without their involvement, and was not taking advantage of the extensive communication and consultation mechanisms that had been put in place over the past several years. This led many to reflect on the importance of alternative avenues for the public to protect community interests when the public participation programs did not do so.

\section{Decision Making}

Study respondents reported that, although the DOE decision-making process remain opaque and somewhat incomprehensible, the public participation program had served an important function. They believed that the program has helped stakeholders understand what decisions were being made and given the $\mathrm{m}$ an opportunity to provide input at various points in the decision- making process. Many respondents noted also that the public participation program had helped EM clarify and understand its own decisionmaking process - which they considered a considerable benefit. While not claiming success, respondents emphasized the satisfaction they had in influencing decisions. They believed that, in some instances, their input had prevented what they considered to be bad or ill-considered decisions, and had helped frame and support decisions that moved cleanup forward in a better, more effective, and publicly acceptable way.

Respondents reported that both they and the public participation process became more effective as they and EM staff had become more knowledgeable and accustomed to working together within the process. However, they interpreted recent changes that shifted decision-making authority from the sites to EM Headquarters as a step backward, reducing the effectiveness of the public participation program by limiting local stakeholders' access to the actual decision makers. A number of respondents commented that this reduced the incentive for stakeholders to engage in site-based participation activities. The failure of DOE-EM to involve them in the formulation of key plans and 
the limitation of their role to one of "review and comment" was seen as further reducing the effectiveness of the participation program. It signaled to them a potential reversion to the non-collaborative "Decide, Announce, and Defend" approach.

\section{Relationships}

Study respondents generally gave the public participation programs credit for creating forums in which diverse stakeholders could come together to listen and talk constructively. Though not without its problems and failures, they also generally acknowledged that the public participation processes in place at the sites had led to interactions that resulted in relationships of mutual respect - both among stakeholders, and among stakeholders, EM staff, and regulators - as well as recognition of the public's legitimate interests in site decisions. The more intensive interaction mechanisms (for example, SSABs, committees, working groups) were identified as the participation components having the greatest impact in terms of relationship building. Their impact was attributed, in part, to their success in creating opportunities for all parties to work together on shared problems of importance to the community.

Respondents reported that contributions of EM staff and contractors conveyed respect for the stakeholders' efforts and signaled to stakeholders that they, and their efforts, were acknowledged and valued. They also reported on the negative message conveyed to the public by DOE-EM Headquarters by their recent interactions (or lack thereof) with the site managers and community stakeholders. This message was that EM Headquarters neither acknowledged the public's stake in site decisions, nor valued them or their viewpoints.

\section{Accountability}

Study respondents generally credited the public participation processes at their sites with clarifying the agreed-upon responsibilities and commitments for site management, cleanup, and regulation. Respondents generally also credited the public participation process with improving accountability by making the relationships and interactions between DOE, the regulators, and the stakeholders more transparent. They indicated that adherence by DOE-EM to its commitment for collaboration and engagement with stakeholders through an effective public participation program provides an important measure of accountability.

For this reason, EM Headquarters' exclusion of stakeholders from the formulation of critical plans signaled that EM was not only retreating from a commitment to collaboration, but was also retreating from accountability. At all sites, respondents cautioned that public participation was not a substitute for enforceable contractual agreements and clear legal performance requirements. Indeed, respondents at many sites

noted that they had alternative avenues for influencing site decisions and that if EM chose not to utilize the public participation process to undertake resolution of issues through dialogue and collaboration they could - and would - redirect their efforts toward other avenues, including legal challenges. 


\section{SECTION 3: SITE SUMMARIES}




\subsection{INTRODUCTION TO THE Site SUMmaRIES}

This section provides summaries for each of the seven sites included in the study. The purpose is to illustrate differences and similarities among sites and to provide a context for the analysis of public participation.

The summaries are presented alphabetically in this section: Fernald, Hanford, Los Alamos, Nevada, Oak Ridge, Paducah, and Savannah River. Each summary includes a background description of key aspects of the site, which is drawn from publicly available information. This information is currently scattered among a number of documents and sources. The summaries are therefore an attempt to organize the information, pulling it together in a way that makes it easily accessible and facilitates understanding of each site and the context in which public participation takes place. The data are current as of early summer 2002.

The PNNL research team prepared the descriptive subsections of each summary prior to conducting the site visits between January and June of 2002. The summaries were reviewed by the site public participation coordinators and their comments were incorporated into the final version. The descriptive subsections of each summary include a brief outline of the following topics: location, population, and land use; historical and current site missions; site management structure; cleanup and waste management activities; structure and staffing of the EM public participation program; and EM public outreach and participation goals and activities.

Following the site visits, the research team added a final subsection, based on their observations and interviews. This final component provides the team's identification, at the time of the study, of the key challenges faced by the site in addressing the four dimensions of the Acceptability Diamond and highlights their assessment of the site's status in relation to the four dimensions. 


\subsection{Fernald Environmental Management Project}

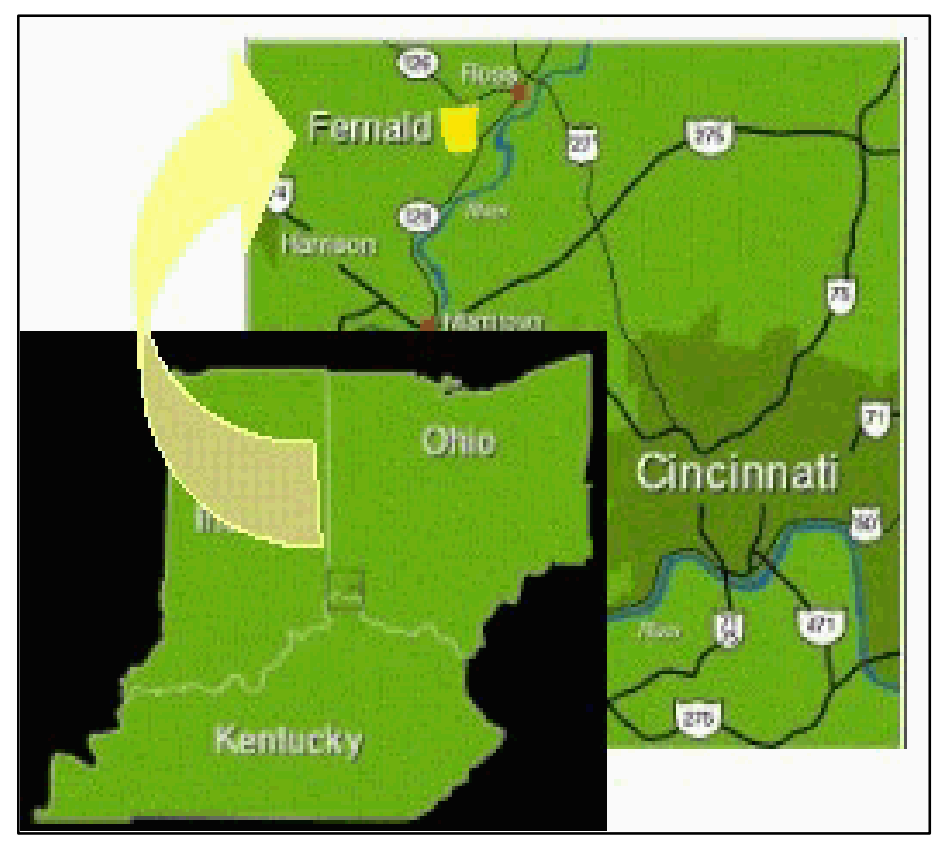

\section{Location, Population, Land Use}

The Fernald Environmental Management Project (FEMP) is located on a 1,050 -acre tract that overlaps the boundaries of Hamilton and Butler Counties in the southwest corner of Ohio. Of the total FEMP property, 850 acres are in Crosby Township of Hamilton County, and 200 acres are in Ross Township of Butler County. The facility is located just north of the small rural community of Fernald. Other small nearby communities are Ross, New Haven, New Baltimore, and Okeona. Harrison is a relatively large incorporated city nearby, while downtown Cincinnati is approximately 18 miles to the southeast. Demographic characteristics of the nearby counties are shown in Table 3.2.1.

\section{Table 3.2.1. Demographic Characteristics of Nearby Counties}

\begin{tabular}{|l|r|r|r|r|}
\hline & Butler County & Hamilton County & \multicolumn{1}{c|}{ Ohio } & \multicolumn{1}{c|}{ US } \\
\hline Total Population, 2000 & 332,807 & 845,303 & $11,353,140$ & $281,421,906$ \\
\hline $\begin{array}{l}\text { \% Population Change, } \\
\text { 1990-2000 }\end{array}$ & $14.2 \%$ & $-2.4 \%$ & $4.7 \%$ & $13.1 \%$ \\
\hline White & $91.2 \%$ & $72.9 \%$ & $85.0 \%$ & $75.1 \%$ \\
\hline Black & $5.3 \%$ & $23.4 \%$ & $11.5 \%$ & $12.3 \%$ \\
\hline American Indian/Alaska Native & $0.2 \%$ & $0.2 \%$ & $0.2 \%$ & $0.9 \%$ \\
\hline Asian & $1.5 \%$ & $1.6 \%$ & $1.2 \%$ & $3.6 \%$ \\
\hline Hawaiian/Pacific Islander & $0.0 \%$ & $0.0 \%$ & $0.0 \%$ & $0.1 \%$ \\
\hline Other & $0.6 \%$ & $0.5 \%$ & $0.8 \%$ & $5.5 \%$ \\
\hline Mixed & $1.1 \%$ & $1.3 \%$ & $1.4 \%$ & $2.4 \%$ \\
\hline Female/Male Ratio & $51.2 / 48.8$ & $52.3 / 47.7$ & $51.4 / 48.6$ & $50.9 / 49.1$ \\
\hline Median Household Income (1999) & $\$ 47,885$ & $\$ 40,964$ & $\$ 40,956$ & $\$ 41,994$ \\
\hline Per Capita Income & $\$ 22,076$ & $\$ 24,053$ & $\$ 21,003$ & $\$ 21,587$ \\
\hline
\end{tabular}

Population of Nearby Communities: Cincinnati 331,285; $\quad$ Harrison City 7,487; $\quad$ Ross CDP 1,971; Ross Township 6,448

Source: Census data for 2000 
Surrounding properties consist of agricultural and residential development with some light industry located within a two-mile radius. Residential units are situated immediately north of the FEMP site, in Ross, and directly east in a trailer park adjacent to the intersection of Willey Road and SR 128. Other residences located around the site are generally associated with farmsteads. Commercial activity is primarily restricted to the village of Ross, approximately three miles northeast of the facility, and along State Route (SR) 128 just south of Ross. Industrial use is concentrated in the areas south of the FEMP site, along Paddy's Run Road, in Fernald, and in a small industrial park on SR 128 between Willey and New Haven roads. At the time of the site visits in early 2002, approximately 50 DOE employees and almost 1800 contractors were employed at the site; this number was expected to decrease to between 1300 and 1500.

\section{Historical and Current Missions}

Established in 1951 as the Feed Materials Production Center, Fernald's original mission was the production of uranium metal for use in DOE's production reactors to make plutonium and tritium. Remediation of the site began with community controversy and a lawsuit over environmental and health issues, brought by local residents in reaction to news of uranium air-borne releases and contamination of water wells. A notice of noncompliance was issued by the U.S. Environmental Protection Agency (EPA) in 1985, and Fernald was placed on the National Priorities List in 1991. In 1986, DOE, the site contractor and Ohio EPA signed the Directors Final Findings and Orders, under which DOE and the site contractor agreed to prepare one remediation plan to comply with CERCLA and RCRA.

Operations were suspended in 1989 and formally ended in 1991, when the facility was renamed to reflect its new environmental mission. This mission is to remove or dispose of all site nuclear materials and to carry out decontamination, decommissioning, and dismantlement of all site buildings and facilities with the goal of returning as much of the site as possible to public use.

\section{Site Management Structure}

Fernald is one of five sites managed by the Ohio Operations Office, which is located in Miamisburg, Ohio. Both Fernald and the Field Office have a single mission under the programmatic direction of the Office of Environmental Management. Two elements have facilitated the development and implementation of public participation: the single site mission, and the relatively small and less complex nature of the EM Program at Fernald, as compared with other DOE sites. Fluor Fernald is the operating site contractor. 


\section{Cleanup and Waste Management Activities}

Cleanup requires: (1) decontamination and demolition of over 250 former uranium processing facilities and associated equipment; (2) treatment and removal of large amounts of waste that is contaminated with uranium, thorium, other radioactive contaminants, and hazardous chemicals (uranium is the most prevalent contaminant found in the soil and groundwater); and (3) restoration of the Great Miami Aquifer. The Aquifer, a sole source aquifer which is a major source of the region's drinking water, was contaminated as a result of releases from the Fernald site. In 1997, DOE partially funded extension of pub lic water lines in the area to avoid the need to draw from contaminated areas of the aquifer. The majority of the Fernald site is being remediated to allow for recreational uses; residential and agricultural uses will be prohibited.

To organize the cleanup and waste management process, the site is divided into five sections (operable units), based on physical location: (1) Waste Pits Remedial Action Project; (2) On-site Disposal Facility, Soil Characterization and Excavation Project; (3) Decontamination and Dismantlement (a major waste management initiative that includes all former process buildings, structures and equipment, inventoried hazardous materials and scrap metal piles); (4) the Silos Project (two of which contain radium-bearing wastes, one containing dried uranium-bearing wastes, and one empty); and (5) the Aquifer Restoration and Wastewater Project. As a result of close collaboration with regulators and the public (in particular, members of the Fernald Citizens' Advisory Board), DOE adopted a waste management strategy of transporting smaller quantities of the more highly contaminated waste off-site and disposing of larger quantities of less contaminated waste in the site's own On-Site Disposal Facility.

The site is working to an aggressive cleanup schedule. The site has conducted a rebaselining and its goal, under its Accelerated Cleanup Plan, is to achieve cleanup by the end of 2006; the overall cost of the project has been reduced from a 25-year project costing $\$ 7.2$ billion to a ten-year project costing \$4.1 billion. Long-term stewardship of the site is a key, on-going issue for stakeholders.

\section{Structure and Staffing of the EM Public Participation Program}

Fernald public affairs staff report to the Ohio Field Office Public Affairs Office, which is closely involved with the program. One DOE staff person at Fernald is responsible for both the Site-Specific Advisory Board (known as the Fernald Citizens' Advisory Board, or FCAB) and other public involvement activities. He is assisted by seven contractor staff. The philosophy of the Field Office, followed through at Fernald, is to integrate public relations and community relations programs into a common site program that emphasizes building and maintaining collaborative relationships between management and the diversity of site "publics." Clearly established public affairs strategies and performance measures are included in the Field Office Strategic Plan. 


\section{EM Public Outreach and Participation Goals and Activities}

\section{Public Participation Goals}

The stated mission of the public affairs program, which extends beyond the regulatory requirements of CERCLA and, RCRA, is to "sustain a social environment conducive to [DOE/EM's] mission execution by:

- Fostering cooperative relationships among all persons who are affected by or interested in DOE operations;

- Ensuring that information needed to make knowledgeable decisions about DOE operations is clearly expressed and readily available to anyone needing to make informed decisions about DOE operations;

- Identifying potential social obstacles to the [DOE] mission and suggesting strategies to avoid them.” (Public Affairs Mission Statement, 1999).

To achieve the above goals, Fernald has adopted a "three-legged stool approach" of public information, management involvement, and person-to-person communication. This approach is outlined in the Communication Plan for 2001.

\section{Information Distribution}

A wealth of publications concerning past, current, and planned activities is available and easily accessible on the Fernald website at www.fernald.gov/NewsUpdate/pubs.htm. The site is especially noteworthy for the combination of technical information about the site, written in a clearly understandable format, and information about opportunities for involvement. Publications are also available through the Fernald Public Environmental Information Center, which is now located on site. Several publications, available on the website, provide regular updates that facilitate tracking of the site's progress in reaching cleanup goals: the Fernald Report, published bi-monthly; A Look Ahead, published monthly; and the Fernald Cleanup Progress Report. Also available on the website are a list of contacts; an activities calendar; a series of fact sheets that provide both technical information about cleanup and public participation information; and an introduction to Fernald (history, cleanup, accomplishments, and public involvement). The FCAB website (www.fernaldcab.org/) provides an overview of past and current activities, including recommendations, reports, and meeting minutes. Dates for the $\mathrm{CAB}$ and other community meetings are clearly posted and current, as are $\mathrm{CAB}$ meeting minutes.

In addition, the Public Environmental Information Center includes information compiled under the Fernald Living History Project, which DOE and other community and academic representatives are supporting to preserve the site's history. As part of the project, DOE has provided documentation; and assisted in conducting and transcribing interviews with employees, retirees, local residents and community leaders. The Center also sets aside shelves where members of the public can access information and publications provided by the Fernald Residents for Environmental Safety and Health 
(FRESH) a local group which has been played an active role in site health and cleanup issues since the mid-1980s.

\section{Non-SSAB Public Participation Activities}

Fernald has established a wide variety of mechanisms to ensure management involvement and person-to-person communication with the full range of stakeholders. A public affairs counselor from the contractor's public affairs staff is assigned to each project and managers attend all public meetings and contact the public directly. Meetings with the public are not limited to those mandated under CERCLA and RCRA, and DOE holds a bi-monthly update meeting with stakeholders, in addition to FCAB board and committee meetings. Public affairs staff make a point of knowing and informally contacting both individual stakeholders and stakeholder groups on a regular basis. Active, involved community groups with whom interactions frequently occur include the FCAB and FRESH, as well as local officials.

In addition to an active speakers' bureau, the Fernald Envoy and Ambassador Programs provide innovative mechanisms through which site employees serve as liaisons to civic groups. The Envoy Program involves targeting key opinion leaders and ensuring that they have a relationship with a credible, trusted site employee who can provide information and access to upper management DOE staff, if needed. The Ambassador Program engages employees at all levels in participating in community activities, including assisting in channeling corporate funds, if needed, to the community.

In early 2000, the International Association for Public Participation announced that DOEFernald had been awarded the Public Participation Organization of the Year Award for best reflecting the group's core values in involving the public in decision-making processes at Fernald. DOE was cited for "overcoming citizen distrust to achieve complex consensus decisions in a very difficult arena" and for their "efforts to maintain an enduring and meaningful relationship with the public at the site."

\section{The Fernald Citizens' Advisory Board (FCAB)}

First established in 1993 as one of the early DOE-EM individual Site-Specific Advisory Boards (SSABs), the FCAB has played an important, albeit not exclusive role, in fostering stakeholder involvement in site cleanup issues and its activities are coordinated with other ongoing public participation efforts.

The 15-member FCAB was originally established as the Fernald Citizens' Task Force to provide advice to DOE and the state and federal regulators. A representative from the Agency for Toxic Substance and Disease Registry is also a non-voting ex-officio member of the board. Members of the public, including local residents, labor representatives, and academia were recruited by an independent University representative following interviews with community groups to provide "typical" views of community members on DOE decisions. New members are now selected through an area-wide recruitment process. Membership is for two years with no limit on the number of consecutive terms. 
The board meets on the second Saturday of each month; both board and committee meetings are conducted by a facilitator.

At the time of the study, an Executive Committee and a Stewardship standing committee met monthly. The Associate Director for Environmental Management regularly attends board meetings. The Site Manager also attends regularly. Board recommendations are tracked and officially acknowledged through correspondence from the Fernald Site Director.

Particular achievements of the board include its report entitled, Fernald Citizens Task Force Recommendations on Remediation Levels, Waste Disposition, Priorities and Future Use. The report, published in 1995, provided recommendations on four specific questions that were initially posed: (1) What should be the future of the Fernald site? (2) What residual risk and remediation levels should remain following remediation? Where should the waste be disposed? and (4) What should be the priorities among remedial actions? DOE and the regulators adopted the report's comprehensive recommendations almost in their entirety. Since that time, the board has continued to provide advice and recommendations on remediation, transportation, and stewardship. It has played an active role in working in tandem with the local community on key issues. In 1999 and 2000, for example, the board initiated Future of Fernald workshops to engage the community in providing input on future uses of the site following cleanup; stewardship is a continuing focus of the board's activities. The board has earned high visibility and has been cited as a model for citizens' boards.

\section{Key Public Participation Challenges and Status in Relation to the Acceptability Diamond}

Based on site visits and interviews, conducted between January and June 2002, the PNNL research team identified challenges faced by the Fernald Environmental Management Project in addressing the four dimensions of the Acceptability Diamond (substantive issues, decision-making process, relationships, and accountability).

\section{Challenges}

- At Fernald, citizen litigation prompted development of an extensive public participation program. During the 1980s and early 1990s, the site faced a highly media-visible, controversial situation characterized by deep distrust of DOE and the absence of constructive dialogue.

- Fernald was one of the first DOE sites to initiate a public participation program the site was a pioneer, with no generally accepted DOE model to follow.

- As compared with other sites, the site faced fewer challenges in terms of agreement about the scope and purpose of public participation, conflict and diversity among stakeholders, the salience of site issues to the general population, and effective stewardship of the public participation process. Fernald was a relatively small, less complex site; its mission was focused solely on cleanup; the 
surrounding population was not widely dispersed and was culturally homogeneous with no previous history of community conflict (although several persons noted that this situation may be changing with the influx of newcomers); and site issues were salient to the general population, especially in the early days. Further, diverse sources of employment were available to community members and the community was not as dependent on DOE for employment; public involvement activities were sponsored by both DOE and FRESH, with active participation by the regulators.

\section{Status in Relation to the Acceptability Diamond}

The following summarizes the research team's assessment of the site's status in relation to the Acceptability Diamond at the time of the study:

- The lawsuit provided the impetus for change to which both site staff and the public contributed. Site staff recognized, very early, the need for openness and relationship building and initiated a broad public program that was specifically designed to provide "many doors and windows" for public participation. The Fernald public was also very engaged and active in defining what public participation meant: the lawsuit made site issues very salient to the general public and a broadly based group of stakeholders mobilized the community in pushing for change in the way DOE interacted with the community.

- Substantive issues: The PNNL study team found widespread agreement that the site has been very open in providing information and that the public is able to identify and get its issues on the agenda. Synergy among members of FRESH, the $\mathrm{CAB}$, and union representatives has facilitated this process: these persons have played a very active role in insisting on information disclosure, learning about the issues, observing and questioning DOE closely, and taking the lead in alerting and educating the broader public about issues of importance to the community.

- Decision making: With only a few exceptions, study respondents agreed that the public has been able to contribute to and affect site decisions. Specific examples were cited of the public's (and especially the CAB's) influential role in decisions about storing the waste on site rather than shipping it out west, as well as the mode of shipment to be used (e.g., trains rather than trucks). A number praised the willingness of DOE site staff to provide draft information so that the public could be involved early. As one person noted, "Part of effective decision making is for DOE to be sure that they give out right information and letting people see they have options." However, many were critical of a perceived reversal to a stance of Decide-Announce-Defend (DAD) on the part of EM Headquarters staff over the past year and concerned about what this change foretold both for future public participation in decision making and the nature of the relationship with the community.

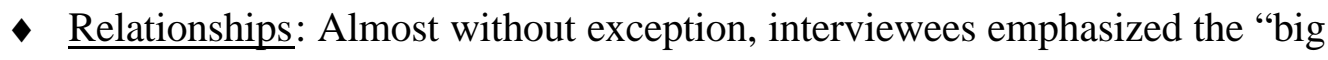
change" from antagonistic to civil relationships and the collaborative nature of the relationship between DOE site personnel and the community, which had been 
built over a period of years. Many noted that the site's public participation program is now at a mature stage and reflects the fruits of a concerted effort by site personnel to develop a track record of being open in providing information to a wide range of community groups, responding to questions and listening to public input, and showing respect for public views and the community's welfare. The word respect was explicitly highlighted by several members and in particular, by one member who emphasized the need for continued vigilance, explaining that "there can never be 100 percent trust." Continuity of both site personnel and active stakeholders was frequently mentioned as having contributed to good, mutually beneficial working relationships in which both parties know one another, and understand and respect the value of the other's contribution. As noted above, however, recent indications that EM Headquarters is moving away from collaboration with stakeholders are viewed with grave foreboding.

- Accountability: Fernald study respondents emphasized the importance of DOE accountability to the local community. They placed particular importance on open information and the role of an active public in questioning and verifying information and documenting DOE agreements and commitments. Accountability issues related to stewardship are of high salience as the site nears closure. Interviewees frequently mentioned the past advantage to their site of continuity in site personnel and board membership, which provided the opportunity to develop long-term relationships and expectations among the various parties. At the same time, they expressed concern that "as you get further from the site, accountability gets lost," and pointed to many unanswered questions about future roles - the role and budget commitment of a replacement agency, once site cleanup is officially achieved, and the role of stakeholders in ensuring DOE's long-term accountability. Many board members emphasized the need for a continued board role in safeguarding their community's welfare - stating that this should continue outside of the current Federal Advisory Committee Act (FACA) advisory board process, if that process limited length of membership. 


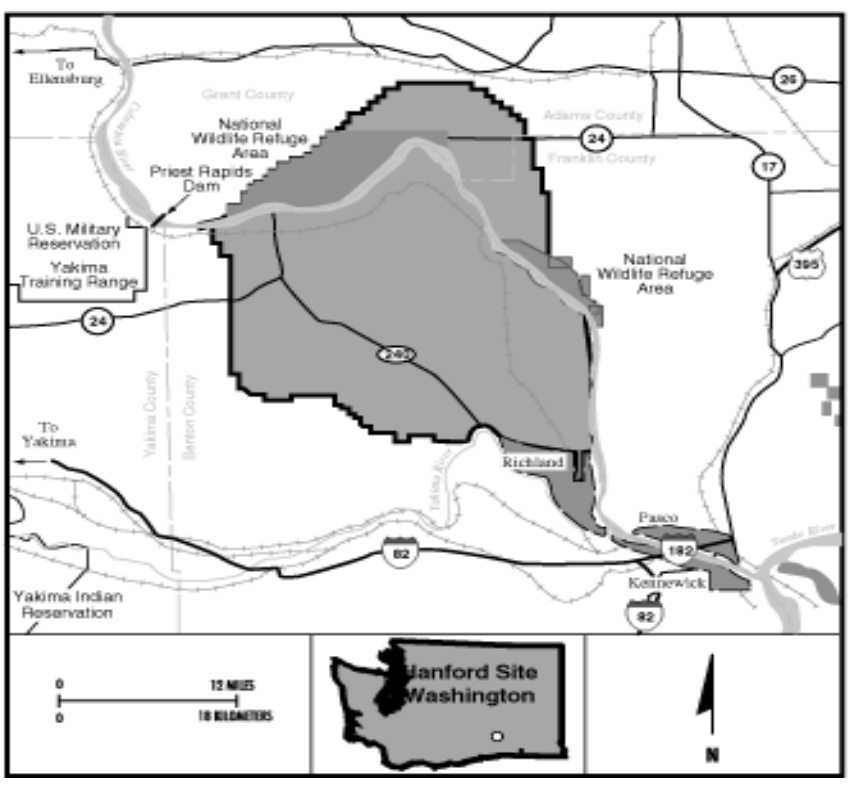

Location, Population, Land Use

The Hanford site, located in southeastern Washington State, occupies an area of about 586 square miles and includes parts of Benton, Grant, and Franklin Counties. The city of Richland is located at the southeastern border of the site, and the cities of Kennewick and Pasco are located approximately 15 miles to the southeast. In mid-2002, approximately 10,500 employees (460 DOE and 10,500 contractor staff) worked at the site, and site activity played a very prominent role in the

economic and social life of the three cities (known as the Tri-Cities), as well as in other parts of Benton and Franklin Counties. The region of influence extends beyond the TriCities to four additional counties in eastern Washington and three counties in northeastern Oregon. Table 3.3.1 presents demographic characteristics for nearby counties and cities.

The Columbia River flows through the northern part of the Hanford Site and, turning south, forms part of the Site's eastern boundary. The Yakima River runs near the southern boundary of the Hanford Site and joins the Columbia River at the city of Richland, which bounds the Site on the southeast. The rivers are highly valued local and regional resources, sustaining numerous fish and wildlife species; providing irrigation, drinking water, and recreation for communities in the Northwest; and playing a significant role in the culture of Indian Tribes in the area. Land adjacent to the Hanford site to the southeast and generally along the Columbia River includes residential, commercial, and industrial uses. The Tri-Cities, located along the Columbia River, are the closest major urban land uses. Irrigated fruit and vegetable crops, and dry-land farming and grazing are also important land uses. At the Hanford Site several areas, totaling 257 square miles (665 sq km), have been set aside for special uses. The Fitzner Eberhardt Arid Lands Ecology Reserve (ALE), used for ecological research, was established in 1967 on land between the southern boundary of the Hanford Site and State Route 240. On the north end of the site is the Saddle Mountain National Wildlife Refuge.

On June 9, 2000, President Clinton, by Presidential Proclamation, created the Hanford Reach National Monument under the authority of the 1906 Antiquities Act. As established, the Monument totals 306 square miles (792.6 sq km) and includes the ALE, Saddle Mountain Wildlife Refuge, McGee Ranch/Riverlands Area, and land one-quarter 
Table 3.3.1. Demographic Characteristics of Nearby Counties and Cities and Population for Affected Tribes and Other Communities

\begin{tabular}{|c|c|c|c|c|c|c|c|}
\hline & \multirow{2}{*}{$\begin{array}{l}\text { Benton } \\
\text { County }\end{array}$} & \multirow{2}{*}{$\begin{array}{c}\text { Franklin } \\
\text { County }\end{array}$} & \multicolumn{3}{|c|}{ Tri-Cities } & \multirow[t]{2}{*}{ Washington } & \multirow[t]{2}{*}{ US } \\
\hline & & & Richland & Kennewick & Pasco & & \\
\hline $\begin{array}{l}\text { Total Population } \\
2000\end{array}$ & 142,475 & 49,347 & 38,708 & 54,693 & 32,066 & $5,894,121$ & $281,421,906$ \\
\hline $\begin{array}{l}\text { \% Population } \\
\text { Change/1990-2000 }\end{array}$ & $26.6 \%$ & $31.8 \%$ & $19.8 \%$ & $29.7 \%$ & $57.7 \%$ & $21.1 \%$ & $13.1 \%$ \\
\hline White & $86.20 \%$ & $61.90 \%$ & $89.5 \%$ & $82.9 \%$ & $52.8 \%$ & $81.8 \%$ & $75.1 \%$ \\
\hline Black & $0.90 \%$ & $2.50 \%$ & $1.4 \%$ & $1.1 \%$ & $3.2 \%$ & $3.2 \%$ & $12.3 \%$ \\
\hline \begin{tabular}{|l|} 
American \\
Indian/Alaska \\
Native \\
\end{tabular} & $0.80 \%$ & $0.70 \%$ & $0.8 \%$ & $0.9 \%$ & $0.8 \%$ & $1.6 \%$ & $0.9 \%$ \\
\hline Asian & $2.20 \%$ & $1.60 \%$ & $4.1 \%$ & $2.1 \%$ & $1.8 \%$ & $5.5 \%$ & $3.6 \%$ \\
\hline $\begin{array}{l}\text { Hawaiian/Pacific } \\
\text { Islander }\end{array}$ & $0.10 \%$ & $0.10 \%$ & $0.1 \%$ & $0.1 \%$ & $0.1 \%$ & $0.4 \%$ & $0.1 \%$ \\
\hline Other & $7.00 \%$ & $2.90 \%$ & $1.9 \%$ & $9.4 \%$ & $37.4 \%$ & $3.9 \%$ & $5.5 \%$ \\
\hline Mixed & $2.70 \%$ & $4.10 \%$ & $2.3 \%$ & $3.4 \%$ & $3.9 \%$ & $3.6 \%$ & $2.4 \%$ \\
\hline Female/Male Ratio & $50.3 / 49.7$ & $47.8 / 52.2$ & $51 / 49$ & $50.4 / 49.6$ & $48.4 / 51.6$ & $50.2 / 49.8$ & $50.9 / 49.1$ \\
\hline $\begin{array}{l}\text { Median Household } \\
\text { Income (1999) }\end{array}$ & $\$ 47,044$ & $\$ 38,991$ & $\$ 53,092$ & $\$ 41,213$ & $\$ 34,540$ & $\$ 45,776$ & $\$ 41,994$ \\
\hline Per Capita Income & $\$ 21,301$ & $\$ 15,459$ & $\$ 25,494$ & $\$ 20,152$ & $\$ 13,404$ & $\$ 22,973$ & $\$ 21,587$ \\
\hline \multicolumn{3}{|c|}{ Population of Tribes: Nez Perce $\quad 1,839$} & \multicolumn{4}{|c|}{8 Umatilla $1,388 / 2,927$} & \\
\hline \multicolumn{3}{|c|}{$\begin{array}{l}\text { Population of Other Nearby Communities: } \\
\text { Yakima County 222,581; } \\
\text { Walla Walla County 55,180; }\end{array}$} & $\begin{array}{l}\text { Adams Cou } \\
\text { Yakima Cit } \\
\text { Walla Wall }\end{array}$ & $\begin{array}{l}\text { Inty } 16,428 \\
\text { ty } 71,845 \\
\text { a City } 29,68\end{array}$ & \multicolumn{2}{|c|}{$\begin{array}{l}\text { Grant County } 74,698 \\
\text { Columbia } 4,064\end{array}$} & \\
\hline
\end{tabular}

Source: Census data for 2000; Nez Perce and Yakima tribe populations provided by Bureau of Indian Affairs (Yakima on-reservation tribe population, 9,434 according to information obtained from tribe office). Umatilla information represents tribal population living on reservation/total tribal population and was provided by the Umatilla Tribe.

mile inland from the mean high-water mark on the south and west shores of the 51-mile long Hanford Reach, the last free-flowing stretch of the Columbia River. On June 14, 2001, DOE-RL and the U.S. Fish and Wildlife Service signed an amended Memorandum of Understanding (MOU) delegating management responsibilities for the Hanford Reach National Monument. The MOU spells out the roles and responsibilities of each agency for the Wahluke Slope and ALE Reserve.

In prehistoric and historic times, the Hanford reach of the Columbia River was populated by Native Americans of various tribal affiliations. Archeological sites dating back 10,000 years are located on the site. The Hanford Site is located on land ceded to the United States government by the Yakama Nation and the Confederated Tribes of the Umatilla Indian Reservation in the Treaties of 1855. These tribes, as well as the Nez Perce Tribe, have treaty fishing rights on portions of the Columbia River. These tribes reserved the right to fish at all usual and accustomed places and the privilege to hunt, gather roots and berries, and pasture horses and cattle on open and unclaimed land. The Wanapum People are not a federally recognized tribe; however, they have historic ties to the Hanford Site, as do the Confederated Tribes of the Colville Reservation, whose 
members are descendants of people who utilized the area that is known as the Hanford Site.

\section{Historical and Current Missions}

Hanford was originally created as part of the Manhattan Project during World War II to be the nation's first, full-sized plutonium production operation. Multiple facilities were constructed to produce the plutonium needed for nuclear weapons: nine production reactors and the K-Basin storage area for spent nuclear fuel along the Columbia River (the 100 area); processing plants and associated facilities, including the Plutonium Finishing Plant and 149 single-shell and 28 double-shell tanks for storing more than 53 million gallons of high-level radioactive waste (on a plateau which became known as the 200 area); and fuel fabrication buildings, laboratories, and other support facilities near the southern boundary (the 300 area). As plutonium production was reduced, Hanford's mission was reoriented to developing non-military applications for nuclear energy; the advanced test reactor and the Fast Flux Test Facility were located on the site. Hanford's current mission, which no longer includes production, is focused on environmental remediation; storage of nuclear materials, including special nuclear materials; and support for national scientific research efforts, especially in environmental sciences.

\section{Site Management Structure}

Site management is divided between the Headquarters Office of Environmental Management (EM), which is the lead Program Secretariat Office for Hanford, and the National Nuclear Security Administration (NNSA). EM site management functions are further subdivided into those of the Richland Operations Office (RL) and the Office of River Protection (ORP), which was established in 1998 as a separate Field Office reporting directly to EM, yet jointly responsible with RL for managing contractor activities. The roles and responsibilities of the latter three entities are specified in a formal Memorandum of Agreement. The RL Field Office is responsible primarily for environmental restoration, demolition and decommissioning, waste management, and plutonium stabilization. Fluor Hanford Inc. is the Management and Integration Contractor for this work and does groundwater remediation for RL. ORP is responsible for tank waste remediation. Bechtel National is the subcontractor responsible for tank waste retrieval, treatment, storage, and disposal, including construction and operation of a new vitrification facility. $\mathrm{CH}_{2} \mathrm{M}$ Hill is respons ible for day-to-day tank farm operations.

\section{Cleanup and Waste Management Activities}

The Hanford site is widely acknowledged to be DOE's most complex and costly cleanup effort. More than 40 years of plutonium production resulted in hundreds of square miles of contaminated soil and groundwater, following the discharge of untreated radioactive wastes to the soil and leakages from the K-Basins and from the tanks where waste was stored. 
The site was placed on the National Priorities List in 1989. In the same year, DOE, the United States Environmental Protection Agency (EPA) and the Washington State Department of Ecology signed the Tri-Party Agreement (TPA) to reach compliance for major waste streams over a 30-year period. The Agreement established milestones and interim milestones, as well as penalties, procedures for change, and requirements for public participation.

Cleanup tasks include stabilizing the various types of nuclear material and contaminated facilities; facility decontamination and decommissioning; remediating soils, groundwater, subsurface and surface water; and treatment, safe storage, and disposal of the different waste types currently stored on site. Some of the waste types will remain on site; others are scheduled for shipment to the Waste Isolation Pilot Plant and a repository.

Preventing contaminants from reaching the Columbia River is a key priority. Hanford's approach to completing key pieces of the Hanford cleanup by 2012 is spelled out in the Hanford 2012 Plan. Major near-term tasks for which RL is responsible in order to achieve this goal include moving over 1,000 metric tons of spent fuel from its current storage location in the $\mathrm{K}$ basins, which are located only a quarter of a mile from the Columbia River; stabilizing four tons of plutonium; placing the nine reactors in safe storage; and continuing deactivation of several old weapons production and nuclear energy facilities such as the Plutonium Finishing Plant. The focus of the Office of River Protection is on the tank farms - specifically, waste retrieval, treatment, and disposal of the approximately 53 million gallons of low and high- level waste stored in single and double-shell storage tanks, some of which have leaked into the groundwater. Construction and operation of a vitrification facility is being undertaken as part of this task. To date, the contents of many of the tanks have been stabilized and a site-wide vadose and groundwater program was established in 1998 to help protect the Columbia River.

\section{Structure and Staffing of the EM Public Participation Program}

The public participation manager is responsible for activities related to the site's Site Specific Advisory Board (the Hanford Advisory Board (HAB)), NEPA, and the Community Relations Plan and associated CERCLA activities. Following staff reductions in late 2002, the Public Participation Manager is assisted by one and a half full-time staff and contractor assistance equivalent to one and a half full-time staff. A subcontractor is responsible for administration and facilitation of the HAB.

\section{EM Public Participation Goals and Activities}

\section{Public Participation Goals}

The goals of public participation are stated in a brochure, Public Involvement Policy, published by RL in October 1997:

- To actively seek and consider public input; to incorporate or otherwise respond to the views of regulators, Tribes, stakeholders, and the general public in making decisions; 
- To inform the public in a timely manner and provide the opportunity to have input on the decision-making processes, which are open and understandable;

- To clearly define access points for public input from the earliest stages of a decision process and provide adequate time for regulators, Tribes, stakeholders and the general public to participate;

- To consistently incorporate credible, effective public participation processes into program operations, planning activities, and decision-making processes. Every employee shares responsibility to promote, practice, and improve public involvement;

- To keep the public informed of key decisions made, progress of ongoing activities, emerging technologies and opportunities for economic diversity.

Public participation at Hanford is driven to a greater degree than at other DOE sites by agreements with the regulators (for Hanford, the TPA). The regulators have established local offices to oversee the cleanup work. Public participation activities are guided by the Tri-Party Community Relations Plan, which is regularly updated (a fourth revision to the Plan was issued in January 2002). The Washington State Department of Ecology plays a very active role both in developing the plan and in site public participation activities. It has also established a memorandum of agreement with the State of Oregon to facilitate the latter's participation in Hanford site activities.

\section{Information Distribution}

The Tri-Parties publish and distribute a wide variety of hard copy and electronic information materials through mailing lists, websites, and public information repositories. The repositories are located in Portland, Oregon; and in Richland, Seattle, and Spokane, Washington. In combination, these sources provide a wealth of easily accessible, up-todate information both about the site itself and about opportunities to participate in cleanup decisions.

The EPA, Washington Department of Ecology, DOE (http://www.hanford.gov/pubinvolve.html) and the HAB (http://www.hanford.gov/hab/) have their own web pages. Information includes a Hanford Happenings calendar of public participation opportunities; a list of contacts including a hotline number, Hanford Cleanup Line, which is monitored by the Washington State Department of Ecology; links to detailed information and reports about the site; copies of the bi-monthly Hanford Update at http://www.hanford.gov/tpa/updates.html, ${ }^{26}$ and the Community Relations Plan for the Hanford Federal Facility Agreement and Consent Order at http://www.hanford.gov/crp/toc.htm. The latter provides a comprehensive overview of the role of the Tri-Parties, the Hanford cleanup status and decision process, as well as information about public information sources and involvement opportunities. The HAB web page includes a list of members, the board's charter and ground rules, a calendar,

\footnotetext{
${ }^{26}$ Though subsequently brought up to date, the most recent edition available at the time of the study was published in May 2001
} 
board advice and responses, board correspondence, summaries of board meetings, and annual progress reports.

The Tri-Parties maintain two mailing lists that are tailored to different levels of interest: (1) a list of persons "highly interested" in site decisions who receive detailed information - fact sheets, meeting notices and schedules, and copies of Hanford Update and Hanford Happenings; and (2) a list of persons who receive general information on the site through mailings of Hanford Update and Hanford Happenings.

\section{Non-SSAB Public Participation Activities}

Because of the significance of the Columbia River for the entire northwestern region, the area from which stakeholders are drawn extends beyond the immediate Tri-Cities to Seattle and Spokane, as well as to Oregon. The site represents a major source of employment in the local area; local government, trade union, and industry representatives are closely affected by the status of site work. Several public interest groups from across the region have long maintained an interest in the site's environmental and health impacts. In addition, the DOE maintains a government-to-government relationship with Tribes that have treaty rights at the Hanford site (Nez Perce, Yakama, and Confederated Tribes of the Umatilla Indian Reservation) and consults with the Wanapum and the Colvilles that live nearby.

The range of public participation activities is broad and includes a variety of non-SSAB, as well as SSAB, activities. These include formal and informal meetings, an active Speaker's Bureau, and sponsorship by both DOE and contractor organizations of a range of educational activities and opportunities. Opportunities are also provided for regular stakeholder evaluation of Tri-Party involvement activities.

As at all DOE sites, opportunity for input on CERCLA, RCRA, and NEPA decisions is provided through public meetings and formal comment and response procedures. Hanford is also noteworthy, however, for the additional opportunities provided by the Tri-Parties. These include quarterly Tri-Party public involvement meetings that are held with the State of Oregon, the HAB, local government officials and interested members of the public to discuss current and future public involvement activities, as well as periodic informal meetings, including meetings as requested by local governments and civic organizations. For example, for the last two years, the Tri-Parties have held a series of regional "State of the Hanford Site" discussion meetings among agency officials, public interest groups, and the public. In addition, the TPA specifies a role for the public in changes proposed to the Tri-Party Agreement.

\section{The Hanford Advisory Board}

The Hanford Advisory Board (HAB) has been in existence since 1994. It meets for two weekdays every other month at different locations within the region. The board is funded by DOE but was created by the Tri-Parties to advise all three agencies on major cleanup policy decisions. It is composed of 31 members plus alternates, who are chosen to represent a broad range of regional stakeholder interests. The HAB's selection process is 
unique among the SSABs. Members are recruited and nominated by organizations representing the interests of the various interest groups, plus at-large members recruited and nominated by the Washington Department of Ecology and EPA. Members are approved by EM Headqua rters, with re-appointment every two years. Two members of the Confederated Tribes of the Umatilla Indian Reservation participate as ex-officio members; the other two affected Tribes are represented on the HAB. Board meetings are conducted by the Chairman, with assistance from a professional facilitator; decisions are reached by consensus. Currently, there is an Executive Committee and four standing committees: Budget and Contracts; River and Plateau; Tank Waste; and Health, Safety and Environmental Protection. In addition, a Public Involvement and Communication Committee convenes when needed and requested by the HAB.

The Board also includes representatives of the three sponsoring agencies (DOE, EPA, and the Washington State Department of Ecology) who serve in an ex-officio capacity.

From its inception, the HAB has provided consensus advice on a wide variety of key site decisions. It publishes an annual report, in which it highlights areas of focus and describes particular achievements of interest to the broader public, often focusing attention on TPA commitments, tank issues, progress at the K-Basin and the Plutonium Finishing Plant, cleanup along the Columbia River, the potential for accepting waste from other sites, funding levels, and effective management of tax dollars. The HAB also plays an important role in providing linkages to the broader community. This is achieved in part through its members' direct connections with key interest groups within the region and in part through sponsoring well-attended forums for the public during the evening preceding its regular board meetings.

\section{Key Public Participation Challenges and Status in Relation to the Acceptability Diamond}

Based on site visits and interviews conducted in the spring of 2002, the PNNL research team identified several challenges facing the Richland Operations Office (RL) and the Office of River Protection (ORP) - and the other members of the Tri-Party Agreement in establishing an effective public participation program and addressing the four dimensions of the Acceptability Diamond (substantive issues, decision-making process, relationships, and accountability).

\section{Challenges}

- The magnitude and complexity of the site's cleanup and waste management needs create significant challenges of coordination, prioritization, and planning for DOE and the regulators and significant challenges of "seeing the big picture" and "getting up to speed" for stakeholders. The sheer number of decisions to be made and the pace of the process - which extends over many years and across administrations and personnel changes - places high demands on all parties seeking to achieve effective participation. The level of effort required to gain a 
command of the information and to keep current is widely characterized as daunting by public participants.

- The recent separation of site management into two components, each responsible for cleanup decisions, created coordination and consistency challenges for DOE and the regulators, and coverage challenges for the stakeholders.

- The large impact area poses an ongoing challenge to provide equitable opportunities for participation and influence. The impact area extends over two states and includes several tribal nations.

- DOE's efforts to develop innovative institutional and technical solutions to the large quantities of highly toxic material in the Hanford tanks (e.g., the strategy for privatization) have increased the complexity of the internal policy-making process and schedule.

\section{Status in Relation to the Acceptability Diamond}

The following summarizes the research team's assessment of the site's status in relation to the Acceptability Diamond based on research conducted between January and June 2002:

- The Tri-Parties have traditionally placed a priority on public participation: DOE has a site public participation policy; ORP undertook the development of an openness policy; and the Tri-Party agreement specifies a process for preparing and updating a Community Relations Plan and requires participation. Site stakeholders have a long history of attention to and engagement in Hanford issues.

- The EM public participation process has been successful in maintaining the participation of a wide diversity of stakeholders, both on the HAB and in the broader participation processes. Mechanis ms to provide staff support to the large and complex HAB have been developed, including maintenance of board-related records and documents.

- Substantive issues: The advisory board, its committees, and other mechanisms such as working groups were generally recognized by the respondents as influential and effective in enabling the public to identify and participate in the framing of issues. Respondents generally agreed that these multiple mechanisms, combined with public attention and effort, enabled the public to get the issues it thought important on DOE-EM's and the regulators' agenda. The relatively high number of stakeholders who were able to dedicate long hours to studying and dealing with Hanford issues made this feasible, given the range and complexity of site cleanup issues. The active participation of regulators, who have good access to information, was also identified as important in enabling the board and other stakeholders to obtain the information they needed to identify and frame issues as were the relationships they had established with site workers. Respondents reported that the public participation program, combined with their own networks, generally enabled them to obtain the information they needed to perform their responsibilities in issue identification and prioritization relatively effectively. 
Many commented that DOE-EM and contractor staff at the site had been helpful, open, and increasingly effective, in providing information that was clear and understandable. Nevertheless, as one board member noted:

A lot of issues are raised and discarded - so to keep something on the agenda until it is resolved requires effort and determination.... It helps when people participate to show which things matter and are relevant.

In part because they thought that long years of effort by both stakeholders and DOE-EM had been needed to achieve this level of collaboration and effectiveness, many respondents expressed dismay about the change in posture taken by DOE-EM Headquarters concerning the release of information and consultation with stakeholders on the Top-to-Bottom Review, the Performance Management Plans, and the FY04 budget request.

- Decision making: Almost all interviewees agreed that the public has had the opportunity to provide input to and influence site decisions, although a number raised concern about EM Headquarters' ability to "exert its power over decisions when it wants," thus effectively negating site-based decision processes. Most advisory board members interviewed believe that they have played an important role in decision making at the site: One respondent, who captured the position expressed by a number of those interviewed for the study, stated:

The HAB has worked hard to...make decision making more transparent - to get answers to questions and response to advice... The clarity of decision making is better now than at the beginning, and public participation is critical. It is by having outsiders ask the questions and insist upon getting the answers about what decisions are being made, and how, and with what information and criteria, that you have informed decisions.

- Relationships: Many respondents expressed alarm that the actions of DOE-EM Headquarters regarding the Top-to-Bottom Review, Performance Management Plans, and the FY04 budget were jeopardizing the progress that had been made in building an effective working relationship with the stakeholders at Hanford. A number of respondents commented that these actions, which had occurred shortly before the study interviews were conducted, were leading them to re-evaluate their participation in DOE-sponsored public participation activities and to adopt a more suspicious perspective regarding DOE's actions and statements. This was seen as a significant setback, counteracting the progress that had been made through years of effort to develop an effective dialogue between "Tri-Cities representatives" and other stakeholders. It had allowed them to sustain a forum in which constructive dialogue among the diverse stakeholders could occur (though tension between stakeholders who were proponents of nuclear power and related facilities and those who opposed them was noted by several respondents).

A number of respondents commented that the participation process had succeeded in developing a sense of shared interests that moderated (though did not entirely 
dispel) initial concerns about participants, including DOE, "having their own agenda." The long hours working together within the forums created by the advisory board, working groups, and the public meetings were credited with helping forge a sense of shared purpose. As one respondent said: "The board has been effective in bringing the wide variety of stakeholders together and having them work productively together - and getting to the point where they understand one another's viewpoints." Respondents reported that Hanford stakeholders are characterized - by both themselves and agency representatives - as "pretty sophisticated" about the nature of their relationship with DOE. The fact that the organizations nominated their representatives for approval by EM-Headquarters was noted by a number of respondents as important and beneficial in increasing the independence, effectiveness, and credibility of the board. A number of respondents commented with approval that DOE-RL and DOE-ORP and the regulators have started talking with one another more frequently and effectively lately. The "C3T" effort, where the top managers of DOE, EPA, and Washington Department of Ecology meet regularly to try to work out issues and identify ways to expedite cleanup, was seen as an important illustration of this increased communication.

- Accountability: Most respondents gave considerable emphasis to public participation's role in ensuring and enhancing accountability at the site, although many noted that legally binding agreements, such as the TPA - and the willingness of organizations such as regulators and the State Attorney General to enforce those agreements - were the best assurance of accountability. However, they also noted that, in the words of one respondent: "Holding regulators accountable for enforcing the TPA is a key function of the public participation activities, especially the Board.... That is why public concern and attention is so important." Another noted: "The HAB is an important avenue to hold all the players' feet to the fire - they are having these discussions in public, which does promote accountability." The Federal Advisory Committee Act (FACA) standing of the HAB was also identified as contributing to DOE's accountability. A number of respondents commented, however, that DOE was trying to avoid accountability by "shuffling people and managers around" and by shifting the locus of decision-making from the site to EM Headquarters. 


\subsection{Los Alamos National Laboratory}

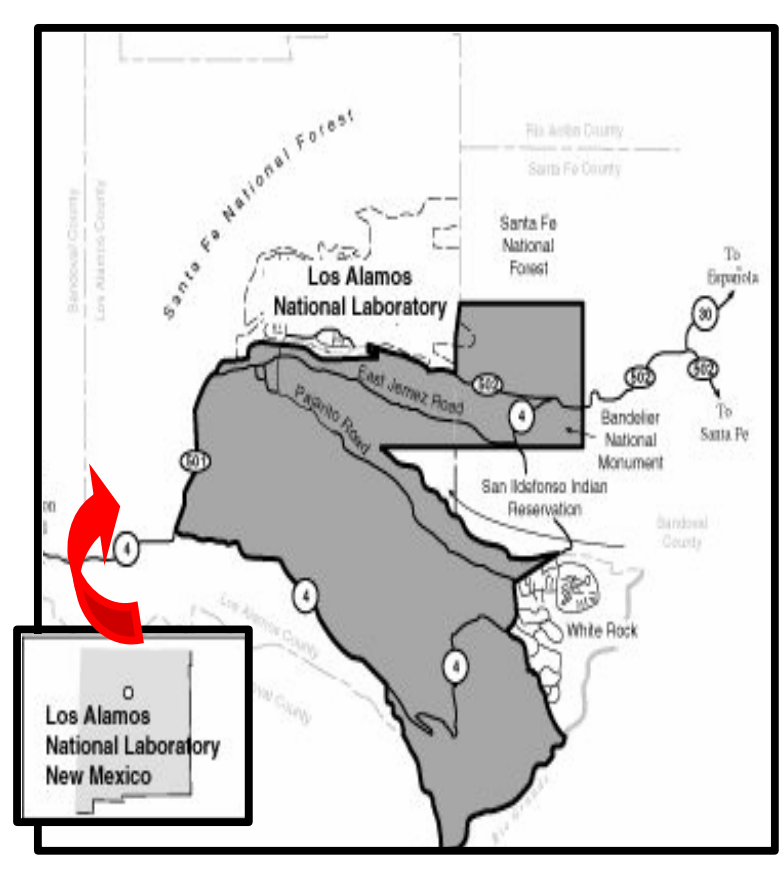

\section{Location, Population, Land Use}

The Los Alamos National Laboratory (LANL) site covers approximately 27,520 acres in north-central New Mexico, 60 miles north-northeast of Albuquerque, in Los Alamos and Santa Fe Counties. The nearest population centers are Los Alamos, Espanola, and White Rock; Santa Fe is located approximately 35 miles away (see Table 3.4.1 for a summary of demographic characteristics in nearby communities and counties). LANL is one of the largest institutions and largest employers in the State of New Mexico. Approximately 80 DOE personnel are employed in the Office of the Los Alamos Site Operations and approximately 7,000 LANL employees plus 5,000 subcontractors are employed on work at LANL. The Office of Community Relations estimates that $91.6 \%$ of LANL employees reside in the tri-county region of Los Alamos, Santa Fe, and Rio Arriba counties. Reservations of four Pueblo Tribes are located adjacent to, or near the site: the San Ildefonso Indian Reservation, the Santa Clara Indian Reservation, the Jemez Indian Reservations, and the Cochiti Indian Reservation.

Most developments in Los Alamos County are confined to mesa tops. The surrounding land is largely undeveloped with large tracts north, west, and south of the LANL site administered by the U.S. Forest Service (Santa Fe National Forest), the National Park Service (Bandelier National Monument), and Los Alamos County. The San Ildefonso Pueblo borders the LANL site to the east.

\section{Historical and Current Missions}

Established in 1943 for the sole purpose of designing, developing, and testing nuclear weapons, the mission of the Laboratory has since broadened and evolved to include a wide variety of non-nuclear defense programs and basic science. From the very beginning, research programs were conducted to support the primary mission. Plutonium processing, which took place between 1945 and 1978, was originally an important function. Currently, LANL's central mission continues to be national security specifically, to reduce the danger of nuclear weapons and materials world-wide in five areas: (1) stockpile stewardship, (2) stockpile management, (3) nuclear materials management, (4) non-proliferation and counter proliferation, and (5) environmental 
Table 3.4.1. Demographic Characteristics of Nearby Counties and Communities

\begin{tabular}{|c|c|c|c|c|c|c|c|c|}
\hline & \begin{tabular}{|c|} 
Los \\
Alamos \\
County
\end{tabular} & $\begin{array}{c}\text { Santa } \mathrm{Fe} \\
\text { County }\end{array}$ & $\begin{array}{l}\text { Río } \\
\text { Arriba } \\
\text { County }\end{array}$ & $\begin{array}{c}\text { Los } \\
\text { Alamos } \\
\text { City }\end{array}$ & $\begin{array}{l}\text { White } \\
\text { Rock } \\
\text { City }\end{array}$ & $\begin{array}{l}\text { Santa Fe } \\
\text { City }\end{array}$ & $\begin{array}{c}\text { New } \\
\text { Mexico }\end{array}$ & US \\
\hline $\begin{array}{l}\text { Total Population, } \\
2000\end{array}$ & 18,343 & 129,292 & 41,190 & 11,909 & 6,045 & 62,203 & $1,819,046$ & $281,421,906$ \\
\hline \begin{tabular}{|l|} 
\% Population \\
Change, \\
$1990-2000$
\end{tabular} & $1.3 \%$ & $30.7 \%$ & $19.9 \%$ & $4.0 \%$ & $-2.4 \%$ & $18.5 \%$ & $20.1 \%$ & $13.1 \%$ \\
\hline White & $90.3 \%$ & $73.5 \%$ & $56.6 \%$ & $89.1 \%$ & $92.8 \%$ & $76.3 \%$ & $66.8 \%$ & $75.1 \%$ \\
\hline Black & $0.4 \%$ & $0.6 \%$ & $0.3 \%$ & $0.4 \%$ & $0.2 \%$ & $0.7 \%$ & $1.9 \%$ & $12.3 \%$ \\
\hline $\begin{array}{l}\text { American Indian/ } \\
\text { Alaska Native }\end{array}$ & $0.6 \%$ & $3.1 \%$ & $13.9 \%$ & $0.6 \%$ & $0.5 \%$ & $2.2 \%$ & $9.5 \%$ & $0.9 \%$ \\
\hline Asian & $3.8 \%$ & $0.9 \%$ & $0.1 \%$ & $4.5 \%$ & $2.7 \%$ & $1.3 \%$ & $1.1 \%$ & $3.6 \%$ \\
\hline $\begin{array}{l}\text { Hawaiian/Pacific } \\
\text { Islander }\end{array}$ & 0 & $0.1 \%$ & $0.1 \%$ & $0.0 \%$ & $0.0 \%$ & $0.1 \%$ & $0.1 \%$ & $0.1 \%$ \\
\hline Other & $2.7 \%$ & $17.7 \%$ & $25.6 \%$ & $3.0 \%$ & $1.9 \%$ & $15.3 \%$ & $17.0 \%$ & $5.5 \%$ \\
\hline Mixed & $2.3 \%$ & $4.1 \%$ & $3.3 \%$ & $2.4 \%$ & $1.9 \%$ & $4.2 \%$ & $3.6 \%$ & $2.4 \%$ \\
\hline Female/Male Ratio & $49.6 / 50.4$ & $51.1 / 48.9$ & $50.5 / 49.5$ & $49.7 / 50.3$ & $49.6 / 50.4$ & $52.2 / 47.8$ & $50.8 / 49.2$ & $50.9 / 49.1$ \\
\hline $\begin{array}{l}\text { Median Household } \\
\text { Income (1999) }\end{array}$ & $\$ 78,993$ & $\$ 42,207$ & $\$ 29,429$ & $\$ 71,536$ & $\$ 92,813$ & $\$ 40,392$ & $\$ 34,133$ & $\$ 41,994$ \\
\hline Per Capita Income & $\$ 34,646$ & $\$ 23,594$ & $\$ 14,263$ & $\$ 34,240$ & $\$ 36,288$ & $\$ 25,454$ & $\$ 17,261$ & $\$ 21,587$ \\
\hline
\end{tabular}

Tierra Amarilla n/a;

Source: Census data for 2000

stewardship. LANL is well known for its basic research in a wide variety of sciences and, in staff and technical capabilities, is one of the largest multidisciplinary, multiprogram laboratories in the world.

\section{Site Management Structure}

The Laboratory is managed by the regents of the University of California, pursuant to a management and operating contract with DOE. The University has managed the Laboratory since its inception in 1943. The Office of Los Alamos Site Operations (OLASO) administers the contract. The National Nuclear Safety Administration (NNSA), which was established in 2000, is the LANL lead program secretarial office and site landlord. EM, which accounted for approximately 4 percent of total DOE Laboratory funding in 2001, is a relatively small component in comparison with Defense Programs and Nonproliferation and National Security, which are the predominant concerns. A number of other DOE programs also provide programmatic direction. 


\section{Cleanup and Waste Management Activities}

Primary cleanup tasks facing LANL are the upgrade of the Radioactive Liquid Waste Treatment Facility and stabilization of radioactive wastes stored on site, as well as cleanup of a variety of facilities and structures contaminated by past Laboratory operations. Large quantities of legacy wastes are stored on site, including transuranic wastes to be shipped to WIPP, as well as mixed low-level waste that needs proper disposal. Remediation tasks include decommissioning and demolition of facilities previously used for tritium, uranium, and plutonium processing; former research reactors; nuclear research facilities; and miscellaneous structures such as concrete bunkers and storage magazines contaminated with high-explosive residue, and radiological, asbestos, and other hazardous material. Inactive waste sites include large material disposal areas, septic systems, drain lines, high explosive areas, and outfalls. Following cleanup, plans are to transfer a small portion of land to Los Alamos County and the San Ildefonso Pueblo, primarily for industrial use.

The primary regulatory driver for environmental management is the Hazardous and Solid Waste Amendments to the Resource Conservation and Recovery Act (RCRA), implemented by the U.S. Environmental Protection Agency and the New Mexico Environmental Department. The Laboratory is not a party to the Federal Facilities Agreement. Under the Environmental Restoration (ER) Project, site investigation and remediation efforts are organized according to the watersheds in which potential release sites are found: evaluation includes the entire watershed from a mesa top, through a canyon, to the Rio Grande River. The Laboratory's ER Project was established in 1989 as part of the Department of Energy's nation-wide Environmental Management Program. Ongoing waste management activities are operated by the NNSA.

\section{Structure and Staffing of the EM Public Participation Program}

The LANL Communications and External Relations Division, which speaks for the Laboratory as a whole, includes Public Affairs, Government Relations, and Community Relations. Public outreach is conducted on a program-specific basis and, with the exception of Environmental Management - known as Environmental Restoration (ER) there is little public participation other than what is required under NEPA. ER is the only project that has its own public participation staff, under the direction of the ER Communications and Outreach Team Leader. The Leader has one contractor and two part-time public participation staff to assist her. She reports to the ER Project Program Manager, coordinates with the Communications and External Relations Division, and acts as liaison to the Site Specific Advisory Board. She also manages other ER public involvement activities such as quarterly meetings. The advisory board, which is known as the Northern New Mexico Citizens' Advisory Board (CAB), is coordinated by one DOE staff person in the Office of Los Alamos Site Operations and managed by three contractor staff in the $\mathrm{CAB}$ office located in Santa Fe. One of the contractors acts as a technical advisor to the $\mathrm{CAB}$ and coordinates all subcommittee meetings, as well as providing technical assistance for the members. 


\section{EM Public Outreach and Participation Goals and Activities}

\section{Public Participation Goals}

The goal of public participation, as articulated in the ER Public Involvement Plan, is to provide the public with the opportunity to obtain information from, and provide input to, the ER Project on its investigation and cleanup activities. Specific goals for the communications and outreach project (listed on the ER web page) are to:

- Broaden the base of involved individuals and groups;

- Continue to build trust by focusing on personal contact, dialogue and mutual education;

- Obtain meaningful public input in decisions regarding cleanup issues;

- Learn a better, more cost-effective way of involving the public early in the Environmental Restoration Project process;

- Promote sustainability within the Environmental Management Program and the Laboratory by incorporating sustainability principles into Environmental Restoration Project activities and programs whenever possible;

- Ensure that all Environmental Restoration Project activities comply with all Department of Energy and New Mexico Environmental Department requirements for public participation.

\section{Information Distribution}

The LANL Public Participation Plan states that a variety of information materials are prepared for the public, including progress reports, community fact sheets, news releases, information materials and citizen toolkits, and information sheets and summaries about major projects. Some of these are prepared in Spanish. Materials are distributed at meetings and workshops and are available on the web. However, at the time of the study, the website, http://erproject.lanl.gov was inaccessible at the request of NNSA, following the events of September 11,2001; a limited amount of information is available by searching the ER website, http://erproject.lanl.gov/outreach. The CAB has its own website (http://www.nnmcab.org/) and publishes its own newsletter, $N N M C A B$ Newsletter. The website also includes an overview page with convenient links to several topics, including notices and calendar page, a brief annual report for 2001, meeting minutes for board and committee meetings, and the CAB bylaws. With the exception of the notices and calendar page, however, the links were not current as of January 2002: only two editions of the NNMCAB Newsletter were available, the most recent being December 2000. The most recent minutes of a full board meeting were for May 2001; the most recent for a committee meeting (the Waste Management Committee) were for July 2001.

Meeting announcements can be located on the web. Meetings are also announced through the local radio stations and in paid advertisements in five area newspapers, as well as through the Laboratory Facility mailing list, which includes approximately 1250 
names. The ER Project web page provides a telephone number for members of the public to contact the Communications and Outreach team. There were plans to develop an ER Newsletter later in 2002. ER Project documents, which are currently not available on the web, are housed in the LANL reading room in Los Alamos.

\section{Non-SSAB Public Participation Activities}

ER public participation activities outside of the CAB are focused on quarterly project public meetings, as well as on the public meetings required under RCRA. Various interactions are conducted with the pueblos as part of the broader Laboratory-wide initiatives, conducted by the Tribal Relations Team in the Community Relations Office. The Laboratory maintains a Speakers' Bureau and provides an extensive number of educational activities; however, the ER Project also seeks out opportunities to speak with both Laboratory and local groups. Meetings are scheduled regularly with local officials and a limited number of educational activities are sponsored. Examples of the latter include providing tours to college and university students and visits to local schools to discuss the ER project.

\section{The Northern New Mexico Citizens' Advisory Board}

The CAB was initially established in 1995 following a two-year selection process, and subsequently operated for two years before being disbanded and restructured. The board that has operated since restructuring is composed of 21 members recruited by the board and appointed by DOE; at the time of the study there were 18 members. Criteria for selection are based on the DOE/EM Site-Specific Advisory Board Guidance. Terms of office are two years, with no limit on the number of terms. The CAB meets bi-monthly during the afternoon and evening; the board's Chairperson chairs the meetings. The board's decisions on recommendations are made by consensus; the board is authorized to advise DOE. There are five committees that meet monthly: Environmental Restoration, Waste Management, Budget, Monitoring and Surveillance, and Community Outreach. There is an Executive Committee, which, with DOE, sets meeting agendas. The DOE OLASO Deputy Director attends board meetings regularly as an ex officio member and plays an active role in CAB activities. Board recommendations are tracked by the DOE's Deputy Designated Federal Officer (DDFO). Status reports on all open recommendations are provided monthly to the Executive Committee.

\section{Key Public Participation Challenges and Status in Relation to the Acceptability Diamond}

Based on their site visits and interviews conducted in the spring of 2002, the PNNL research team identified several challenges facing the Los Alamos site in establishing an effective public participation program and addressing the four dimensions of the Acceptability Diamond (substantive issues, decision-making process, relationships, and accountability). 


\section{Challenges}

- The organizational structure and program focus at Los Alamos has created a challenge for the public participation program. Los Alamos, an NNSA laboratory, continues to have a key role in the U.S. nuclear weapons program, along with other scientific research activities. This has created requirements for high levels of security and boundaries between programs that make access to the site and disclosure of information more complex than at sites without such ongoing missions. Institutional arrangements are further complicated by the relative autonomy of the Laboratory, as compared with contractors at other sites: DOE and the Laboratory are seen by the pub lic as separate organizations, each with its own management structure, decision-making process, and agenda, including public disclosure and participation policies.

- The EM program is relatively small compared to the NNSA effort and its budget has been declining sharply. Key managers have restricted expenditures on disclosure and public participation efforts. At the same time, EM-related public participation activities do not extend to many key site activities that are of interest to different stakeholder groups - for example, laboratory operations and management, ongoing operations characteristics, and continuing weapons development. The boundaries between programs have been the source of conflict over the appropriate scope of the advisory board.

- The past history of public participation at the site, including the dissolution and reconstitution of the advisory board, has diverted attention from site cleanup issues and created lingering resentments that continue to affect the new board and public participation efforts. DOE's role in dissolving the previous board and selecting the members for the new board have raised public concerns that, in the words of one respondent, "the CAB represents a select group of stakeholders who support DOE."

- The economic, cultural, educational, and linguistic disparities among the neighboring communities (for example, see the variability in median household income across communities in Table 3.4.1) create additional challenges for the site's publics in developing an effective means of communicating among themselves and developing agreement about their common interests and concerns.

\section{Status in Relation to the Acceptability Diamond}

The following summarizes the research team's assessment of the site's status in relation to the Acceptability Diamond, based on research conducted between January and June 2002:

- DOE has reconstituted an advisory board that is making progress in coming up to speed on the environmental cleanup and legacy waste disposal issues at the site and providing a forum for both the board members and the community to obtain information, hear explanations, and discuss issues. Both the DOE-EM site manager and the Laboratory program manager have been effective in conveying support and interest in the public participation and advisory board processes 
through both the Advisory Board and the ER focus group meetings. However, recent budget reductions have raised questions about the strength of the commitment to public participation.

- The Laboratory has made an organizational commitment to address EM issues, and has established a forum for providing information to interested publics through regular quarterly meetings. In addition, the Laboratory has initiated a series of ER focus groups to facilitate informed input; the focus group participants have primarily been non-CAB members of the public. The Laboratory has both technical staff and public participation support directly associated with the ER program. However, the resources to support this public participation effort may be jeopardized by reduced EM budgets.

- Substantive issues: A number of respondents questioned the ability of the community to obtain information and to get issues on DOE's agenda. However, they frequently reported that, as one respondent said, "Ground water issues have percolated to the top because of public interest." The advisory board has initiated several actions to restructure the board's activities in an attempt to increase its effectiveness in identifying and framing environmental remediation and waste management issues pertinent to the community. These include changing the board meeting locations and schedules, providing a sound system and refreshments, amending the bylaws to establish four $\mathrm{CAB}$ positions for the four accord Pueblos, and instituting committee chairs and requirements for participation. In addition, DOE has established a new CAB office in Santa Fe and hired three staff persons, including a technical advisor to assist the board.

- Decision making: Most respondents reported that public attention and demonstration of interest does have influence on DOE and the Laboratory. CAB respondents, in particular, believe that they have influence on DOE-EM decisions, in part because they generate "a steady stream of input." They pointed to the increased number of recommendations on issues of importance to the community that the board had made since it was reconstituted. The ER program is generally recognized for its efforts to hold meetings to explain how they are undertaking the assessment and cleanup process. However, the public's impact on decisions was questioned by many respondents. They noted the small, and decreasing, EM role and budget in comparison with other DOE programs. One respondent commented: "Decisions are driven technically from the bottom up but financially from the top down." A critic commented that "The so-called accelerated cleanup fund is a stroke of machiavellian genius by DOE with a goal of breaking existing compliance agreements and without public involvement." Another stated:

The local population here sees that DOE and the Lab are here, and you can't get rid of them.... The impression they have is that the local DOE office can't really do much, particularly with NNSA programs. DOE-EM's change in criteria to focus only on sites that could be closed was disadvantageous to us [the local communities] - and was done without any local discussion. 
- Relationships: Respondents at Los Alamos were more likely than at other sites to make distinctions about the nature of relations hips at the site according to the participants. They distinguished between DOE and the Laboratory, and between the Los Alamos community, the neighboring communities, and the "rest of the state." (For example, "The relationship between the Lab and the public is very different from the relationship between ER and the public....The Lab is not trusted.") Many singled out the area's economic dependence on the Laboratory as a factor, one person noting that "The high dependency on Los Alamos economically has given the other areas a chip on their shoulder." Comments generally indicated that neither the DOE site manager nor the Laboratory director had gained the community's confidence: both were generally seen as placing a low priority on thinking about how their policies and actions would affect the local communities or on building solid relationships with community representatives. However, people did appreciate the efforts made by the DDFO and by individual ER technical staff, who were commonly described as committed and caring.

To a large extent, relationships were characterized in terms of tensions, though with recognition that the ongoing interactions created by the current advisory board and focus groups were helping stakeholders from different communities get to know one another in a constructive environment. The outpouring of aid and assistance to the Laboratory and to Los Alamos residents by neighboring and more distant communities during and following the catastrophic forest fire in 2001 was cited as influential in reframing perceptions and relationships encouraging Los Alamos and other residents alike to see themselves sharing a sense of community.

- Accountability: Study respondents frequently cited lack of accountability of DOE and the Laboratory to the surrounding communities - although one person who was interviewed emphasized that the Laboratory is and should be nationally (rather than locally) accountable through constitutional and democratic mechanisms. Few saw the Laboratory as accountable to the local area. As one person commented, "On one level, the Lab sees themselves as accountable to the local community, yet it rarely goes beyond the Mesa. They feel they have solved problems in relation to the environment... that they were not negligent, and that the problems are only marginal." Other comments were: "The idea of DOE being accountable is so strange in these parts that you have to stop and think about it." "Their actual accountability to the community is marginal because the public doesn't have the ability to make them accountable." "I don't think they know the word." Another characterized Laboratory attitudes as: "I don't owe you anything. I'm only in New Mexico because I am at LANL." And:

DOE/LANL are mission-driven - accountability ranks much lower than achieving their mission. If they were given a new mission...They would say that they would still do it, even it if led to ground water pollution. 


\subsection{Nevada Test Site}

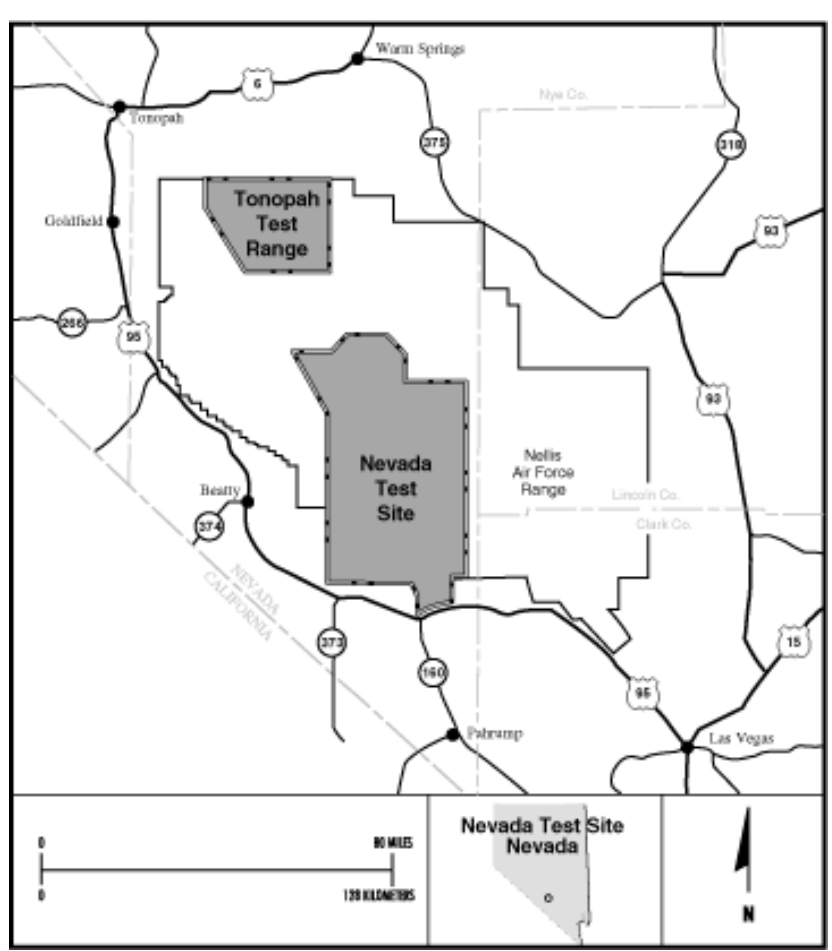

Location, Population, Land Use

The Nevada Test Site (NTS) encompasses an area of 1,350 square miles and is located in Nye County, approximately 65 miles northwest of Las Vegas in Clark County, Nevada. The remote, arid, restricted site is surrounded by other federal lands that provide a buffer zone between NTS and public lands. On the north, east, and west, it is bordered by the Nellis Air Force Range; U.S. Bureau of Land Management lands are on the south and southwest. Primary land uses in Nye County in the vicinity of the site include mining, grazing, agriculture, and recreation.

Demographic characteristics in the areas near NTS are shown in Table 3.5.1. Population density near the site is low. The nearest population centers are Amargosa Valley (25 miles southwest), Beatty (54 miles northwest), Pahrump (36 miles south), and Indian Springs (19 miles east). Regional economic linkages supporting production activity at the NTS occur primarily in the Las Vegas Valley region of Clark County. Most of the offsite supporting contractors, and the labor and capital supporting indirect activity linked to NTS are also located in this area. In mid-2002, approximately 239 DOE employees (full time equivalents) and 2,705 contractors (full time equivalents) were funded to support U.S. Department of Energy National Nuclear Security Administration (NNSA)/NV operations.

\section{Historical and Current Missions}

The primary role of the NTS - to support national security missions - has evolved from nuclear testing to stockpile stewardship. For more than 40 years, the site's primary mission was to conduct testing of conventional and nuclear explosives in conjunction with the research and development of nuclear weapons. Most of the field testing was conducted at the NTS, which was first established in 1950. From 1951 to 1992, when a world-wide moratorium on nuclear testing went into effect, the U.S. Department of Energy and its predecessor agencies conducted a total of 928 tests at the NTS. In addition to weapons tests, areas of the NTS have been used for various secondary missions, including neutron and gamma ray interaction studies; open-air nuclear reactor, 
Table 3.5.1. Demographic Characteristics of Nearby Communities

\begin{tabular}{|l|r|r|r|r|r|r|}
\hline & Nye County & \multicolumn{1}{c|}{ Beatty } & \multicolumn{1}{c|}{ Pahrump } & \multicolumn{1}{l|}{ Las Vegas } & \multicolumn{1}{c|}{ Nevada } & \multicolumn{1}{c|}{ US } \\
\hline $\begin{array}{l}\text { Total Population } \\
2000\end{array}$ & 32,485 & 1,154 & 24,631 & 478,434 & $1,998,257$ & $281,421,906$ \\
\hline $\begin{array}{l}\% \text { Population } \\
\text { Change, } \\
1990-2000\end{array}$ & $82.7 \%$ & $-28.9 \%$ & $231.8 \%$ & $85.2 \%$ & $66.3 \%$ & $13.1 \%$ \\
\hline White & $89.6 \%$ & $90.9 \%$ & $91.0 \%$ & $69.9 \%$ & $75.2 \%$ & $75.1 \%$ \\
\hline Black & $1.2 \%$ & $0.1 \%$ & $1.3 \%$ & $10.4 \%$ & $6.8 \%$ & $12.3 \%$ \\
\hline $\begin{array}{l}\text { American } \\
\text { Indian/Alaska Native }\end{array}$ & $2.0 \%$ & $1.5 \%$ & $1.3 \%$ & $0.7 \%$ & $1.3 \%$ & $0.9 \%$ \\
\hline $\begin{array}{l}\text { Asian } \\
\text { Hawaiian/Pacific } \\
\text { Islander }\end{array}$ & $0.8 \%$ & $1.2 \%$ & $0.9 \%$ & $4.8 \%$ & $4.5 \%$ & $3.6 \%$ \\
\hline Other & $0.3 \%$ & $0.0 \%$ & $0.4 \%$ & $0.4 \%$ & $0.4 \%$ & $0.1 \%$ \\
\hline Mixed & $3.0 \%$ & $3.1 \%$ & $2.3 \%$ & $9.7 \%$ & $8.0 \%$ & $5.5 \%$ \\
\hline Female/Male Ratio & $48.7 / 51.3$ & $45.6 / 54.4$ & $49.4 / 50.6$ & $49.2 / 50.8$ & $49.1 / 50.9$ & $50.9 / 49.1$ \\
\hline $\begin{array}{l}\text { Median Household } \\
\text { Income (1999) }\end{array}$ & $\$ 36,024$ & $\$ 41,250$ & $\$ 34,860$ & $\$ 44,069$ & $\$ 44,581$ & $\$ 41,994$ \\
\hline Per Capita Income & $\$ 17,962$ & $\$ 16,971$ & $\$ 17,7087$ & $\$ 22,060$ & $\$ 21,989$ & $\$ 21,587$ \\
\hline
\end{tabular}

Population of nearby communities: Clark County 1,375,765; Indian Springs 1,302; Amargosa Valley n/a

Source: Census data for 2000

nuclear engine, and nuclear furnace tests; and experiments conducted by the Department of Defense (DOD) involving radioactive and other materials. Currently, the site's mission is to maintain the safety and reliability of the U.S. nuclear stockpile. Activities include subcritical and other weapons-related physics experiments, training, and demonstration for defense systems; advanced high hazard operations; and other national security experimental programs. The site also supports a hazardous materials spill center for testing the environmental effects of toxic and hazardous materials, training exercises for emergency personnel, and a low-level waste operation for disposing of DOEgenerated waste. Cleanup of contaminated portions of the site began in 1989 with establishment of the Office of Environmental Restoration and Waste Management (EM) in Washington, D.C., and the associated Nevada Test Site EM Program.

\section{Site Management Structure}

The National Nuclear Security Administration (NNSA) was formally established on March 1, 2000, as a semi-autonomous part of the U. S. Department of Energy. NNSA was created to address security issues at nuclear weapons and testing facilities and has responsibility for nuclear weapons stockpile, international nuclear safety issues, and management of the nuclear propulsion program. The DOE/NV is now known as the U.S. Department of Energy, National Nuclear Security Administration Nevada Operations Office (NNSA/NV), where NNSA is the lead program secretarial office. At the Nevada Test Site, NNSA primarily deals with defense programs, while the Environmental 
Management program continues as before with its mission to remediate contaminated sites, manage radioactive and hazardous waste, and deploy innovative technologies.

The Yucca Mountain Site Characterization Office, whose high-visibility activities related to the potential siting of a high-level waste repository in Nevada have been subject to state opposition for almost 15 years, is within a separate DOE management structure, which NNSA/NV is careful to emphasize.

The NNSA/NV EM Program includes three divisions: Environmental Restoration, Waste Management, and Program Support. As described below, the EM Program is responsible for cleanup on sites in a number of different locations and jurisdictions; this situation increases the complexity of the program's planning and decision making.

Bechtel Nevada is the current site management and operating contractor; the prime contractor for environmental management activities is Shaw Environmental and Infrastructure, Inc. (formerly IT Corporation).

\section{Cleanup and Waste Management Activities}

Most NNSA/NV EM projects in the State of Nevada are located within the boundaries of the NTS. However, additional activities take place at two sites located in Nevada but off the NTS: Project Shoal, located in western Nevada 30 miles southeast of Fallon; and the Central Nevada Test Site, located in south-central Nevada about 60 miles northeast of Tonopah. In addition, NNSA/NV is responsible for remediation activities at former nuclear test locations in Alaska, Colorado, Mississippi, and New Mexico. This study focuses on public participation programs for the Nevada Test Site.

The dominant regulatory driver for DOE environmental restoration activities in Nevada is the Federal Facility Agreement and Consent Order (FFACO) of May 1996. Under the FFACO, DOE and the Department of Defense (DOD) propose priorities and discuss them with the State of Nevada. The State then makes recommendations that are presented for public review and subsequently developed into a final prioritization of corrective actions for investigation and remedial action. NNSA/NV and the State have also entered into an Agreement in Principle under which the State monitors and independently oversees NNSA/NV routine operational activities. An appendix to the Agreement provides an increased role for the State in monitoring management of low-level wastes generated and disposed of at NTS.

Historical nuclear testing activities, associated support facilities, and nuclear rocket experiments resulted in both surface and sub-surface contamination of the NTS. The level of concern about environmental impacts from NTS on nearby communities has been limited by the remote location of the site and the arid nature of the environment. Potential groundwater impacts are a concern for nearby Nye County communities, but other than transportation, EM issues at the Test Site have not been a central concern in Las Vegas and Clark County. 
NNSA/NV EM remediation activities are grouped into the Industrial Sites Project, the Offsites Project, the Soils Project, and the Underground Test Area (UGTA) Project. Industrial sites generally consist of sites containing discarded drums, batteries, lead bricks, and other debris that can be removed; and more complex sites such as septic tanks, leachfields, waste dumps, mud pits, and facilities used in testing and support activities. The Soils Project involves the assessment and implementation of corrective actions for surface soils that were contaminated from activities such as cratering experiments and above-ground nuclear tests. The UGTA Project addresses the problems caused by detonations that were conducted in shafts and tunnels ranging from approximately 90 to 4,800 feet below the ground surface; about one-third of the approximately 900 detonations occurred near or below the water table, resulting in contamination of the groundwater. UGTA studies are designed to explore the effects of underground testing on the groundwater at the NTS by conducting modeling activities to determine the potential for contaminant migration and define boundaries for safe water use. To date, no evidence of groundwater contamination off-site has been detected by the monitoring network.

NTS radioactive waste management activities include disposal of low-level waste that is generated at the NTS and also by approved DOE and DOD generators across the U.S (two disposal sites are located on the site); disposal of NNSA/NV mixed low-level waste generated in the State of Nevada; storage and treatment of NTS mixed waste; and temporary storage of transuranic and mixed transuranic waste pending transfer to the Waste Isolation Pilot Plant (WIPP) in New Mexico.

\section{Structure and Staffing of the EM Public Participation Program}

EM public participation activities are planned and managed by NNSA/NV staff who report to the Assistant Manager for Environmental Management. Activities are also coordinated with the NNSA/NV Office of Public Affairs. One full-time federal staff member and five full-time contractor staff support NNSA/NV EM public involvement activities.

\section{EM Public Outreach and Participation Goals and Activities}

\section{Public Participation Goals}

The major stated goal of the NNSA/NV EM public participation program is to "establish and maintain a two-way exchange of information and ideas between the public and the DOE regarding environmental management issues and priorities" (Appendix V, Public Involvement Plan, January 1999).

The latter plan distinguishes between four basic levels of interest that the public participation program is designed to address: aware, informed, involved, and highly involved. For consistency, the following discussion integrates these distinctions within the three categories used in other site summaries in this report (information distribution, 
public participation activities other than the Site Specific Advisory Board (SSAB), known as the Community Advisory Board (CAB), and SSAB activities).

\section{Information Distribution}

The NNSA/NV EM Program publishes and distributes a variety of public information materials through a comprehensive mailing list of over 2000 names, a website (http://www.nv.doe.gov/programs/envmgmt/default.htm), and public reading room. The website provides an electronic link to the CAB's site: http://www.ntscab.com), although at the time of the study in mid-2002, no new information about meetings or activities had been posted since April 2001. The Office of Public Affairs is responsible for maintaining a Speakers' Bureau and organizing site tours. The NNSA/NV-EM Coordination and Information Center is co-located with the DOE public reading room in Las Vegas. The Public Involvement Plan, Appendix $V$ also provides a useful overview of public information sources, activities, and ways to become involved, as well as information on the NNSA/NV-EM program, including regulatory drivers, and a brief background on the history of the NTS.

Fact sheets, available on the website, provide a succinct description of key aspects of the NNSA/NV-EM Program. A quarterly newsletter, the EM Update, describes current EM activities, programs, upcoming events, and recaps the $\mathrm{CAB}$ activities and recommendations.

\section{Non-SSAB Public Participation Activities}

Several types of public information/participation activities provide opportunities for stakeholder involvement, although the principal focus of public participation effort for the Test Site is the CAB. NNSA/NV-EM holds periodic meetings with local, city, and state officials. The Site Technology Working Group meets two to four times each year to provide input on how best to use technology information for environmental restoration and waste management activities. Membership includes DOE managers, contractors, staff from DOE's national laboratories, members of key stakeholder groups, and CAB representatives. The Transportation Working Group, established in response to stakeholder concerns about the transport of low-level waste and hazardous materials to and from the NTS, meets quarterly. Its members inc lude representatives from the Nevada Department of Transportation, the Nevada Agency for Nuclear Projects, various county governments, the University of Nevada, Las Vegas, the Yucca Mountain Site Characterization Project, representatives from waste generator sites (e.g., Fernald), and NNSA/NV. Although the meetings of these working groups are open to the general public and information is available on-line (http://www.nv.doe.gov/programs/xportmgt/default.htm), public awareness and attendance is generally limited.

\section{The Community Advisory Board for Nevada Test Site Programs (CAB)}

Established in 1994, the CAB is a key focus of the NNSA/NV-EM public participation program. At the time of the study, it was composed of 22 members plus ex-officio 
representatives from NNSA/NV, the Defense Threat Reduction Agency, the State of Nevada, Nye County, and the Nevada Alliance for Defense, Energy, and Business. NTS is not a CERCLA site and, unlike other DOE Site Specific Advisory Boards, the U.S. Environmental Protection Agency is not included as an ex-officio member. Members are selected to be broadly representative of the area's demographic diversity and viewpoints and may serve for two years, with a three-term limit. Membership includes citizens from Clark, Washoe, Nye, and Lincoln Counties. Over the past several years, a conscious effort has been made to recruit more members from the rural communities near the Test Site. Tribal representatives have declined to participate; however, the Board maintains communication with the Timbisha-Shoshone community.

The board conducts at least four public information meetings a year. In addition, the Administrative Committee meets monthly to discuss subcommittee initiatives, and subcommittees meet on an as-needed basis to accomplish their work. Board meetings are advertised through local press, radio broadcasts, and community mailings, with special emphasis on advertising in rural areas. Meetings are conducted with professional facilitation and decisions are made by consensus. Recommendations are made to NNSA/NV-EM and the State of Nevada; responses are formally tracked. Several subcommittees are active: Administrative, Budget, Transportation and Waste, and the Underground Test Area (UGTA). The Assistant Manager for Environmental Management plays a very active role in board affairs, attending all public board meetings and subcommittee meetings on an as- needed basis. NNSA/NV-EM staff formally track and respond to formal recommendations in writing.

A key focus area for the $\mathrm{CAB}$ has been the issue of groundwater contamination resulting from the historical underground testing program. Members of the CAB's Underground Test Area Committee reviewed the site's strategy for evaluating the extent of groundwater contamination from Test Site activities - discussing key points with site representatives and regulators, and studying the current strategy and modeling and presenting their findings to the whole $\mathrm{CAB}$. Upon completion of their review, some $\mathrm{CAB}$ members still had reservations about the strategy, particularly the level of uncertainty associated with the groundwater modeling, given the planned well monitoring program. The CAB therefore requested that the Department of Energy conduct an independent peer review of the strategy. Although site officials believed their existing approach to be the most effective option, they agreed to sponsor a peer review. They then contracted with the American Society of Mechanical Engineers (ASME) and the Institute for Regulatory Science to assemble and oversee an independent technical peer review. The results were presented to the $\mathrm{CAB}$, which then provided written feedback and recommendations to NNSA/NV EM regarding the recommendations presented in the peer review report. That feedback was under review at the time of the study.

The $\mathrm{CAB}$ has also attempted to draw upon the capabilities of their technical advisor and other $\mathrm{CAB}$ members to conduct public education workshops on topics important to the Test Site and to bring this information to residents of the rural communities. For example, the technical advisor and several CAB members held a workshop on 
groundwater and groundwater modeling was held for community members in association with a $\mathrm{CAB}$ meeting in Amargosa.

\section{Key Public Participation Challenges and Status in Relation to the Acceptability Diamond}

The site visit and interviews conducted by the PNNL research team identified several particular challenges faced by the Nevada Test Site and its stakeholders in establishing an effective public participation program and addressing the four dimensions of the Acceptability Diamond (substantive issues, decision-making process, relationships, and accountability).

\section{Challenges}

- The Test Site and its cleanup issues are overshadowed and complicated by issues associated with the DOE Yucca Mountain program. The political context created by Yucca Mountain has made it difficult for those dealing with cleanup and waste management at the test site to gain the attention of the public. It has also prompted the two programs to expend considerable effort clarifying the distinctions between them. The two programs are conducted separately, which, according to several respondents, has raised issues of consistency of methodology and sharing of information, particularly regarding transportation and ground water modeling.

- The large distances between the Test Site and the DOE office and staff (located in Las Vegas), and the large distances between the rural communities within the site impact area make travel times prohibitive for frequent face-to-face meetings. The different lifestyle in the rural communities and Las Vegas exaggerates the impact of DOE's location in the city on NNSA/NV-EM's relationship with residents of the rural communities.

- The high growth rate and the "event rich" nature of the Las Vegas economy, combined with the extraordinarily high numbers of tourists continually transitioning through the community, have made it particularly difficult for the public participation program to be visible and capture the attention of the broader public in Las Vegas. In addition, there are few organizations focused on environmental issues located in the site's impact area.

- Most area residents do not perceive that the waste at the Test Site is creating an imminent hazard to their health and safety, although concern is expressed about transportation of radioactive and hazardous material through their communities, and about contamination of the ground water/aquifer, and soil.

- The relationship between DOE and the Air Force and its impact on site cleanup and waste management decisions is not well understood. 


\section{Status in Relation to the Acceptability Diamond}

The following summarizes the research team's assessment of the site's status in relation to the Acceptability Diamond at the time of the study:

- The advisory board has achieved increased representation from the rural communities and has held more meetings in the rural areas over the past several years. This has provided a more effective linkage with stakeholders who are most directly affected by, and most interested in, site activities and decisions. It has also revitalized the board, which has seen increased regularity of attendance by members and greater continuity of discussions within the board.

- The board has obtained the assistance of a technical advisor, who is widely recognized as effective in helping the board review materials and identify issues that warrant attention and in helping individual board me mbers gain the background needed to understand the issues. The technical advisor, in collaboration with board members, has extended this service to the broader public through educational workshops. The workshop on groundwater held in Amargosa was identified by a number of respondents as an important accomplishment.

- Substantive issues: Most respondents felt that the board had made significant progress in identifying and addressing key site issues, primarily as a consequence of the efforts of the technical advisor, the establishment of committees, and the recruitment of members with interest and expertise. By focusing on a few issues, respondents reported that their participation was both more effective and more satisfying.

The committee structure provided additional opportunities for leadership, and enabled the participants to feel that they were more "in charge" and engaged. By giving responsibility to the committees for moving forward on issues, dealing with site staff to frame and clarify issues, and presenting the results of committee work to the overall board, the work was distributed more widely and more leadership opportunities were created. Nevertheless there are some concerns that the issues important to the public are not really getting on DOE's - and the community's - agenda. For example, one respondent cautioned that:

DOE has dismissed issues that were really important to the community, for example, transportation, by insisting that there is not risk. DOE believes that they are right and so don't take public concerns seriously. It is the same with water, but more subtly. DOE is determined not to be diverted from their agenda.... There are serious equity issues that are not getting addressed, for example why so much LLW is coming to NTS.

- Decision making: Respondents emphasized the complexity of the decisionmaking process affecting the Test Site, which was frequently described as "only one part of a larger mission" and influenced significantly by decisions made at 
other sites as well as the relationship between DOE and the Air Force. ${ }^{27}$ In general, respondents indicated that they did not understand the DOE decisionmaking process. Although the board constituted the primary avenue for public participation in test site decisions, respondents questioned the ability of the board to influence the important decisions, which most felt were primarily made at HQ. However, they also acknowledged that participation on the advisory board enabled members to gain some understanding of this process - as one respondent said, "the $\mathrm{CAB}$ has matured to the point where they have a better idea of what they want to know and what they want to address." Participation has also enabled them to provide input on some important issues, although many respondents emphasized the limitations created by the lack of wider public attention and engagement. Their ambivalence about their ability to influence DOE's decision making was reflected in descriptions about their role in the peer review of NNSA/NV's ground water modeling: On one hand most felt that the board's recommendation to undertake a peer review had been accepted by DOE but, on the other hand, many felt that the board's specifications for the review had been significantly modified by DOE without consultation. Respondents also indicated that reaching decisions within the board continued to be difficult, with lingering issues about how minority opinions should be handled.

- Relationships: The combination of infrequent interactions with rural residents because of the long distances and DOE's location in Las Vegas, the lack of DOE Test Site visibility within the urban community, and spillover from Yucca Mountain led few respondents to characterize DOE's relationship with the community as particularly strong or good, although a number indicated positive personal relationships with the DOE staff they dealt with themselves. The increased interaction with DOE program managers that had resulted from the board's committee meetings was identified as leading to greater familiarity and more productive working relationships. Most respondents reported that they had little interaction with site regulators and issues of independence were still present. In general, however, respondents indicated that the public participation activities were promoting better working relationships: One respondent noted, for example, that "Respect is important and is facilitated by the board."

- Accountability: The history of secrecy at the Test Site, the location of the Test Site activities within NNSA, the remote, closed geography of the site, and the lack of interest on the part of the public (which, when expressed, was uniformly characterized as overwhelmingly focused on Yucca Mountain) were seen as affecting DOE's sense of accountability to the community for the Test Site. In addition, respondents felt that DOE's perspective toward cleanup at the site was

\footnotetext{
${ }^{27}$ EM management is complicated by several factors. First, overlapping issues exist between NTS remediation and larger DOE policy issues such as (1) transportation, which is beyond EM's sole jurisdiction or (2) impacts such as groundwater issues that are also an issue for the Yucca Mountain project. Second, because of ongoing DOD missions, agreement must be reached with DOD as well as the State of Nevada over corrective actions for investigation and remedial action. As an example of the added complexity this introduces, DOE and the Air Force were deadlocked for an extended period over the desired corrective action cleanup level. Finally, NTS environmental work may compete for funding and resources with other, out-of-State projects that are under DOE/NV-EM management.
} 
significantly affected by the fact that the site was remote and was never going to be released to public use. The only regulator, a representative of the Nevada

Department of Environmental Protection (NDEP), is not seen as very accessible to the members, though one respondent indicated that, since the DEP person is at the board meetings, "if repeated concerns are raised, they can hear them there, and that will make them attentive to the issues." Given this context, respondents felt that the ongoing continuity of the $\mathrm{CAB}$, which enabled them to track issues from beginning to end, did enhance accountability and is particularly important. Board recommendations require a response from DOE and members have established a system to track responses. The recent reduction in the NTS EM budget, and the subsequent slowdown/postponement of planned cleanup activities, raised concerns about both progress on cleanup and about maintaining a pace of activity that made participation worthwhile. 


\subsection{OAK RIDGE RESERVATION}

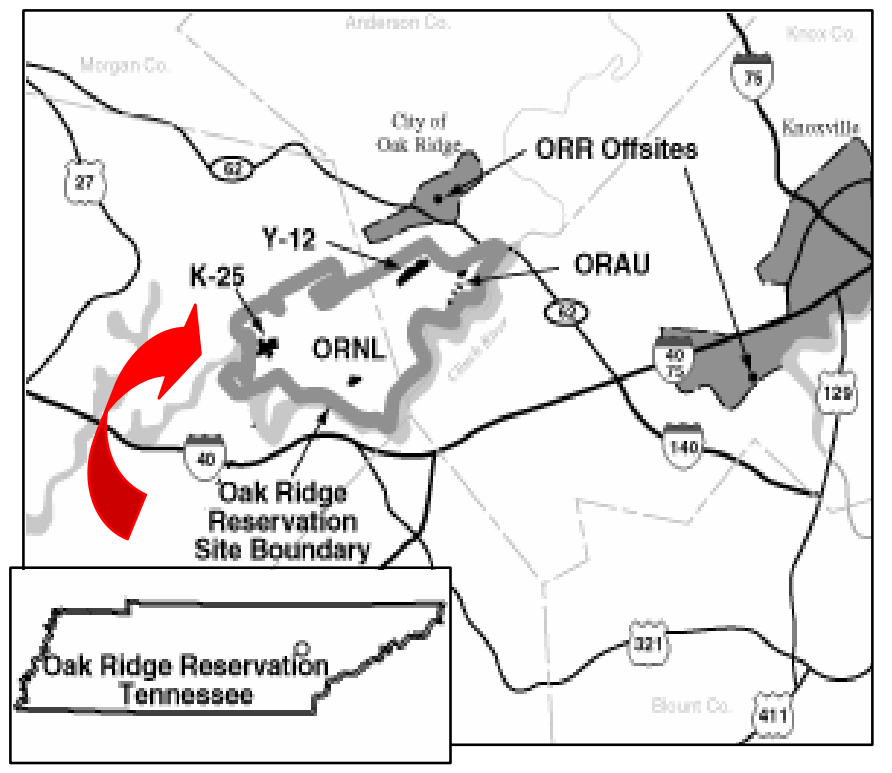

Location, Population, Land Use

The Oak Ridge Reservation (ORR) is located within Anderson and Roane Counties in eastern Tennessee. It lies on 34,000 acres of federally owned land within the incorporated city limits of Oak Ridge and is bordered on the southeast and southwest by the Clinch River. Knoxville, the largest area city, is approximately 20 miles to the southeast.

The population varies in the six counties that are closest to and most affected by Reservation activities. ${ }^{28}$ As

illustrated in Table 3.6.1, the area around Knoxville is a developed urban area, with a Census 2000 population of 173,890. With the exception of the City of Oak Ridge (population 27,387), the area surrounding the ORR is sparsely populated. Several small communities are within an easy commuting distance of the site (Clinton, Kingston, Oliver Springs, Lenoir City, Harriman, and Rockwood).

Land uses bordering the ORR are primarily forest and agriculture. Residential and commercial uses occur along the northeast and northwest boundary in the City of Oak Ridge. Department of Energy work on the Reservation plays an important role in all of the local economies. In 2001, more than 550 DOE employees and 13,000 contractors were employed on the many Oak Ridge projects and missions.

\section{Historical and Current Missions}

Originally created as part of the Manhattan Project during World War II to extract uranium from the raw ore to fuel an atom bomb, the Reservation is one of the largest and most diverse complexes in the nation, involving continuing operations as well as cleanup. It includes three primary complexes, each with distinct missions and located on separate sites: (1) the Y-12 National Security Complex, whose original mission to enrich uranium using an electromagnetic process has been replaced by precision machining of special

\footnotetext{
${ }^{28}$ The six counties, as shown in Table 3.6.1, are Anderson and Roane Counties (in which the Reservation is jointly located), and Knox, Loudon, Meigs, and Rhea Counties. The SSAB draws from a seven-county area, which also includes Campbell County.
} 
Table 3.6.1. Demographic Characteristics of Nearby Counties and the City of Oak Ridge

\begin{tabular}{|c|c|c|c|c|c|c|c|c|c|}
\hline & $\begin{array}{c}\text { Anderson } \\
\text { County }\end{array}$ & \begin{tabular}{|c|} 
Knox \\
County
\end{tabular} & $\begin{array}{l}\text { Loudon } \\
\text { County }\end{array}$ & \begin{tabular}{|l|} 
Meigs \\
County
\end{tabular} & $\begin{array}{l}\text { Rhea } \\
\text { County }\end{array}$ & $\begin{array}{l}\text { Roane } \\
\text { County }\end{array}$ & $\begin{array}{c}\text { Oak } \\
\text { Ridge } \\
\text { City }\end{array}$ & Tennessee & US \\
\hline $\begin{array}{l}\text { Total } \\
\text { Population } \\
2000 \\
\end{array}$ & 71,330 & 382,032 & 39,086 & 11,086 & 28,400 & 51,910 & 27,387 & $5,689,283$ & $281,421,906$ \\
\hline \begin{tabular}{|l|} 
Percent \\
Population \\
Change, \\
$1990-2000$
\end{tabular} & $4.50 \%$ & $13.90 \%$ & $25.1 \%$ & $38 \%$ & $16.70 \%$ & $9.90 \%$ & $0.30 \%$ & $16.7 \%$ & $13.1 \%$ \\
\hline White & $93.4 \%$ & $88.1 \%$ & $95.9 \%$ & $97.7 \%$ & $95.4 \%$ & $95.2 \%$ & $87.0 \%$ & $80.2 \%$ & $75.1 \%$ \\
\hline Black & $3.9 \%$ & $8.6 \%$ & $1.1 \%$ & $1.2 \%$ & $2.0 \%$ & $2.7 \%$ & $8.2 \%$ & $16.4 \%$ & $12.3 \%$ \\
\hline $\begin{array}{l}\text { American } \\
\text { Indian/ } \\
\text { Alaska } \\
\text { Native }\end{array}$ & $0.3 \%$ & $0.3 \%$ & $0.3 \%$ & $0.2 \%$ & $0.4 \%$ & $0.2 \%$ & $0.3 \%$ & $0.3 \%$ & $0.9 \%$ \\
\hline Asian & $0.8 \%$ & $1.3 \%$ & $0.2 \%$ & $0.2 \%$ & $0.3 \%$ & $0.4 \%$ & $2.1 \%$ & $1.0 \%$ & $3.6 \%$ \\
\hline $\begin{array}{l}\text { Hawaiian/ } \\
\text { Pacific } \\
\text { Islanders. }\end{array}$ & $0.0 \%$ & $0.0 \%$ & $0.0 \%$ & $0.1 \%$ & $0.0 \%$ & $0.0 \%$ & $0.0 \%$ & $0.0 \%$ & $0.1 \%$ \\
\hline \begin{tabular}{|l|} 
Other \\
\end{tabular} & $0.4 \%$ & $0.5 \%$ & $1.4 \%$ & $0.1 \%$ & $0.8 \%$ & $0.2 \%$ & $0.8 \%$ & $1.0 \%$ & $5.5 \%$ \\
\hline Mixed & $1.2 \%$ & $1.2 \%$ & $1.0 \%$ & $0.6 \%$ & $1.1 \%$ & $1.2 \%$ & $1.7 \%$ & $1.1 \%$ & $2.4 \%$ \\
\hline $\begin{array}{l}\text { Female/Male } \\
\text { Ratio } \\
\end{array}$ & $52.3 / 47.7$ & 51.7/48.3 & $51.3 / 48.7$ & $50 / 50$ & $51.5 / 48.5$ & 51.6/48.4 & $53.2 / 46.8$ & $51.3 / 48.7$ & $50.9 / 49.1$ \\
\hline \begin{tabular}{|l|} 
Median \\
Household \\
Income \\
$(1999)$ \\
\end{tabular} & $\$ 35,483$ & $\$ 37,454$ & $\$ 40,401$ & $\$ 29,354$ & $\$ 30,418$ & $\$ 33,226$ & $\$ 41,950$ & $\$ 36,360$ & $\$ 41,994$ \\
\hline $\begin{array}{l}\text { Per Capita } \\
\text { Income }\end{array}$ & $\$ 19,009$ & $\$ 21,875$ & $\$ 21,061$ & $\$ 14,551$ & $\$ 15,672$ & $\$ 18,456$ & $\$ 24,793$ & $\$ 19,393$ & $\$ 21,587$ \\
\hline
\end{tabular}

2000 Population of Nearby Communities: Clinton 9,409; Oliver Springs 3,303; Kingston City 5,264

Rockwood 5,774; Harriman City 6,744; Lenoir City 6,819; Knoxville 173,890;

Source: Census data for 2000

nuclear materials for bomb manufacture; (2) the Oak Ridge National Laboratory, which originally conducted weapons research and development, especially purification of plutonium, and is now a multi-program science and technology laboratory; and (3) the East Tennessee Technology Park (ETTP), formerly the gaseous diffusion plant, or K-25 facility, which is closed and currently undergoing environmental cleanup and reindustrialization.

\section{Site Management Structure}

Environmental Management (EM) is only one of four Oak Ridge Operations (ORO) Offices that provide programmatic direction. Other programs are the Office of Science, which has been the lead program office for ORO since May 1999; the Office of Energy 
and Efficiency and Renewable Energy; and the Office of Nuclear Energy, Science and Technology. Establishment of the NNSA in March 2000 resulted in the creation of the Y-12 Area Office, which is responsible for activities at the Y-12 National Security Complex. It reports directly to the Office of Defense Programs within the NNSA (ORO continues to provide several business and administrative services to the Y-12 Area Office).

Bechtel Jacobs Company, LLC, is the management and integration contractor for DOE EM in Oak Ridge, and also for other ORO-managed facilities in Portsmouth, Ohio, and Paducah, Kentucky.

\section{Cleanup and Waste Management Activities}

The Office of Environmental Management manages legacy and newly generated waste as well as cleanup of contaminated sites on the Reservation. The Reservation was placed on the National Priorities List in 1989 and a Tri-Party agreement was implemented in January 1992 between DOE, the Environmental Protection Agency (EPA) Region 4, and the Tennessee Department of Environment and Conservation (TDEC) to establish the procedural framework and schedule for developing, implementing and monitoring cleanup response actions. Sixty years of weapons production and energy research have resulted in contamination with radioactive elements, mercury, PCBs, asbestos, and industrial wastes. Unlined radioactive and mixed waste burial grounds, inactive tanks, surplus facilities, and unlined ponds are located on over a thousand acres. Contamination of soil, surface water, and groundwater has spread off site.

Each of the three major complexes presents both technical and public involvement challenges. End use of the sites, determined with the assistance of the End Use Working Group established by the Site Specific Advisory Board (SSAB) is assumed to be a combination of controlled access, controlled industrial, recreational, and unrestricted. At ETTP, following shutdown of uranium production in 1985, the site is being reindustrialized through leasing vacated facilities and establishing partnerships with commercial organizations. Progress is being made on interim soil remediation in the area outside the main fence (Zone 1). Subsequently, all of the contaminated buildings, pits, and burial grounds will be demolished and/or excavated and additional data will be collected to support a final remediation decision. At Y-12, progress has been made on cleanup of the Bear Creek Valley and on cleanup of mercury and other heavy metals in the East Fork Poplar Creek, which flows though the City of Oak Ridge near community residences and exits into the Watts Bar Lake, a popular local recreatio nal and fishing area. At ORNL, the laboratory complex is contaminated with radioactive and chemical waste, primarily strontium-90, cesium-137, tritium, and transuranics; several hundred contaminated areas exist in and outside of the complex within the Melton and Bethel Valleys. Clean up and waste management tasks exist at inactive reactors and facilities that were originally used for shielding studies, separation of fission products, and investigation of the molten salt reactor experiment facility; buildings used for storage of radioactive material, including special nuclear material and uranium; disposition of large quantities of low-level waste; and construction of a facility for treatment of contact and 
remote handled transuranic waste, pending off-site shipment to the Waste Isolation Pilot Plant.

\section{Structure and Staffing of the EM Public Participation Program}

Responsibility for public involvement activities with stakeholders in the City of Oak Ridge and surrounding counties is divided among the DOE-ORO programs and the Y-12 NNSA Office. EM public participation activities, including the Site-Specific Advisory Board, are managed by one DOE staff person, who draws on 2.25 contractor staff for assistance with EM public participation activities. The DOE-EM SSAB federal coordinator works closely with the ORO Community Relations Manager, who has overall responsibility for public involvement activities sponsored by the other DOE programs, except those sponsored by NNSA. Because of the nature of the CERCLA cleanup work at the Oak Ridge Reservation, the Oak Ridge EM Program provides for a greater degree of collaboration and informal interaction with stakeholders than is provided by other programs at the site.

\section{EM Public Outreach and Participation Goals and Activities}

\section{Public Participation Goals}

The stated goal of public participation is to "educate citizens and seek their meaningful involvement, consistent with our department's public participation policy" (http://www.oakridge.doe.gov/public_activ.html).

Various EM public outreach and involvement opportunities are provided for stakeholders in the City of Oak Ridge and surrounding communities. While the Oak Ridge SiteSpecific Advisory Board (ORSSAB) provides a key focus for long-term, intensive involvement of stakeholders, other activities are structured to provide for broad information distribution and different levels and kinds of involvement.

\section{Information Distribution}

ORO publishes and distributes a wide variety of public information materials through mailing lists, the DOE Information Center (located in Oak Ridge), the ORO web site, and the contractor's web site. The web site (http://www.oakridge.doe.gov/public_activ.html) is especially notable for its wealth of easily accessible, up-to-date information about the EM Program, as well as for its provision of web links to other DOE information sources. The web site includes a monthly calendar of stakeholder activities, contact lists, a series of facts sheets, and the advisory board's individual page, as well as links to EM and DOE-wide newsletters, information, and publications. The Public Involvement Plan for CERCLA Activities at the U.S. Department of Energy Oak Ridge Reservation provides a very helpful overview of public information sources and EM involvement activities.

Several newsletters providing current information about Oak Ridge activities are distributed. Cleanup Progress, published annually, and Public Involvement News, 
published monthly, are available through the DOE Information Center and are distributed to a large mailing list. The ORSSAB publishes its own newsletter, The Advocate, which is available on the web at http://www.oakridge.doe.gov/em/ssab/, as well as through the DOE Information Center. All SSAB meetings and committee meetings are clearly posted on its web page and meeting minutes are current. Also available is a guidebook for new SSAB members that includes background on the SSAB Initiative, an outline of key SSAB activities and accomplishments since its establishment, an overview of DOE and SSAB members' responsibilities, a summary of the board's organizational structure and committees, and a list of current members.

\section{Non-SSAB Public Participation Activities}

Legally required meetings that, traditionally, are structured around formal DOE presentations and public commenting periods may be held in conjunction with CERCLA and NEPA decision documents. In addition, the EM Program in Oak Ridge has played a lead role in initiating more informal activities to seek public input and interact with a broad range of stakeholders in the local area. Examples of such activities in 2001 included workshops and public meetings related to the lifecycle baseline and accelerated cleanup initiatives. The Program is also active in educational activities, involving school students in local schools, such as having environmental ecology classes write executive summaries for some of the environmental monitoring documents to ensure the readability level is appropriate for other school and public organizations.

Many active stakeholders, including former site workers and public interest groups, are located in the City of Oak Ridge and surrounding areas. Health and worker safety issues continue to be of concern - these extend beyond EM to the wider DOE organization. Other longstanding stakeholder groups with interests that overlap those of EM include a Health Effects subcommittee, sponsored by ATSDR; and the Local Oversight Committee (LOC), which is funded by DOE under the DOE/State of Tennessee Oversight Agreement.

\section{The Oak Ridge Site-Specific Advisory Board (ORSSAB)}

The Board, which meets one evening per month, has been in operation since September 1995 , following a two-year formation process. It is composed of up to 20 members, chosen to reflect the diversity of gender, race, occupation, views, and interests of nearby residents, and selected in a "blind" process. Membership is for two years with a threeterm limit. At the time of the study, there were 20 board members. Over the past two years, significant changes have occurred in board membership as original board members have retired. The board is authorized to advise each of the ex-officio agencies (DOE, EPA and TDEC), with agreement on recommendations reached by a parliamentary majority vote process rather than consensus. The Assistant Manager of Environmental Management plays an active role in Board activities and is the Deputy Designated Federal Officer (DDFO). The Oak Ridge Operations Office Manager also attends meetings occasionally and shows his interest in apprising the SSAB on specific items that are of interest to the board. Board recommendations are tracked by the DOE SSAB Federal Coordinator and the SSAB Executive Committee. Responses to the 
recommendations are referred back to the committee that initiated the recommendation for follow-up. At the time of the study, there were an Executive Committee, three standing committees that met monthly (Environmental Restoration, Stewardship, and Waste Mana gement) and two ad-hoc committees (Board Process and Public Outreach). The Chairperson conducts board meetings; a facilitator conducts board-sponsored committee meetings.

Particular achievements of the board in recent years include work on stewardship including publishing a second report, ORR Stakeholder Report on Stewardship; and hosting a national SSAB workshop on stewardship in October 1999. The ORSSAB has also played a very proactive role in involving the broader public in board activities and EM issues. For example, the Stewardship Working Group, sponsored by the board, led a broad-based community effort in addressing stewardship issues; some board meetings were scheduled in locations other than the City of Oak Ridge; and board members operate a speakers' bureau, supported by public involvement staff. In addition, board meetings are videotaped and meeting minutes and recommendations posted on the board's web site.

\section{Key Public Participation Challenges and Status in Relation to the Acceptability Diamond}

Based on site visits and interviews conducted in spring 2002, the PNNL research team identified challenges faced by the Oak Ridge EM public participation program in addressing the four dimensions of the Acceptability Diamond (substantive issues, decision making, relationships, and accountability).

\section{Challenges}

- Issues of scope and budget pose a particular challenge for EM. As discussed above, management of DOE Oak Ridge activities is divided between ORO (EM is only one of four ORO Offices that provide programmatic direction) and the NNSA Y-12 Area Office, which has a continuing production mission. Both NNSA and the ORO/Office of Science provide for public participation and thus three sets of separate public participation activities are conducted. EM is the most proactive of the three programs but is constrained from responding on a number of issues that are of concern to the public, yet not within EM scope. EM is also faced with a diminishing budget, which represents a smaller proportion of overall site funding than formerly.

- Site issues are numerous, complex and, from the public's perspective, difficult to separate neatly into EM and non-EM issues. Remediation of the highest-risk sites is scheduled for completion in 2006, with closure of the ETTP site by 2008, but some cleanup issues are related also to on-going site activities. For example, several respondents mentioned stewardship issues related to ETTP activities and/or also noted that an overwhelming proportion of the waste produced at Y-12 and at the ORNL is actually EM waste. Many interviewees also expressed concern about factors outside of EM control (but related to EM) that affect EM- 
community relationships. EM's public participation program is widely acknowledged as being the most open, interactive, and credible; yet issues of concern to the community are being addressed outside of EM. For example, many questioned the adequacy of the approach to issues such as land use, health impacts from former operations, impacts on the Scarboro community, and changing contractual relationships that make it difficult to assign responsibility for workers' welfare.

- Although population is not as widely dispersed and ethnically and racially diverse as at Hanford, Savannah River, or Nevada, there are neverthe less cultural differences between residents in the city of Oak Ridge and surrounding rural communities that need to be accommodated. In particular, there has been a history of conflict between the site and opponents of weapons production, and more recently, conflict over health issues that have affected community and interpersonal relationships and SSAB activities, at least in the early days of the board.

\section{Status in Relation to the Acceptability Diamond}

The following summarizes the research team's assessment of the site's status in relation to the Acceptability Diamond at the time of the study:

- Substantive Issues: Stakeholders interviewed by the research team generally acknowledged the limitations of EM's authority in addressing issues of broader scope, although some remained critical that the public and SSAB are too tightly focused on issues that may not be the most important from the community's perspective. Assessments of the public's ability to identify and get EM issues on the agenda were very much colored by skepticism about recent changes in the EM Headquarters approach. On the positive side, several respondents emphasized the contributions of local residents, whom they described as "smart scientists who can hold their own with DOE." Some expressed appreciation for public participation activities in helping to increase public awareness or, as one person said, "involve [DOE] in listening to what people are saying." Another person pointed to various avenues by which the public could get issues on the agenda - the SSAB, the LOC, and the City's Environmental Quality Advisory Board. A number of respondents highlighted the value of two boards (the SSAB and the LOC) in identifying issues. As one said, "Having two boards is good because, collectively, they obtain and translate information in a way that makes it accessible to the public." However, such positive assessments were outweighed by frequent expressions of concern that the openness of the local EM office in providing information and addressing stakeholders' concerns was being undermined by recent EM Headquarters actions ("Information disclosure is pretty good - when the local DOE are permitted;" "The current Secretary does not care about EM - and an agency's mission and efficacy is a direct influence of Headquarters leadership;" "The public says to DOE 'please let us help you,' but DOE-HQ isn't seeking input, especially right now;" "People are disturbed because they have had no input on the budget for the past two years;" and "The last six-eight months and 
the recent budget is a prime example of the cloak and dagger approach, which made everyone flounder around.")

- Decision making: The majority of those interviewed agreed that the public is able to influence decisions and that DOE responds to them - EM may not always take advice but "at least listens and gets back with an answer." Several cited specific examples (e.g., the End Use Working Group), where EM "took seriously" and incorporated recommendations from the public. Most stated that they do understand DOE's decision-making process and that the SSAB provides a valuable opportunity for DOE-EM feedback - as one person noted, other public participation activities do not provide an opportunity for feedback, whereas EM is "obligated" to respond to the SSAB, and "this makes us feel better." EM was praised for "doing much better than other parts of DOE. Actually, doing a pretty good job - in some cases, an excellent job."

- Relationships: Comments on relationships were mixed. Some reported that public participation activities, and in particular the SSAB, had been beneficial for building personal relationships, although some expressed concern that relationships could be perceived as being too close and jeopardizing the objectivity of the board. In describing positive relationships, respondents used words and phrases such as: "Access," "personal contacts," "friendly chats," "trust," "EM is open to recommendations," "responsive," "cooperative," "helpful in getting information and supporting people in the community to figure things out." The board's support staff was singled out for praise as being good, loyal, and helpful. One person pointed out the mutuality of relationships and that the public, in being serious and knowledgeable, had gained credibility and thus helped build relationships with DOE-EM.

Of those who more critical, one person saw the DOE-community relationship as "arms' length at best" and commented that public participation is not having an impact because the people who are participating "already know the site people anyway." Most who were critical focused on factors outside of EM control that they believe have affected EM's relationships with the community. Concerns were expressed that responsibility for key issues such as land use and health is assigned to other DOE departments and that decisions are not always made in the interests of the community. As a major employer, DOE holds power over jobs and its actions have an effect on the community - thus, changes in employment patterns and the increased fragmentation of contractors, together with changes in DOE staffing (described as "like musical chairs") are viewed as having a negative effect on relationships and creating resentment. Within EM, respondents interpreted lack of prior consultation on the Top-to-Bottom Review and Performance Management Plan, and effectively taking the budget off the public's agenda, as DOE Headquarters reverting to Decide-Announce-Defend and bringing into question the future role of the SSAB.

- Accountability: In general, study respondents reported that DOE's accountability is limited. One person noted that DOE's accountability was to Congress and not to the local community, and that it was the regulators' responsibility to keep the agency accountable. Others were split between those who reported that people 
help make an agency accountable and those who believed that active regulators and binding agreements are needed. Most of the former singled out the SSAB and LOC as playing an important role in raising issues and pressing DOE to be open - a few noted that the recent personnel changeover in EM Headquarters and in the local office reduced personal accountability on the part of agency staff. Those who emphasized the need for institutional accountability were unanimous in agreeing that this was lacking. One person, for example, pointed to the need for statutory mandates to "provide teeth" on stewardship. Most were critical of the EPA as being a barrier or "obstructionist," and one person expressed the hope that the state regulators would not "let DOE off the hook," despite budget cuts. 


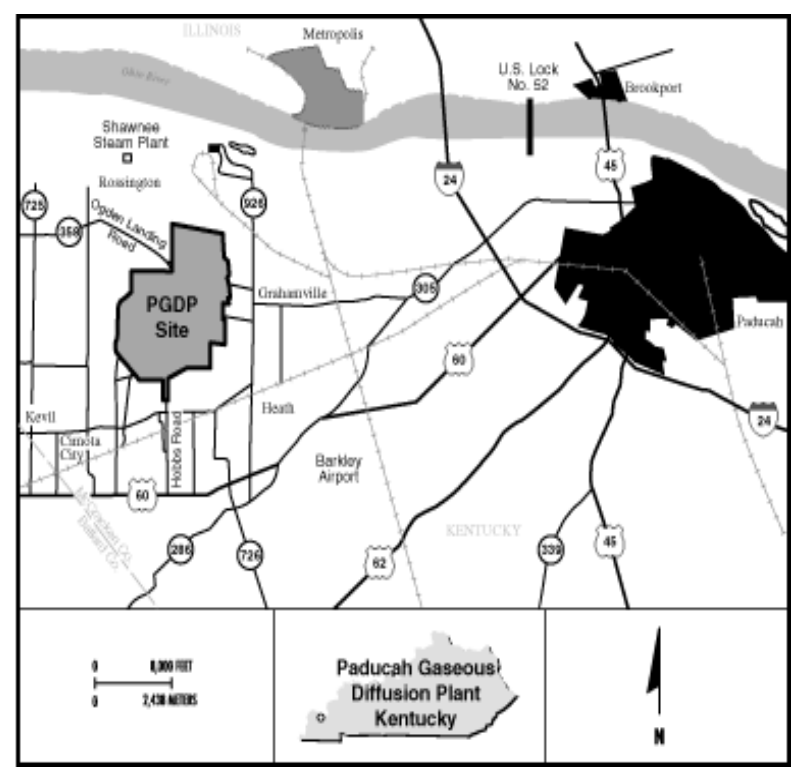

\section{Location, Population, Land Use}

The Paducah Gaseous Diffusion Plant (PGDP) is located in McCracken County, approximately 10 miles west of the City of Paducah in far western Kentucky, and three miles south of the Ohio River. The DOE reservation consists of approximately 3,556 acres, a portion of which is leased to the U.S. Enrichment Corporation (USEC), established by Congress in 1993 as a private entity responsible for enriched uranium production. Although USEC enriches uranium for commercial nuclear power use, DOE owns the plant and property and oversees environmental restoration and waste management activities on the site.

USEC has been a significant source of regional employment and, though reduced compared with its former size, continues to employ approximately 1,400 persons. The major area of socioeconomic impact is McCracken County, where the majority of USEC plant workers live. However, the region of influence includes five counties in Kentucky (McCracken, Ballard, Carlisle, Graves, and Marshall) and one county in Illinois (Massac), where average travel time to work is less than 30 minutes. An office building in Kevil, in Ballard County, is leased for several environmental management-related companies including the DOE Management and Integrator Contractor (M\&I), Bechtel Jacobs Company LLC (BJC). BJC and its subcontractors employ more than 700 people

The Tennessee Valley Authority Shawnee Steam Plant is located about two miles north of the PGDP on the Ohio River. Other area employment is provided by light industry and the service and retail industry. Table 3.7.1 shows demographic characteristics for nearby counties and communities.

The area surrounding PGDP is mostly agricultural and open land, with homes scattered along rural roads around the plant. The plant is in the drainage areas of Big Bayou Creek and Little Bayou Creek, which flow around the eastern and western boundaries. The two streams converge about three miles north of PGDP and flow into the Ohio River. Much of the water in both creeks comes from controlled discharges at the plant. PGDP is above an 80-foot-deep gravel pit that provides water to private wells. An uninhabited buffer zone, consisting of 2,100 acres, is provided by the Western Kentucky Wildlife Management Area; this area is an important recreational resource used by more than 10,000 persons per year. 


\section{Table 3.7.1. Demographic Characteristics of Nearby Counties and the City of Paducah}

\begin{tabular}{|l|r|r|r|r|r|r|}
\hline & $\begin{array}{c}\text { Ballard } \\
\text { County, } \\
\text { Kentucky }\end{array}$ & $\begin{array}{c}\text { McCracken } \\
\text { County, } \\
\text { Kentucky }\end{array}$ & $\begin{array}{c}\text { Massac } \\
\text { County, } \\
\text { Illinois }\end{array}$ & \multicolumn{1}{|c|}{$\begin{array}{c}\text { Paducah } \\
\text { City }\end{array}$} & Kentucky & US \\
\hline Total Population,. 2000 & 8,286 & 65,514 & 15,161 & 26,307 & $4,041,769$ & $281,421,906$ \\
\hline $\begin{array}{l}\text { Percent Population } \\
\text { Change, } \\
1990-2000\end{array}$ & $4.9 \%$ & $4.2 \%$ & $2.8 \%$ & $-3.5 \%$ & $9.6 \%$ & $13.1 \%$ \\
\hline White & $95.3 \%$ & $86.8 \%$ & $92.6 \%$ & $72.8 \%$ & $90.1 \%$ & $75.1 \%$ \\
\hline Black & $2.9 \%$ & $10.9 \%$ & $5.5 \%$ & $24.1 \%$ & $7.3 \%$ & $12.3 \%$ \\
\hline $\begin{array}{l}\text { American Indian/Alaska } \\
\text { Native }\end{array}$ & $0.1 \%$ & $0.2 \%$ & $0.2 \%$ & $0.3 \%$ & $0.2 \%$ & $0.9 \%$ \\
\hline Asian & $0.2 \%$ & $0.5 \%$ & $0.3 \%$ & $0.6 \%$ & $0.7 \%$ & $3.6 \%$ \\
\hline $\begin{array}{l}\text { Hawaiian/ Pacific } \\
\text { Islanders }\end{array}$ & $0.0 \%$ & $0.1 \%$ & $0.0 \%$ & $0.1 \%$ & $0.0 \%$ & $0.1 \%$ \\
\hline Other & $0.1 \%$ & $0.4 \%$ & $0.3 \%$ & $0.5 \%$ & $0.6 \%$ & $5.5 \%$ \\
\hline Mixed & $1.4 \%$ & $1.2 \%$ & $1.2 \%$ & $1.6 \%$ & $1.1 \%$ & $2.4 \%$ \\
\hline Female/Male Ratio & $50.6 / 49.4$ & $52.5 / 47.5$ & $52.2 / 47.8$ & $54.5 / 45.5$ & $51.1 / 48.9$ & $50.9 / 49.1$ \\
\hline $\begin{array}{l}\text { Median Household } \\
\text { Income }\end{array}$ & $\$ 32,130$ & $\$ 33,865$ & $\$ 31,498$ & $\$ 26,137$ & $\$ 33,672$ & $\$ 41,994$ \\
\hline Per Capita Income & $\$ 19,035$ & $\$ 19,533$ & $\$ 16,334$ & $\$ 18,417$ & $\$ 18,093$ & $\$ 21,587$ \\
\hline
\end{tabular}

2000 Population of Nearby Communities: Heath 8,527; Metropolis 6,482;
Carlisle City 1,917; Carlisle County 5,351; Kevil 574; Mayfield 10,349; $\quad$ Massac CDP 3,888

Source: Census data for 2000

\section{Historical and Current Missions}

Historically, PGDP property, which had been owned by the Kentucky Ordnance Works during World War II, was approved in 1950 for production of enriched uranium to support the nation's production of atomic weapons. Production began in 1952. Since 1991, the plant has produced only low-enriched uranium for use as fuel in commercial nuclear power plants - a mission that continues to the present time, although under a lease to USEC. The site thus has a dual mission and a dual management structure. One mission - production of enriched uranium - is the responsibility of USEC, while the second mission, environmental management, is DOE-EM's responsibility. The DOE mission is focused solely on environmental restoration and related waste management activities

\section{Site Management}

DOE maintains a small on-site office under its Environmental Management and Enrichment Facilities Program, which reports to the Oak Ridge Operations Office (ORO). Additional DOE and contractor support is provided by their respective OakRidge-based offices. Of the total 3,556 acres included in the site boundary, 748 acres are contained within the security fence where the USEC-leased process buildings, containing the uranium enrichment process equipment and support buildings are located. 
The lease between DOE and USEC spells out the respective responsibilities of each entity. Under the terms of the lease, USEC has responsibility for compliance activities directly associated with uranium enrichment operations, but DOE maintains responsibility for other site environmental restoration and waste management operations. These include the site Environmental Restoration Management Program; the Depleted Uranium Hexafluoride Cylinder Program; the majority of the Waste Management Program, including waste inventories predating July 1, 1993; wastes generated by current DOE activities; legacy wastes containing asbestos, polychlorinated biphenyls (PCBs), and transuranic constituents; and Kentucky Pollutant Discharge Elimination System compliance at outfalls not leased to USEC.

\section{DOE Cleanup and Waste Management Operations}

Current EM tasks include remediating areas of actual and potential release, as well as treatment, storage, and disposal of radioactive and mixed wastes.

PGDP operations produced a number of contaminated areas, both at the site and beyond its boundaries. The site was placed on the National Priorities List in 1994 and agreement on response actions was reached with the Environmental Protection Agency (EPA) and the Commonwealth of Kentucky in 1998. Groundwater contamination has been a primary concern. Particular contaminants of concern are Technetium-99 (Tc-99) resulting from the reprocessing of nuclear fuel; trichloroethylene (TCE), formerly used for cleaning metals and machinery parts; and PCBs used in electrical equipment, hydraulic systems, and as a fire retardant. In 1988, after detectable levels of Tc-99 and TCE were found in an off-site drinking water well north of the plant, DOE supplied water to community residents. Six additional off-site wells affected by groundwater plumes contaminated with Tc-99 and TCE have since been identified; and PCBs have been found in off-site drainage ditches, sediments, and fish. In 2000, high visibility and widespread media coverage were given to DOE's alleged lack of disclosure concerning employee work-related illnesses.

A total of 28 solid waste management units, which constitute potential sources of releases to ground and surface water, are being evaluated and remediated. They include former burial grounds for both radioactive and non-radioactive wastes, spill sites, surface impoundments, and underground storage tanks. Priority is being given to imminent threats and hot spots associated with off- site contamination. Other site activities are addressing treatment, storage, and disposal of large quantities of waste generated by past operations, current environmental restoration projects, and future decommissioning of plant facilities. Some waste has been shipped off-site for disposal; a recent example is the shipment of crushed drums of depleted uranium tetrafluoride, one of the most visible signs of waste that was locally referred to as "drum mountain." Planned future off-site shipments include trans uranic waste that is being temporarily stored on site pending shipment to the Waste Isolation Pilot Plant in New Mexico. Wastes planned for on-site disposal include general sanitary waste, construction debris, and soil with residual radioactivity. 


\section{Structure and Staffing of the EM Public Participation Program}

Paducah's public involvement activities are directed by the deputy manager for public affairs in Oak Ridge. The Citizens' Advisory Board (CAB) is managed by one DOE staff person.

\section{EM Public Outreach and Participation Goals and Activities}

\section{Public Participation Goals}

The web site for the Oak Ridge Operations Office states that the goal of public participation is to "educate citizens and seek their meaningful involvement, consistent with our department's public participation policy."

\section{Information Distribution}

Web access to public information is primarily focused on activities of the Paducah Citizens Advisory Board (CAB) and other electronically available information is very limited. However a variety of written information is available at the Environmental Information Center. The $\mathrm{CAB}$ web site, which is accessed through the Oak Ridge Operations site (www.oakridge.doe.gov) includes general information about the CAB its structure, committees and membership - as well as a calendar; the board's bylaws and operating procedures; detailed, informative current meeting minutes and scheduled meetings; and board recommendations. Also included, on a News and Community Outreach link, are copies of the CAB's newsletters (initiated by the board in 2001). The M\&I Contractor's website also includes information about Paducah; however, the site was under review at the time of the study, and very little information was available.

The Environmental Information Center offers several types of written information. The Center, which has recently been relocated to a more convenient location across from the Paducah Community College, serves as the location for board activities and meetings, as well as for information. In addition to housing formal CERCLA and NEPA documents, the Center provides a variety of information materials: a number of brief, two-page fact sheets on key technical activities at the site; hard copies of the CAB newsletter; and a quarterly publication entitled Paducah Update which includes an overview of current technical projects, a list of documents that are available for public review, and a calendar of upcoming meetings. Also available are copies of a clearly written and illustrated summary version of the Paducah Site Environmental Report for 2000. A full-time assistant is available to help with information searches and several computers are available for public use. The site maintains a mailing list of approximately 1,500 persons who receive $\mathrm{CAB}$ newsletters, the site newsletter, and other general information. $\mathrm{CAB}$ members and members of the public who attend the CAB meetings also receive handouts of an updated monthly calendar of activities. The 1998 Community Relations plan is not available in the Center. 


\section{Non-SSAB Public Participation Activities}

The listing of public participation activities for FY 2000 indicates that most are focused on the CAB. One CERCLA-related public meeting concerning a groundwater feasibility study is reported. Also reported are several presentations by the DOE site manager to local community groups (Rotary, Chamber of Commerce, and users of the Western Kentucky Wildlife Area). Several activities appeared to be related to the media publicity concerning worker health (a meeting with the former Secretary of Energy, Bill Richardson, a new citizens' group called Active Community for Truth, and a Harvard/MIT training on dealing with an angry public, to which a "wide range of stakeholders" were invited). In 2001, CERCLA public involvement activities included three meetings. In addition, meetings were held to fulfill NEPA requirements for two projects.

\section{The Paducah Citizens' Advisory Board}

The board, which meets one evening per month, has been in operation since October 1996, following an eighteen-month formation process. It is composed of up to 18 members of the public, recommended by the CAB's Nominations and Membership Committee for appointment by the Assistant Secretary of Environmental Management. Stakeholders are selected from 11 specified categories to reflect diversity and balance in terms of gender, age, race/ethnicity, type of employment, area of residence, expertise, income, and education. Terms of office are two years, with a maximum tenure of ten years. The board is authorized to advise DOE and includes ex-officio representatives of the U.S. Environmental Protection Agency (EPA), the Kentucky Division of Waste Management, Kentucky Department of Fish and Wildlife Resources, and the Kentucky Radiation Control Branch. Board meetings are facilitated by a professional facilitator. The DOE Site Manager plays a very active role in Board activities and attends all board meetings. DOE formally responds to Board recommendations by letter.

At the time of the study, there was one standing board committee that meets as needed: Nominations/Membership and Public Involvement. In addition, the board uses three task forces to focus on specific projects: Water (Surface and Ground), Waste Operations, and Long-Range Strategy and Stewardship. This structure, refined from the original framework, was developed in 2000 to meet the changing needs of the CAB.

Particular achievements of the board are related to the linkage it provides to the broader community. A recent study of the board noted members' emphasis on their sense of responsibility in speaking for the community's welfare. Increased interest and level of public involvement by non- $\mathrm{CAB}$ members over the past several years is illustrated by: (1) increased participation by members of the public in CAB meetings; (2) the CAB's new emphasis on publicizing its activities through $C A B$ newsletters; and (3) the CAB's prompting DOE to conduct an area teleconference on a key issue of concern. The board is also taking a more issue-based approach to its mission by clearly utilizing the task forces. Its discussion and recommendations have prompted some change in direction by DOE. The technical debate is useful for DOE and for the public to better understand the complexities of environmental management. 


\section{Key Public Participation Challenges and Status in Relation to the Acceptability Diamond}

\section{Challenges}

Based on site visits and interviews conducted in spring 2002, the PNNL research team identified several challenges faced by the Paducah Site in establishing its public participation program and by the site and its stakeholders in addressing the four dimensions of the Acceptability Diamond (substantive issues, decision making, relationships, and accountability).

- Though now producing for the commercial market rather than for the weapons program, production continues at the Paducah site. DOE is the property and plant owner, with responsibility for environmental restoration and waste management on the site. The U.S. Enrichment Corporation (USEC), a private company, leases the plant from DOE and produces enriched uranium for commercial nuclear power use. The complicated relationship between the USEC and DOE-EM raises questions for public involvement participants about the boundaries between remediation and facility maintenance and upgrading.

- The plant has been historically, and is currently, a major employer for area residents. The potential for a "next generation" facility - or for the closure of the plant - has created an additional dynamic between DOE and the community, and generated tensions between those concerned about site waste management and cleanup issues and those concerned about the community's business environment.

- Production activities have resulted in measurable off- site contamination. Widespread media coverage in 2000 concerning undisclosed issues of contamination and exposure raised community concerns, both about contamination and worker safety, and about access to accurate information about the site.

- Few area residents had historically been involved in site-related environmental issues; indeed, many respondents indicated widespread lack of awareness of environmental and hazardous waste issues within the community before the 2000 media reports called attention to these issues.

- The site manager does not report directly to DOE-EM Headquarters. DOE maintains a small on-site office under its Environmental Management and Enrichment Facilities Program, which reports to the Oak Ridge Operations Office. Additional DOE and contractor support is provided by their respective Oak Ridge-based offices. Following the Top-to-Bottom Review in 2002, this reporting hierarchy was modified, making the site manager's link to EM Headquarters even less direct. 


\section{Status in Relation to the Acceptability Diamond}

The following summarizes the research team's assessment of the site's status in relation to the Acceptability Diamond at the time of the study (substantive issues, decision making, relationships, and accountability):

- From essentially a no-involvement process, the site has succeeded in establishing an advisory board that has recruited and maintained a diverse membership. After a rocky start, board members have made considerable progress in becoming familiar with site remediation and waste management issues and informed about the institutional and regulatory context in which the issues are discussed and addressed. Board interactions have become more focused, and a forum that promotes dialogue and exchange among me mbers and with DOE has been created. Task forces have been established to enable members to focus on a subset of issues and hence become more knowledgeable and engaged. Exchanges on the board generally reflect mutual recognition and respect.

- Substantive issues: Although the site manager and public participation support staff received high marks for their personal efforts in working with the advisory board, many of those interviewed questioned DOE's commitment to disclosure and openness, and its willingness to provide the $\mathrm{CAB}$ with information that would enable members to identify issues and get them addressed constructively. This was raised starkly by the restrictions on communication - with either the board or the regulators - imposed on the site manager by EM-HQ following the Top-toBottom Review and shortly after the Performance Management Plan process was initiated. Respondents did believe that the $\mathrm{CAB}$ has provided a forum where issues are being raised and framed, and that it has had a positive effect on getting cleanup issues (such as about the -746-U landfill) on DOE's agenda. However, some reported that "the community really has to fight to get issues on the agenda." Some believe that the CAB had succeeded in raising the level of information and awareness in the community about site-related waste management and cleanup issues, and that the task teams had enabled the board to move beyond formal presentations to more in-depth discussions and analysis. One respondent commented that he thought the $\mathrm{CAB}$ would be more effective if it were able to ask questions that DOE and its contractors (or someone else) would be responsible for answering to the satisfaction of board members. Several study respondents indicated that the $\mathrm{CAB}$ provided the primary mechanis $\mathrm{m}$ through which community issues could be raised.

- Decision making: Most respondents questioned the extent to which the public was able to influence DOE's decisions, though most indicated that their efforts had had some effect. One person expressed the view that the board was "used as a safety valve where activists have a place to talk so they won't do anything worse." Most respondents expressed concern about the recent consolidation of power in EM-HQ - which they saw as detrimental to their understanding and access to decision making - and frustration about what they experienced as a reluctance by DOE to take advantage of their knowledge and advice. As a consequence, a number of respondents were questioning whether they would be 
more effective outside DOE-EM's public participation process - essentially accessing legal mechanisms, for example Freedom of Information Act requests and lawsuits, to obtain information, raise their issues, and exert their influence.

- Relationships: Most respondents indicated that the relationship between DOE and the community, and between DOE and the board, had become better since the arrival of a new DOE Paducah Site Manager in the Spring of 2000, in part because they believed "he always tells us what he can." However, they also said that the community had a very limited relationship with DOE, partly because of the DOE/UESC arrangement (where UESC was the primary employer), and partly because most residents thought about the site primarily in terms of "money and jobs." "Most residents," one respondent commented, "don't know who is who." A new member of the board, for example, commented "I can't really say much about relationships because I didn't pay attention until after I joined the CAB." Another observed that "As a whole, the community wants little to do with DOE, except for the payroll. DOE is viewed as a job machine." Despite this, the efforts of the site manager and public participation manager to develop relationships that convey respect for the efforts and viewpoints of the participants and to ensure that the participation program provides a forum that is conducive to civil exchange have been recognized and appreciated by the participants.

- Accountability: Based on their recent experience of being deceived and denied access to information, many of those interviewed expressed the opinion that DOE was not effectively being held accountable for either its behavior or for being open and honest with its stakeholders or regulators. In part, this was attributed to lack of attentiveness by members of the community and lack of strength by the regulators. One respondent reported that "Not enough people [in the community] care to have any impact on accountability. The Board does not make enough of a difference to affect it either, although it does provide a way to keep DOE's feet to the fire." Another reflected that "The only way to establish accountability is to expend a huge amount of effort, have access to inside information... and keep pushing, and pushing, and pushing - leveraging the regulators and being prepared to sue." "Or," added another, "get high visibility in the media." Nevertheless, most respondents expressed a sense of responsibility to the community to continue working through the $\mathrm{CAB}$ in an effort to raise community health and safety issues and influence site decisions. 


\subsection{SaVAnNah River Site}

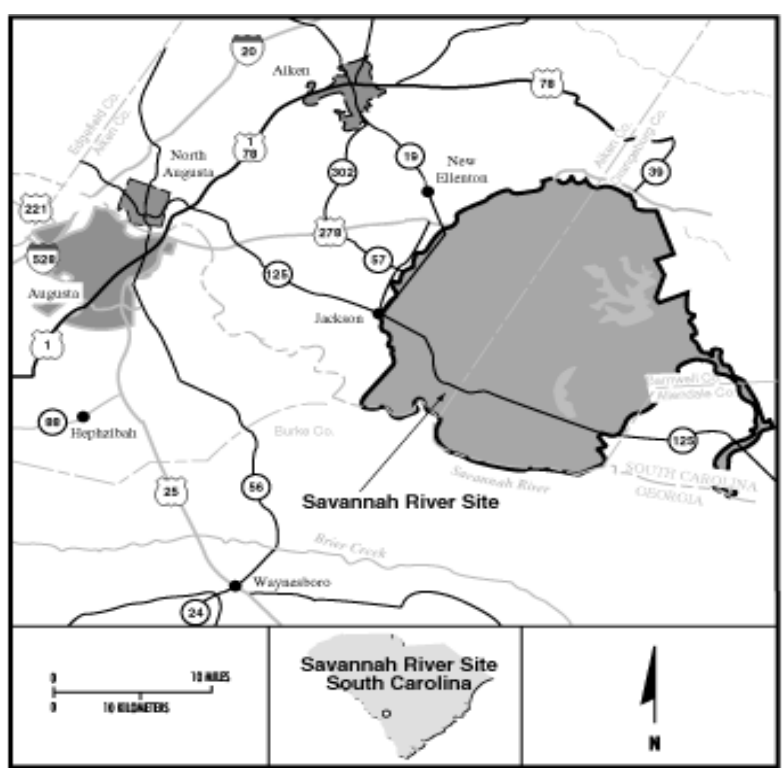

Location, Population, Land Use

The Savannah River Site (SRS) covers an area of approximately 198,000 acres in a rural area of western South Carolina bordering the Savannah River. It includes portions of Aiken, Barnwell and Allendale Counties. The site is approximately 15 miles south of Aiken, South Carolina, and 25 miles southeast of Augusta, Georgia. The area of influence extends to six counties: four in South Carolina (Aiken, Allendale, Bamberg, and Barnwell) and two in Georgia (Columbia and Richmond).

Table 3.8.1 presents data on the

demographic characteristics of the counties and communities near the site. The majority of the workforce resides in the two counties nearest SRS, Aiken (South Carolina), and Richmond (Georgia). The site is one of the largest employers in South Carolina; total workforce in 2000 was approximately 450 DOE, 80 Forest Service, and 12,500 contractor staff.

Land use bordering the site is primarily forest and agriculture; various small industrial, manufacturing, medical, and farming operations are located in areas surrounding the site. Several federal and state recreation facilities are also located nearby.

\section{Historical and Current Missions}

SRS has played, and continues to play, an important role in national defense. The site was originally established in 1950 to produce the basic materials used in the fabrication of nuclear weapons, primarily tritium and plutonium-239. Five reactors were built on the site, which produced nuclear materials by irradiating target materials with neutrons. These irradiated materials were then moved to two chemical separation facilities (known as "canyons") where they were chemically processed to separate useful products from waste. The site's mission was later expanded to include the production of other special radioactive isotopes to support research in nuclear medicine, space exploration, and commercial applications. Currently, in addition to environmental restoration and waste management, SRS continues to operate in support of current and future national security requirements, nuclear materials and nonproliferation activities, and mission-supportive research and technology development. 
Table 3.8.1. Demographic Characteristics of Nearby Counties and Communities

\begin{tabular}{|l|r|r|r|r|r|r|r|}
\hline & $\begin{array}{r}\text { Aiken } \\
\text { County SC }\end{array}$ & $\begin{array}{r}\text { Allendale } \\
\text { County SC }\end{array}$ & $\begin{array}{c}\text { Bamberg } \\
\text { County SC }\end{array}$ & $\begin{array}{r}\text { Barnwell } \\
\text { County SC }\end{array}$ & $\begin{array}{c}\text { Columbia } \\
\text { County } \\
\text { GA }\end{array}$ & $\begin{array}{c}\text { Augusta } \\
\text { Richmond } \\
\text { County } \\
\text { GA }\end{array}$ & US \\
\hline $\begin{array}{l}\text { Total Population } \\
2000\end{array}$ & 142,552 & 11,211 & 16,658 & 23,478 & 89,288 & 199,775 & $281,421,906$ \\
\hline $\begin{array}{l}\% \text { Population } \\
\text { Change, 1990-2000 }\end{array}$ & $17.9 \%$ & $-4.4 \%$ & $-1.4 \%$ & $15.7 \%$ & $35.2 \%$ & $5.3 \%$ & $13.1 \%$ \\
\hline White & $71.4 \%$ & $27.4 \%$ & $36.5 \%$ & $55.2 \%$ & $82.7 \%$ & $45.6 \%$ & $75.1 \%$ \\
\hline Black & $25.6 \%$ & $71.0 \%$ & $62.5 \%$ & $42.6 \%$ & $11.2 \%$ & $49.8 \%$ & $12.3 \%$ \\
\hline $\begin{array}{l}\text { American } \\
\text { Indian/Alaska } \\
\text { Native }\end{array}$ & $0.4 \%$ & $0.1 \%$ & $0.2 \%$ & $0.3 \%$ & $0.3 \%$ & $0.3 \%$ & $0.9 \%$ \\
\hline Asian & $0.6 \%$ & $0.1 \%$ & $0.2 \%$ & $0.4 \%$ & $3.4 \%$ & $1.5 \%$ & $3.6 \%$ \\
\hline $\begin{array}{l}\text { Hawaiian/ Pacific } \\
\text { Islander }\end{array}$ & $0.0 \%$ & $0.1 \%$ & $0.0 \%$ & $0.0 \%$ & $0.1 \%$ & $0.1 \%$ & $0.1 \%$ \\
\hline Other & $0.8 \%$ & $0.8 \%$ & $0.1 \%$ & $0.8 \%$ & $0.8 \%$ & $1.0 \%$ & $5.5 \%$ \\
\hline Mixed & $1.2 \%$ & $0.5 \%$ & $0.5 \%$ & $0.7 \%$ & $1.6 \%$ & $1.8 \%$ & $2.4 \%$ \\
\hline Female/Male Ratio & $51.8 / 48.2$ & $47.9 / 52.1$ & $53 / 47$ & $51.9 / 48.1$ & $51.1 \%$ & $51.8 / 48.2$ & $50.9 / 49.1$ \\
\hline $\begin{array}{l}\text { Median Household } \\
\text { Income (1999) }\end{array}$ & $\$ 37,889$ & $\$ 20,942$ & $\$ 24,007$ & $\$ 28,591$ & $\$ 55,682$ & $\$ 33,086$ & $\$ 41,994$ \\
\hline Per Capita Income & $\$ 18,772$ & $\$ 11,293$ & $\$ 12,584$ & $\$ 15,870$ & $\$ 23,496$ & $\$ 17,088$ & $\$ 21,587$ \\
\hline
\end{tabular}

\begin{tabular}{|c|c|c|c|c|c|c|c|}
\hline & $\begin{array}{l}\text { Aiken City } \\
\text { SC }\end{array}$ & $\begin{array}{c}\text { Bamberg } \\
\text { Town } \\
\text { SC } \\
\end{array}$ & $\begin{array}{c}\text { Barnwell } \\
\text { City } \\
\text { SC }\end{array}$ & $\begin{array}{c}\text { New } \\
\text { Ellenton } \\
\text { City SC }\end{array}$ & $\begin{array}{c}\text { Jackson } \\
\text { Town } \\
\text { SC }\end{array}$ & Georgia & $\begin{array}{c}\text { South } \\
\text { Carolina }\end{array}$ \\
\hline $\begin{array}{l}\text { Total Population } \\
2000\end{array}$ & 25,337 & 3,733 & 5,035 & 2,250 & 1,625 & $8,186,453$ & $4,012,012$ \\
\hline $\begin{array}{l}\text { \% Population } \\
\text { Change, } 1990-2000\end{array}$ & $27.5 \%$ & & $-4.2 \%$ & $-10.5 \%$ & $-3.3 \%$ & $26.4 \%$ & $15.1 \%$ \\
\hline White & $66.6 \%$ & $45.2 \%$ & $49.8 \%$ & $60.6 \%$ & $88.6 \%$ & $66.1 \%$ & $67.2 \%$ \\
\hline Black & $30.3 \%$ & $53.6 \%$ & $47.4 \%$ & $35.8 \%$ & $9.0 \%$ & $28.7 \%$ & $29.5 \%$ \\
\hline $\begin{array}{l}\text { American } \\
\text { Indian/Alaska } \\
\text { Native }\end{array}$ & $0.3 \%$ & $0.2 \%$ & $0.4 \%$ & $0.6 \%$ & $1.1 \%$ & $0.3 \%$ & $0.3 \%$ \\
\hline Asian & $1.3 \%$ & $0.3 \%$ & $1.1 \%$ & $0.4 \%$ & $0.3 \%$ & $2.1 \%$ & $0.9 \%$ \\
\hline $\begin{array}{l}\text { Hawaiian/ Pacific } \\
\text { Islanders }\end{array}$ & $0.0 \%$ & $0.0 \%$ & $0.0 \%$ & $0.0 \%$ & $0.1 \%$ & $0.1 \%$ & $0.0 \%$ \\
\hline Other & $0.4 \%$ & $0.1 \%$ & $0.3 \%$ & $0.9 \%$ & $0.2 \%$ & $2.4 \%$ & $1.0 \%$ \\
\hline Mixed & $1.1 \%$ & $0.6 \%$ & $1.0 \%$ & $1.7 \%$ & $0.7 \%$ & $5.3 \%$ & $1.0 \%$ \\
\hline Female/Male Ratio & $53.4 / 46.6$ & $54.8 / 45.2$ & $53.5 / 46.5$ & $52.1 / 47.9$ & $51.4 / 48.6$ & $50.8 / 49.2$ & $51.4 / 48.6$ \\
\hline $\begin{array}{l}\text { Median Household } \\
\text { Income (1999) }\end{array}$ & $\$ 44,172$ & $\$ 21,736$ & $\$ 26,722$ & $\$ 38,125$ & $\$ 35,924$ & $\$ 42,433$ & $\$ 37,082$ \\
\hline Per Capita Income & $\$ 23,172$ & $\$ 13,512$ & $\$ 17,709$ & $\$ 17,915$ & $\$ 17,357$ & $\$ 21,154$ & $\$ 18,795$ \\
\hline
\end{tabular}

Source: Census data for 2000 


\section{Site Management Structure}

Organizationally, management of the site is divided between the Savannah River Operations Office and the Savannah River National Nuclear Security Administration (NNSA) Area Office. The primary mission of SRS is to support EM, which manages approximately 80 percent of the SRS budget. EM components include Environmental Restoration, Materials and Facility Stabilization, Waste Management, natural resources and ecosystem management, and Science and Technology research and development. The NNSA Area Office, which was established in March 2000, includes Defense Program Operations and Defense Nuclear Nonproliferation. The NNSA now oversees tritium operations at the site, as well as nuclear materials safeguards and security, and disposition of excess nuclear weapons materials. Westinghouse Savannah River Company (WSRC) is the integrating management contractor.

\section{Cleanup and Waste Management Activities}

The site began its cleanup operations in 1981. It was placed on the National Priorities List in 1989 and the Environmental Restoration Program was developed in 1991. Because of the variety of nuclear materials and the amount of legacy wastes, cleanup is expected to last for more than 35 years. Contamination of groundwater and the Savannah River have been cited as key concerns for local residents. More than 500 inactive waste and contaminated groundwater sites have been identified, including basins, pits, piles, burial grounds, landfills, and tanks. Major tasks are cleanup and disposition of contaminated facilities, which include one of the two chemical separation plants and 49 high-level waste storage tanks. In addition, many types of waste require continuous management. These include approximately 37 million gallons of high-level liquid radioactive waste stored in tank farms, as well as other liquid and solid wastes from previous and current cleanup operations (transuranic, low-level radioactive, mixed, and hazardous wastes). In 1996, the Defense Waste Processing Facility began using a vitrification process to bond high- level radioactive wastes into boroscilicate glass, a more stable storage and disposition form.

\section{Structure and Staffing of the EM Public Participation Program}

Responsibility for public participation at the Savannah River Site is divided between NNSA and the Savannah River Operations Office. The Environment, Science, and Technology Department, which has responsibility for CERCLA and RCRA activities, has an SRS Community Relations Plan. In addition, the Waste Operations Division, and the Environmental Restoration Divisions (two of four divisions under the Department) have their own Public Participation and Communication Plans. The Public Accountability Specialist (who reports directly to the Assistant Manager for Environment, Science, and Technology) coordinates the respective public involvement activities of these divisions. A calendar of site-wide activities is separately maintained to ensure that meetings are not scheduled at the same time. Approximately 1.5 FTE DOE staff and 10 contractor staff are assigned to the EM public participation program. These numbers include one DOE 
and two contractor staff who have primary responsibility for activities related to Environmental Justice issues.

\section{EM Public Outreach and Participation Goals and Activities}

\section{Public Participation Goals}

The goals of public participation, as stated in the Savannah River Site Community Relations Plan, 1999, are to:

- Provide the public and affected communities with understandable, accurate and timely information about on-going or planned programs at the SRS;

- Provide the public with opportunities to engage in a meaningful role in the decision-making process for activities at SRS that could affect public health and safety, its workers, or the environment;

- Establish and maintain two-way communication with the public by considering, addressing and/or responding to stakeholder recommendations, comments, and/or concerns regarding SRS projects and activities.

\section{Information Distribution}

Several newsletters and reports are available to the public. The Environmental Bulletin, published monthly, is mailed to over 3500 individuals; and the Citizens' Advisory Board (CAB) publishes its own newsletter, Board Beat, twice per year. Other publications include the State of the Savannah River, Site Environmental Monitoring Report, the FFA Annual Progress Report, the CAB's Annual Report, and many fact sheets covering a wide variety of restoration and waste management issues. These information products are available at the three information repositories established under CERCLA that are located in Augusta, Savannah and Columbia, and also at the DOE reading room in Aiken. At the time of the study, only the CAB's Board Beat was available on the web. The SRS web site (www.srs.gov) has undergone security reviews following the nation's September 2001 terrorist attacks. Information about the site and a link to the CAB's web site is publicly available. The CAB's web site, in addition to the most recent version of the Board Beat, includes general information about the $\mathrm{CAB}$, an updated calendar of all $\mathrm{CAB}$ meetings, and minutes of those meetings. The bylaws, a list of all $\mathrm{CAB}$ recommendations, and general information about the CAB's organizational structure, current board members, and contact information are also available.

\section{Non-SSAB Public Participation Activities}

Activities other than those associated with the $\mathrm{CAB}$, include those that are legally required under CERCLA, RCRA, and NEPA and also a variety of outreach and educational activities in the community. For example, in the SRS Information Exchanges, DOE and the regulatory agencies - the South Carolina Department of Health and Environmental Control (SCDHEC) and the Environmental Protection Agency (EPA) - hold periodic meetings in nearby areas to communicate the goals and accomplishments 
of the cleanup program and to identify community issues and concerns. DOE has also conducted risk assessment training for the public and placed increased emphasis on risk communication information, in particular on communicating the purpose and results of the SRS environmental monitoring program. Addressing environmental justice issues is also an important priority for the EM program and the responsible DOE-EM staff person works closely with the Public Accountability Specialist within the Environment, Science, and Technology Department. The program also provides a variety of presentations and workshops with local schools and teachers: Traveling Science Demonstration Programs, Engineers' Week Teach-Ins, an SRS Tech Day, College Night, a School-to-Work Program, Science Education for Public Understanding (teachers' program), and High School Awareness workshops. In addition, through a cooperative agreement with the University of South Carolina-Aiken campus, access is provided for approximately 15,000 pre-college students, teachers, and parents to conduct hands-on activities at SRS. Almost 50 percent of the participants are members of minority groups. The U.S. Forest Service and the University of Georgia's Ecology Lab also offer extensive educational outreach programs.

\section{The SRS Citizens' Advisory Board}

The CAB plays a key role in the site's public participation approach, both directly in terms of its meetings and committee meetings, and also more indirectly through the linkage it provides to the broader public. The board, originally established in 1994, is composed of 25 members from the six counties in South Carolina and Georgia affected by SRS operations. Members are selected by a very open approach to represent the demographic diversity of the surrounding counties and participation by all income levels is sought. Terms of office are two years with a limit of three consecutive terms. The board now meets bi-monthly in different counties affected by SRS operations. The first day of the two-day meeting allows the committees to meet to share topics of discussions and prepare individual recommendations for presentation to the following day's full board meeting. Board decisions are made by majority vote and are facilitated by a professional facilitator. The committees are Executive, Administrative, Waste Management, Nuclear Materials Management, Environmental Restoration, Strategic Initiatives, and the recently established Long Term Issues. The EM Manager plays an active role in Board activities and occasionally attends board meetings. The Site Manager has also attended many meetings and shows his interest in the CAB by personally taking a role in timely responses to Board recommendations. Board recommendations are carefully tracked and DOE -EM responds within a 10-day time period.

The $\mathrm{CAB}$ has played an important role in reaching out to the community through its active Speakers' Bureau and by including community members in its committee work. In previous years, for example, "Focus Groups," established by the CAB, were designed to include members of the community who were not $\mathrm{CAB}$ members. These focus groups study specific issues of concern and channel recommendations to DOE and the regulators through the $\mathrm{CAB}$. The $\mathrm{CAB}$ also contributes to establishing remedial options through the input it provides in committee meetings with DOE and the regulators. DOE subsequently presents these proposed remedial action plans to the general public. 


\section{Key Public Participation Challenges and Status in Relation to the Acceptability Diamond}

Based on site visits and interviews conducted between January and June 2002, the PNNL research team identified several challenges faced by the Savannah River Site in establishing its public participation program and addressing the four dimensions of the Acceptability Diamond (substantive issues, decision-making process, relationships, and accountability).

\section{Challenges}

- The site is a continuing production and storage site of national importance and a critical link in DOE's overall mission. This has required balancing security concerns with the EM policy emphasis on openness, as well as addressing issues related to the scope and purpose of EM's public participation activities.

- Prior to the 1990s, discussion of site issues was constrained by secrecy and public participation was very limited. DOE-EM continues to be the primary sponsor for public participation, and environmental activism and/or opposition to the DOE presence does not appear to have gained widespread local support. Both critics and supporters of the site frequently emphasized the site's important role in the area economy, and the strong support and unwillingness to question site operations on the part of nearby residents. Although the release of tritium in the early 1990s raised awareness of the site, particularly downriver, many of those who were interviewed reported that the general population was neither aware of nor involved in site issues.

- The large impact area and demographic characteristics of the surrounding communities continue to pose a challenge. The population is dispersed over six counties and two states and includes a higher percentage of African Americans than at other sites. Many African Americans have historically been unrepresented and not involved in site issues.

- The complexity of the cleanup task poses a major challenge to the general public. Multiple individual decisions are required that stretch out over many years and administrations. People living closer to the site (for example in the city of Aiken) tend to be more familiar with the site, and retired site workers play an important role in helping to define and discuss the issues. Those not previously associated with the site, however, frequently characterized the task of understanding the technical and regulatory complexity as daunting.

\section{Status in Relation to the Acceptability Diamond}

The following summarizes the research team's assessment of the site's status in relation to the Acceptability Diamond at the time of the study:

- EM managers and staff have recognized and worked to overcome the challenges to public participation at their site. The importance of the Savannah River Site to 
the local area economy and the absence of organized opposition (as, for example at Fernald) have facilitated the staff's efforts to address the challenges.

- Substantive issues: Although EM's openness in providing information and its responsiveness in answering questions raised by the public were almost universally commended, some interviewees were critical that issues important to the community were excluded from EM's scope (especially health issues and defense issues). Identifying and prioritizing issues and getting them on the agenda were raised as a continuing challenge both by site critics and by those not previously familiar with the site. Those not previously familiar with site issues were more likely than persons at other sites to emphasize the difficulty of understanding and addressing issues, describing it as "daunting" or "overwhelming." They noted the important role of the Advisory Board, and particularly the board committees and the focus groups, in facilitating the process of identifying, prioritizing, and addressing substantive issues. They reported that the smaller scale and intensive committee discussions, together with support from DOE-EM and contractor staff, provided an opportunity to increase their understanding.

The focus groups, which include a large proportion of site retirees, were praised for playing an active role in getting issues on the agenda, as well as serving as a critical peer group and source of information. Site critics took exception to the separation of NEPA and advisory board responsibilities and viewed the board as being captive to DOE, addressing the issues as defined by DOE, as well as being dependent on DOE and its contractors for information and analysis. Nevertheless, site critics and supporters alike viewed the $\mathrm{CAB}$ as a primary means of obtaining information and getting issues on the agenda. As one critic commented:

It is only through long-term activities that we can keep a handle on being informed. Without this, there is not enough time built into the NEPA process for the public to find out what is happening and have enough time left for making meaningful comments. Ninety percent of what the CAB does is irrelevant. But the important thing is that the $\mathrm{CAB}$ meetings provide a way for us to bring up critical issues to someone's attention.

- Decision making: Almost all interviewees agreed that the public has the opportunity to provide input to site decisions, although some expressed uncertainty about the influence of their input. Most advisory board respondents believe that they have played a role in decision making. At a minimum they believe that the board ensures that EM explains the basis for its decisions and that it has been effective in making sure "all the pieces are in place to make the right decisions." Board members frequently cited as an example of their influence the board's recommendation to work with the State on the potential shutdown of the Consolidated Incineration Facility (CIF). Some pointed to the value of the CAB's early involvement and of being able to press EM to answer the underlying issues and not just respond to literal questions, as in the formal comment-response process. 
Relationships: With few exceptions, study respondents reported that community and personal relationships were good - there was some skepticism about relationships with downriver communities and concern that the $\mathrm{CAB}$ retain its independence ("there is a narrow line to be sure we are not a rubber stamp"). Some attributed good relationships to the longstanding contribution of the site to the area economy. Others attributed good relationships to the efforts of the EM staff in being open and responsive to all stakeholders. Still others attributed it to the relationships developed through $\mathrm{CAB}$ interactions. One respondent, who was otherwise critical of DOE, praised the site staff for being "responsive to anyone who is interested" and cited several examples of their responsiveness. A number of interviewees expressed satisfaction with the level of management attention by both EM and the contractor and commented on the value of the CAB in developing contacts that can be called on to get information and enabling the public to "have a direct line to the top."

The site has also worked to expand its relationships to include the AfricanAmerican community, demonstrating support for minority members and organizations, although some questioned the effectiveness of these efforts. In addition, from its inception, the site established and has adhered to strict $\mathrm{CAB}$ membership rules to ensure diversity of race and background.

Accountability: Views of accountability were mixed. In general, as compared with others sites, accountability was not a priority issue for most stakeholders who talked with the PNNL study team. One person emphasized that DOE's accountability was not to a specific community but to the voter and through the fundamental government framework. Others held varying views. Some, who thought that DOE was not accountable, pointed to the lack of cost accountability (the number of projects that had been started but not completed was an issue here) or failure to talk about high-risk issues. Others were unsure whether DOE was, or could be, made accountable. Most, however, believed that public participation played a role in accountability. To quote one repondent, "Without a public, institutional forum, DOE would not be accountable - it keeps them from being isolated in their own world without seeing the implications of their actions." One respondent pointed to the value of the focus groups, which are "made up of hardheaded retirees." A number noted that the board contributed to accountability in several ways - through informal pressure, through the formal tracking of recommendations and responses, and through their influence on the regulators. 
APPENDICES 


\section{APPENDIX A: THEORY PAPER}

\section{Theoretical Basis for the Acceptability Diamond Framework ${ }^{29}$}

This appendix begins with a description of the Acceptability Diamond, a framework constructed in an applied study, then discusses the framework's consonance with sociological theories related to relationships between public and private actors. The agreement of theory with the Acceptability Diamond indicates that the empirically derived framework can be effective in evaluating and designing DOE-EM's public participation programs. That is, EM may use the Acceptability Diamond to manage public participation programs on an ongoing and long-term basis.

The scope of public participation programs may include citizen advisory boards of all types, individual decision- making processes and products (such as those required by NEPA and CERCLA), and traditional public and community relations activities that attempt dialogues with stakeholders (as opposed to simply disseminating information). Public participation programs include specific decision-making processes; however, they also include ongoing interactions with community groups about broader aspects of the management of government programs, such as long-term strategies for production and storage of nuclear materials and wastes, and land use.

This paper first discusses the public participation literature and the need for theory building. Next, the Acceptability Diamond framework is described. Then the paper discusses scholarly theories that apply to the framework and broaden its usefulness to managers of DOE public participation programs. Finally, the Acceptability Diamond and its theoretical underpinnings are considered together as applied to DOE-EM programs.

\section{Public Participation Literature: Many Case Studies, Little Theory}

The public participation literature encompasses a wide range of case studies, but very little theory; that is, the findings of each individual case study cannot be extended to generalize about other cases. The case stud ies have tended to focus on specific decisions as outcomes and to develop frameworks that are not easily applied to other cases. Furthermore, individual case study results cannot be extended to the design and evaluation of public participation programs overall. By limiting their focus to decisions, many research studies have also limited the value of the advice provided to agencies in evaluating their overall programs.

The focus on decision making makes sense considering the background of public participation programs. Public objections to agency actions that affect the environment have usually arisen in response to either revelations that dangerous conditions exist at specific sites or incidents that send out danger signals to the community. Decisions about what to do in such circumstances quickly become the focus of public interest.

\footnotetext{
${ }^{29}$ This discussion draws heavily on preliminary work, discussions with, and review comments provided by Dr. Thomas Webler, Core Faculty, Department of Environmental Studies, Antioch New England Graduate School, Keene, NH.
} 
Consequently, the public has applied pressure to be informed about and involved in such decisions in a meaningful way. Furthermore, U.S. regulations articulate specific requirements for public participation in some decision-making processes. The decision process has been studied intensively and extensively (see Renn and Webler 1995 for a review). Analysts have studied, for example the extent of and access to participation the modes of information exchange and public input and how the asymmetries of power were addressed. These studies examine two basic questions:

- What happened in this case and why?

- What can we learn from this case so we can do it better next time?

Because the literature consists largely of case studies, it does not advance very far to a theory of effective public participation. Usually, the researchers develop categories relevant to decision making, but stop short of theorizing. Exceptions include Webler et al. (2001), Webler and Tuler (2000), Daniels and Walker (2001), and Guglielmo (1998).

Consistent with the focus on individual cases, the decision outcomes that have included public participation have been treated in isolation from each other and from the context of the ongoing situation within which decisions are made. This shortcoming in the literature results in a lack of assistance to agency official and staff who manage public participation programs on an ongoing basis.

Thus, a theoretical framework is needed to

1. Help generalize the findings of disparate case studies

2. Evaluate public participation programs.

The framework must take into account both micro (individual and person-to-person) and macro (institutional and organizational) aspects of pub lic participation. Furthermore, theory must facilitate the study of an agency's dilemma in simultaneously trying to fulfill its mission and to "take on board" community input that is seemingly unrelated to its mission.

Theories of behavioral change are applicable to public participation programs, but such theories tend to focus on the micro level and to assume an instrumental motivation - that is, that the agency or business simply wants its stakeholders to change their behavior from skeptical and obstructionist to supportive. Although this was probably a good description of public relations, public information, and public participation programs a decade or more ago, many agencies have been seeking to engage their stakeholders as partners in management of their sites. DOE-EM has been in the forefront of this new type of engagement.

Theories that explicitly address the intersection of micro and macro aspects are potentially most fruitful to study public participation programs, and to explore the mutual benefits of such programs (as opposed to the purely instrumental purposes). The theories of Jürgen Habermas about the public sphere and communicative action have been used in the analysis of public participation programs (Webler, et al. 2001) because these theories 
emphasize both non-instrumental action and the macro- micro interactions that constitute effective public participation programs. Thus, communicative action and the public sphere are well suited to third-party evaluations of DOE-EM's public participation programs. In this study, these theories have been extended and related to the Acceptability Diamond.

\section{The Acceptability Diamond}

The Acceptability Diamond framework was developed in the course of studying community viewpoints on the Army's plans to destroy chemical weapons stockpiles (Bradbury, et al. 1994) through interviews and focus groups with involved citizens, employees, and Departmental officials. Fundamentally, those involved in the study identified potential conflicts between the Army's focus on its mission and the well-being of the nearby communities. Like other agencies, the Department of Defense starts with a clear view of its mission. Its challenge is to recognize its responsibility to safeguard its community stakeholders. This is not an easy balance to achieve. Figure 1 shows the four important dimensions of what we call the Acceptability Diamond:

- The substantive decision: What are the issues from both agency and public viewpoints? How was a technology selected, the schedule established, and the program designed? Does the public have sufficient, timely information to enable them to identify the issues of importance to them? Are they able to get their issues on the agenda and have them addressed?

- The decision-making process: Is the decision-making process clear? Who is making the decision? What decision method is being used? Is it fair? What information is being used as the basis for a decision? Has the public been given a genuine opportunity for involvement and to influence the decision?

- Relationships: How do people feel that the agency has treated them? Has the agency demonstrated in previous actions that the well-being of the community is a factor in its decisions or that it will be a factor influencing future decisions? Responsiveness and openness in providing information are important contributors to good relationships. Such relationships give each party, including the public, "standing," i.e., members of the public are affirmed as individuals and treated with respect. With such standing, people expect that all participants will adhere to certain norms that are assumed to be valid, such as honesty and openness.

- Accountability: Does the agency take responsibility for disclosure of pertinent information and the results of its processes and decisions? Do the officials demonstrate by their behavior that they fulfill their commitments? Are there mechanisms to assure that responsibilities and commitments are met? Keeping technical commitments is only part of accountability. Demonstrating commitment to the non-technical concerns of the public means that outcomes are not only technically effective but also promote community health, safety, economic stability, and well-being. 
These dimensions and their relevance for the current study are discussed in more detail in Section 1 of the report.

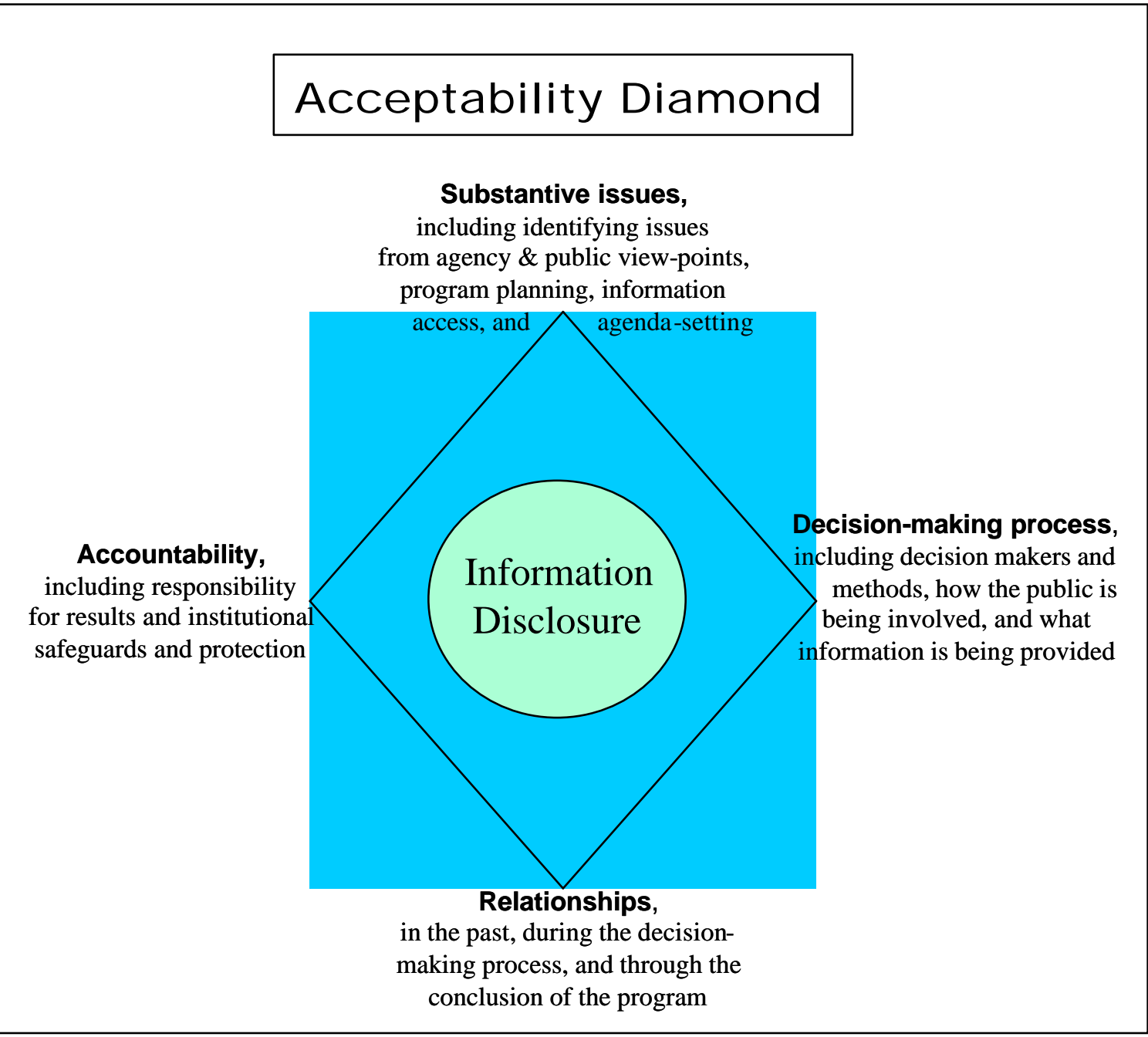

\section{Figure A.1 The Acceptability Diamond}

The important feature of the Acceptability Diamond is its indivisibility. That is, people experience their interaction with an agency (or company) and with public participation programs as all-of-a-piece, not as separate pieces. The four dimensions are closely interrelated. Different stakeholders often tend to rank the four differently, sometimes stating that, if one aspect they consider important is effective, the other dimensions will follow naturally. However, most agree that all facets are essential to a successful program. For example, a well-designed decision process, following the many precepts laid down in the literature, will fail miserably if relationships are characterized by domination on the one hand and mistrust on the other, if the substantive issues are understood differently by agency staff and community members, or if institutional safeguards are considered inadequate by the participants. Beierle (1998) provides a good example of getting only the decision-making process right in discussing the breakdown of a public participation effort in Fort Ord, California. It is not enough to get one, two, or 
three of the dimensions right if the fourth is wrong. There is spillover from any one to all the others.

This viewpoint leads us in the direction of an adequate theory of public participation at the same time that it leads us away from the foci on the individual decision process and on the standard risk framework. The decision process is set firmly in its place as only one (although important) dimension of public participation programs that may have many different goals and types of activities. Similarly, the standard risk framework becomes one of many frameworks that people bring to the interactions in a public participation program (Bradbury 1998, 1989). The proposed theory underscores the community context in which government agency programs operate and the need for the agency to take into consideration community interests, as well as its own mission.

\section{The Theory of the Public Sphere and Communicative Action}

Public participation brings many different viewpoints together. They are usually categorized into two types: the scientific, rational, risk management orientation of the agency or business and the community, everyday-centered viewpoint of the public. ${ }^{30}$ The clash of these two viewpoints can be illuminated by examining the theoretical insights of Habermas (1991[1962], 1984, 1987). His terms for the two viewpoints are, respectively, "system" and "lifeworld." Habermasian discussions of these viewpoints, the "public sphere," and "communicative action" can help program managers understand what is going on in the interaction within the public participation process, as well as helping them evaluate and improve the process.

System and lifeworld viewpoints can communicate meaningfully in the public sphere, where private citizens come together to enga ge government and authority in debates about how they are being and should be governed. The public sphere is "the place where an intelligible unity of the empirical ends of everyone was to be brought about, where legality was to issue from morality" (Habermas 1991[1962]:115). In the public sphere those in the lifeworld speak back to those in the system to develop or correct policies and laws that affect the lifeworld.

Effective public participation thus fits Habermas' definition of the public sphere. In the public sphere of public participation, the private citizens of the lifeworld challenge the system to accommodate their concerns for health, safety, employment, and environmental preservation/restoration. From the system point of view, these are matters for quantitative risk analysis, soil and water measurements, and medical data. Initially, at least, private citizens have difficulty understanding the technical language and concepts and relating their concerns about pollution and health to the system-generated information. How can a public participation program operate successfully, given these differences? Its effectiveness will depend on communication between the two viewpoints.

\footnotetext{
${ }^{30}$ Actually, of course, this is a simplistic categorization; for example, the "community" includes workers, businesses, local government, environmental groups, and so on - each of whom has a different viewpoint.
} 
The problems of communication in public participation programs are well known. The technical explanations and analyses of officials have baffled and angered laypersons who are interested in immediate health and safety concerns. The reaction of federal agencies has often been to answer with more of the same technocratic language, perhaps also claiming that the moral discussion the public seems to want is beyond their purview (see, e.g., Bradbury, et al. 1994). In terms of the theoretical framework we have been discussing, the viewpoints of the system and lifeworld value different kinds of knowledge. Habermas' division of society into system, lifeworld, and public sphere corresponds to a distinction among kinds of knowledge and discourse. Different kinds of knowledge belong to the system, the lifeworld, and a space that may be constituted in between the system and lifeworld - the public sphere. This schema allows discussion of codes being used in different ways as the spheres, types, and purposes of knowledge and discourse change.

So-called "objective" knowledge belongs to the system. The purposes of objective knowledge are instrumental - to explain and to control. For example, this kind of knowledge allows us to build bridges and buildings, produce life-enhancing consumer goods, and provide widespread media dissemination of news and information. The system, with its objective knowledge, is the sphere of the state (political) and the market (economic). The welfare state has also extended the reach of system knowledge into society and individual lives, with benefits to its citizens (in health care, for example).

In contrast to objective knowledge, knowledge related to everyday life belongs to the lifeworld. In their everyday lives, people seek to understand what happens in their lives (what is said and what is done). They act as private persons, members of households, with emotional and social ties to each other. They are responsible for each other and take care of one another; their interests are personal and familial. In these roles, people are the "public" in public participation programs.

Critical knowledge, which emerges in the public sphere, has its roots in the lifeworld but claims a vantage point from which to discuss and debate the system. In other words, people use their everyday concerns and ideas (sense-making knowledge) to examine and critique the "objective" orientation and activities of the government. As they do this, they literally create the public sphere. The dual nature of this public sphere - that it brings together lifeworld and system, everyday and objective knowledge - defines it. Furthermore, the public sphere must be, in principle, open to everyone who wishes to engage in the debate.

A complicating factor in public participation programs is that they are often set up and supported by the agency (or company) - in other words, by a representative of the system. In this case, the programs themselves are not the public sphere. In order for a public sphere to be created, the community must articulate its own viewpoints and critique the organization that is supporting the program - not an easy accomplishment for either the system (supporting critique of itself) or the lifeworld (critiquing its sponsor). 
It is not sufficient to construct only technical understandings (objective knowledge) about how natural systems operate (extent of contamination, dose delivered, pharmokinetic effects, etc.). It is also necessary to articulate and develop the concerns that people have about effects government activities have on their lives (health, safety, jobs, etc.) and to construct mutual understandings about the proper roles and behavior of all parties involved (what would happen if...?). In other words, we need to understand the science of the problem, but we also need to be clear about the expectations each party has for the other. This would include contingency plans in the event that unexpected consequences arise. For instance, in the Army's plan to incinerate chemical weapons, one contingency plan is how evacuation orders will be issued and overseen in the event of a dangerous leak or accident.

Habermas' theory of communicative action provides a framework in which we can understand how the interests and knowledge of the system and those of the lifeworld can be debated in public participation programs, producing critical knowledge that develops understandings on issues such as safety, extent of contamination, cleanup, and methods. Communicative action takes place in the public sphere (for example, in public participation programs), where representatives of the lifeworld and the system come together to debate public issues.

Habermas treats communication as action oriented toward understanding. ${ }^{31}$ Communicative action may serve to establish and renew interpersonal relations, to represent states and events, and to express the speaker's experience. Speakers thus make validity claims that can be judged on the basis of whether they are morally correct, factually true, and subjectively sincere. For example, if a scientist shows data about the probability of risk from exposure, he or she is making a claim about the truth of the statements. Because the scientist knows that such statements can be contested, he or she frames the statements to be acceptable. It is in this sense that speech is oriented toward understanding. Similarly, if a citizen contests the scientist's claim, there is a counter truth claim that the citizen is hoping will be accepted.

To take another example, a member of the public may, in commenting on a proposed decision about a contaminated site, express outrage or a sense of betrayal. Again, the orientation is toward achieving understanding, in this instance understanding of the lifeworld meaning of a system decision. Here the claim involves not only truth but also moral correctness and sincerity. In fact, all communicative speech acts involve all these claims. The scientist who strives for objectivity is also asserting the morality of the scientific findings as well as personal sincerity.

The theory of communicative action paints a picture of an ideal speech situation, where participants are competent listeners and speakers, working toward a rational consensus. The ideal speech situation provides both a standard for participants and a model to be

\footnotetext{
${ }^{31}$ This contrasts with strategic action, which is mediated by power and money towards instrumentally achieving material ends. In Webler's (1995) account of public participation gone wrong, Habermas might diagnose a case of strategic action rather than communicative action. That is, each party to the discussion wanted to force their viewpoint on the other rather than both trying to come to an understanding.
} 
used in design and evaluation of public participation programs. It is an implicit standard, for instance, when people accuse each other of blocking behavior or making ad hominem attacks or arrogance because such accusations presuppose higher standards for communication than those they see in action. It is a model when evaluators judge the effectiveness of public participation activities and plan their improvement.

"Coming to an understanding" is then the goal of communicative action. This means that the participants reach an agreement that recognizes the validity of what the speakers say. Furthermore, agreement to one type of claim (e.g., truth) often implies agreement with the other two implicitly raised claims (e.g., morality and sincerity).

\section{The Public Sphere and the Acceptability Diamond}

In order to evaluate the Acceptability Diamond framework, this section examines it in light of Habermas' theories about how people debate from the different viewpoints of system and lifeworld - in the case of DOE-EM public participation programs, the different viewpoints arising from DOE's mission and community concerns. The consonance found between the theories about the public sphere and communicative action, on the one hand, and the empirically derived Acceptability Diamond, on the other, allows the building of a theoretically grounded framework that may be used to evaluate DOE-EM public participation programs.

For the realization of the public sphere and communicative action in DOE-EM public participation programs, each element of the Acceptability Diamo nd can be evaluated within a site's unique circumstances. Specifically,

- The substantive program issues and impacts are identified and examined in a way that identifies and takes into consideration community interests as well as agency mission;

- The decision-making process is inclusive, egalitarian to the extent possible within the framework provided by the U.S. system of representative government, and otherwise satisfactory to all participants;

- Relationships are currently open with a degree of respect and mutual trust; past issues have been resolved;

- Accountability is provided in explicit terms.

Again, these elements are analytically separate but experienced together. A person does not separate a sense of satisfaction with the decision process from the conviction that the issues were appropriately defined, relationships are open and respectful, and the system will be accountable for its actions. Public participants "relate simultaneously to something in the objective, the social, and the subjective worlds, even when they thematically stress only one of the three components in their utterance" (Habermas 1987[1981]:120). Society, after all, is simultaneously a system and a lifeworld.

Furthermore, communicative acts occur in the context of history, place, and other lifeworld conditions. The nuclear facility is only one of the many concerns that people 
are dealing with. The subject for discussion, say of a facility, has a "horizon" that shifts as new information or contingencies appear on the scene (Habermas 1987[1981]:122). The horizon could be far away if no threat is perceived, but it could suddenly become close if new information indicates a health risk, for example. Decisions about a facility depend upon a host of societal norms and other salient characteristics of individual and social lives.

Figure A.2 integrates Habermasian theory and the acceptability diamond (see Webler, et al. 2001). The diamond appears as the public sphere, the space in which people strive for understanding. But to do so, the y need to engage in multiple speech acts oriented toward understandings that encompass claims to factual truth, morality, and sincerity. The substantive issues, decision-making process, relationships, and accountability must be congruent. Claims that data are scientifically accurate also carry claims that the right course of action is being put forward and that the scientist - backed by the agency - is sincerely recommending it. The audience evaluates and responds to all three claims together. If the public has a basis for mistrust in past actions, if good faith is in question, the audience response to "the facts" will be negative. Similarly, if the decision-making process is designed as it "should be" (the morality claim) but the substantive issues are not agreed on (the truth claim), the public participation process will likely fail to reflect understanding.

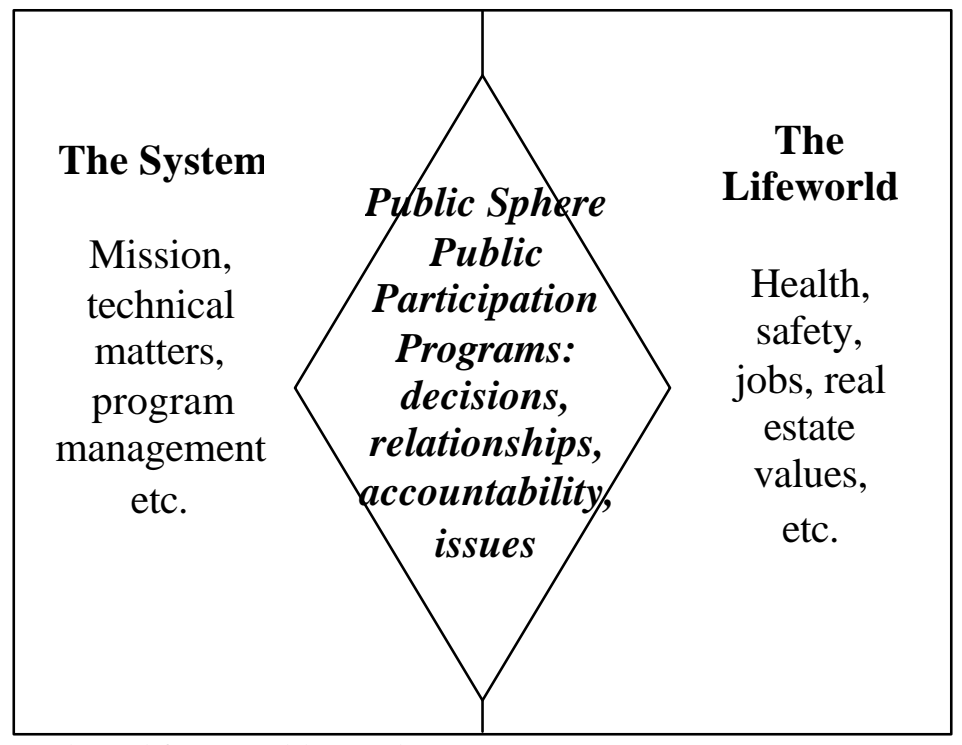

Adapted from Webler et al. 2001.

\section{Figure A.2. The Public Sphere, Where the Lifeworld Critiques the System.}

How do the different viewpoints of system and lifeworld intersect in a public participation program? The knowledge of the system is focused narrowly on technical aspects of effectiveness, efficiency, and safety. From a system perspective the demands 
of the public should be satisfied by the best scientific and technical advice on such matters as parts per million of a pollutant in surface or groundwater, the optimal thickness of a container of toxic waste, and dosimeter measurements. The standpoint of the lifeworld is quite different, centering on human health, economic stability and wellbeing, and trust. In public participation programs, members of the lifeworld adopt a critical stance toward system knowledge and seek resolution of lifeworld issues. In the process of coming to an understanding, problems may be newly identified, reframed, or judged irrelevant to the claims and concerns of public participants.

Substantive Issues: The framing, prioritization and selection of issues to be discussed within public participation programs are the first steps in coming to agreement. By proposing an issue or set of issues, an agency (or business) or its stakeholders warrant that these are "true" issues, i.e., the factual basis for them is accurate and complete; that they are the right issues to tackle, i.e., important and important to the community and not focused solely on an agency's narrow definition of its mission; and that the participants are sincere in their efforts to work toward agreement.

Agenda setting is an ongoing issue in communicative action and in public participation programs. What is discussed - or is not discussed - involves the different "frames" and interests of the lifeworld and system participants. From a system perspective, issues for discussion are technical: what to clean up, when, physical safety, and so on. From a lifeworld perspective, the issues are potential dangers to families, maintenance of ways of life (especially everyday living), and economic issues both personal (will I lose my job?) and community (will local businesses be affected by site funding?). These sets of issues do not necessarily conflict but they are not necessarily complementary, either. If either the agency (or business) or its public have the power to and do set the agenda for public discussion, public participation is no longer communicative action, but instrumental or strategic action. Can issues be identified and defined using critical knowledge to illuminate the lifeworld issues in and around the technical ones? This is an essential and continuing challenge.

Decision-Making Process: The way people are treated, the types and numbers of opportunities for them to give input, and the transparency of the steps in the process are important for communicative action to be effective. Regulations such as those associated with the National Environmental Protection Act (NEPA), Environmental Impact Statements (EISs) and the Comprehensive Environmental Response, Compensation, and Liability Act (CERCLA) prescribe highly articulated processes that are intended to maximize public participation in cleanup and other activities. However, these opportunities for public participation may be implemented in a pro forma manner. That is, the process may be perceived by public stakeholders as a claim to truth, without explicit accompanying claims of morality and sincerity.

Even in relatively open processes such as citizen advisory boards, real opportunities to participate may be limited by the barriers or technical language, formal strictures, inconveniently scheduled meetings, and lack of feedback. A "fair" process - that is, a 
process conducted in strict compliance with the regulations - may be an extremely unwelcoming one.

It is a challenge for public agencies to conduct a process that is fair, open, and genuinely seeks public partners in "coming to an understanding." Each of the communication claims may be open to question. Does the agency really want to communicate the whole truth about a site? Does it want to do the right thing (e.g., at any cost)? And are agency representatives sincere in wanting input from the public, or would they rather make decisions within their own circle? For many of the regulatory processes, the agency is the final decision maker, but what are the implications of this for public input?

Relationships: A strategy often used in public participation programs is to focus on personal relationships of honesty and respect. Agency (or company) officials and members of the community are encouraged to get to know one another as people; the public relations officer has a list of personal contacts to call when issues arise or announcements will be made; continuity of public participation staff is seen as important. When these efforts reflect sincerity (and morality and truth) claims that are backed up over time, personal relationships become an important part of public participation programs. Grunig and Grunig (2001:24), in their guidelines for evaluating public affairs programs, state that "the degree to which a public perceives that it has a communal relationship with an organization is perhaps the purest indicator of the success of the public relations management function."

However, cultivation of personal relationships should be guided by two important caveats. First, the relationships must be based on communicative acts between and among equals, not strategic/instrumental action dominated by one of the actors. Second, relationships so formed are only part of an effective program: issues must also be identified and agreed on, decisions made, and agreements kept. The good feelings that come with socializing are not enough.

People have both needs and expectations from relationships, no matter how personal or impersonal. ${ }^{32}$ First, they need recognition (Honne th 1995) from the others in the relationship of their rights, their acceptance in society, and the validity of their lifestyles. All three forms of recognition are necessary for dignity or integrity. When people are so recognized, they have "standing" in the relationship; they are affirmed as individuals and treated with respect. Second, people expect that all participants will adhere to certain norms that are assumed to be valid. If these norms (honesty, for example) are violated, the result is moral indignation and a crisis in communication.

In important ways, the development of relationships involves the negotiation of meaning - and hence the personal value - in speech acts. Lakoff and Johnson 1980:232) describe the process:

When it really counts, meaning is almost never communicated according to the CONDUIT metaphor, that is, where one person

\footnotetext{
${ }^{32}$ Some argue that highly personal relationships, with their expectation of personal "favors," interfere with the need to come to good, rational decisions in public participation activities.
} 
transmits a clear proposition to another by means of expressions in a common language, where both parties have all the relevant common knowledge, assumptions, values, etc. When the chips are down, meaning is negotiated: you slowly figure out what you have in common, what it is safe to talk about, how you can communicate unshared experience or create a shared vision. With enough flexibility in bending your world view and with luck and skill and charity, you may achieve some mutual understanding.

Accountability: Reciprocity, the principle that any participant can challenge another participant's claims or assertions, implies that the participants mean what they say, are as good as their word, and will correct missteps and failures to act. Further, public agencies are expected to act, through the individuals who are involved in the public participation process, in a socially responsible manner. These strong claims concerning sincerity and morality are coupled with the truth of previous evidence of accountability (or abdication of responsibility, as the case may be). Accountability thus reverberates throughout the other dimensions of the Acceptability Diamond.

Here also the differences among various types of knowledge clarify sources of issues connected with accountability. As critical knowledge emerges from the public participation process, the willingness and capability of the system to make and keep commitments to the community becomes a matter of importance. Keeping technical commitments is only a part of accountability. Demonstrating commitments to the nontechnical concerns of the public means that outcomes are not technical but promote health, safety, economic stability and well-being. Furthermore, when outcomes - even technically successful ones - do not address community concerns, the agency (or business) is accountable to its public.

Some participants in this study argued that good relationships will guarantee accountability; others argued that accountability will guarantee good relationships. These different rankings again indicate that at least these dimensions of the Acceptability Diamond are closely interrelated and are both necessary for a program seen as effective by different stakeholders. Similarly, accountability is an indispensable part of identifying substantive issues and the decision-making process, since coming to agreement on an issue includes at least implicit claims that all involved contribute to a resolution and the resolution will satisfy the needs and requirements that have been articulated.

The accountability of an agency with responsibility for national security is problematic. Some claim that security concerns can supersede the ordinary expectation that the immediate well-being of people who live around a facility will be the paramount concern. Or the risks entailed by national security and those to community well-being may have to be balanced. Furthermore, at sites that have several missions, the public participation may not "cover" all the missions; that is, the agency may only be accountable through its public participation programs for certain aspects of what happens on the site. These system- versus-lifeworld issues need to be recognized and addressed in DOE's public participation programs, although they may not be entirely resolved. 


\section{Multi-Dimensional Public Participation Programs}

We have defined and discussed four dimensions - relationships, accountability, decisionmaking processes, and substantive issues - that together determine the success or failure of a public participation program. The criteria for effectiveness in each dimension and for the whole program, articulated in the second paragraph of the previous section, come from Habermas' ideas about communication action: participants oriented toward coming to an understanding rather than dominating; open debate about the truth, morality and sincerity of claims made in the discussion; and the capability of "ordinary" people to challenge the claims of technical and scientific systems. If the criteria of communicative action are met across the dimensions of the acceptability diamond, the public participation program will be effective.

These dimensions (from the acceptability diamond) and criteria (from communicative action) give us also a framework for evaluating public participation programs. In each dimension we can apply the communicative action criteria and develop causal analysis that points to strengths and weaknesses of the program. That is the objective of this report.

\section{References}

Beierle, Thomas C. 1998. Public Participation in Environmental Decisions: An Evaluation Framework Using Social Goals. Discussion Paper 99-06, Resources for the Future, Washington, DC.

Bradbury, Judith A. 1998. Expanding the rationale for analysis and deliberation: looking beyond Understanding Risk. Human Ecology Review 5(1), 42-44.

Bradbury, Judith A. 1989. The policy implications of differing concepts of risk. Science, Technology, \& Human Values 14(4), 380-399.

Bradbury, J., and K. Branch. 1999. An evaluation of the effectiveness of local sitespecific advisory boards for U.S. Department of Energy Environmental Restoration Programs. Report PNNL-12139. Washington, DC: Pacific Northwest National Laboratory.

Bradbury, J., K. Branch, J. Heerwagen, and E. Liebow. 1994. Community Viewpoints of the Chemical Stockpile Disposal Program. Report prepared by Battelle Pacific Northwest Laboratories, Washington, DC.

Daniesl, Seven E and Gregg B. Walker. 2001. Working through Environmental Conflict: The Collaborative Learning Approach. Praeger, Westport, CT.

Grunig, James E. and Larissa A. Grunig. 2001. Guidelines for Formative and Evaluative Research in Public Affairs: A Report for the Department of Energy Office of Science. Department of Communication, University of Maryland, College Park. 
Guglielmo, Aimee T. 1998. Nuclear Waste, Democracy, and Risk: A Procedural Evaluation of the Columbia River Comprehensive Impact Assessment. Master's Thesis. University of Washington, Spokane. Also available at http://www.sma.washington.edu/people/students/thesis/guglielmo/Index.html

Habermas, Jürgen. 2001. Contributions to a discourse theory of law and democracy. In The New Social Theory Reader, Steven Seidman and Jeffrey C. Alexander (eds). Routledge, London.

Habermas, Jürgen. 1991[1962]. The Structural Transformation of the Public Sphere: An Inquiry into a Category of Bourgeois Society. Translated 1989 by Thomas Burger. MIT Press, Cambridge, MA.

Habermas, Jurgen. 1987. The Theory of Communication Action, Volume 2: Lifeworld and System. Trans. Thomas McCarthy. Beacon Press, Boston.

Habermas, Jurgen. 1984. The Theory of Communication Action, Volume 1: Reason and the Rationalization of Society. Trans. Thomas McCarthy. Beacon Press, Boston.

Honneth, Axel. 1995. Integrity and disrespect principles of a conception of morality based on a theory of recognition. In The Fragmented World of the Social: Essays in Social and Political Philosophy, Charles W. Wright (ed). State University of New York Press, Albany.

Lakoff, G. and M. Johnson 1980 Metaphors We Live By. University of Chicago Press, Chicago.

Renn, Ortwin and Thomas Webler. 1995. Title of essay. In Fairness and Competence in Citizen Participation: Evaluating Models for Environmental Discourse, Ortwin Renn, Thomas Webler, and Peter Wiedemann (eds). Kluwer Academic, Dordrecht.

Tuler, Seth and Thomas Webler. 1999b. Voices from the forest: what participants expect of a public participation process. Society \& Natural Resources 12, 437-453.

Webler, Thomas. 1995. "Right" discourse in citizen participation: an evaluative yardstick. In Fairness and Competence in Citizen Participation: Evaluating Models for Environmental Discourse, Ortwin Renn, Thomas Webler and Peter Wiedemann (eds). Kluwer Academic Publishers, Dordrecht.

Webler, Thomas, Elizabeth Malone, Kristi Branch, and Judith Bradbury. 2001. "Moving Toward a Theory of Evaluating Public Participation in Environmental DecisionMaking." 2001. In Proceedings of the $6^{\text {th }}$ Biennial Conference on Communication and the Environment, Marie-France Aepli, John W. Delicath and Stephen P. Depoe. July 27-30, Cincinnati, $\mathrm{OH}$.

Webler, Thomas and Seth Tuler. 2000. Fairness and competence in citizen participation: theoretical reflections from a case study. Administration \& Society 32(5), 566-595. 


\section{ApPendix B: DOE-EM's Public Participation POLICY ${ }^{33}$}

Definitions: Public Participation is the process by which the views and concerns of the public are identified and incorporated into the Department of Energy's (DOE) decision making. Public participation includes:

- Identifying public concerns and issues;

- Providing information and opportunities for the public to assist DOE in identifying EM-related issues and problems and in formulating and evaluating alternatives;

- Listening to the public;

- Incorporating public concerns and input into decision making; and

- Providing feedback on how decisions do or do not reflect input received.

Public means any affected or interested party, including, but not limited to:

- Representatives of Indian Nations, State and local governments and agencies;

- Congress;

- Other Federal Agencies;

- Review bodies;

- Community groups;

- Environmental and other interest groups;

- Business;

- Labor;

- Academia;

- Professional and technical contractors; and

- Members of the general, unaffiliated public.

Although included as part of the "public," DOE recognizes that Indian Nationals, and State and local governments also have unique roles and responsibilities as government entities.

Public Information supports public participation through the provision of clear, objective, and timely information to enable the public to effectively participate in the EM program. Information products, such as fact sheets, brochures, newsletters, and exhibits,

\footnotetext{
${ }^{33}$ Last updated 9/17/98. The policy is currently being revised.
} 
should identify the means by which the public can comment on and participate in EM planning, design, and implementation activities.

\section{Policy}

The Environmental Management (EM) program is committed to fulfilling the DOE's policy to conduct its programs in an open, responsive, and accountable manner. The public will have the opportunity to participate in the EM decision-making process for program planning, design, and implementation. It is EM's policy to support an aggressive, substantive, EM-wide public participation program in which the public is provided with accurate, complete, and timely information and early, meaningful participation opportunities. As the lead agency for its environmental management activities, DOE retains decision-making responsibility and accountability.

\section{EM Public Participation Goals and Objectives}

EM's overall goal is to create an open and accessible decision- making process that results in decision that are technically and economically feasible, environmentally sound, health and safety conscious, address public values and concerns, and can be implemented. Providing for public participation in the decision-making process is one key means to achieve this goal.

EM's public participation general objectives include:

- Soliciting the public's help in identifying EM-related problems and issues and environmental, economic, social, and cultural values that relate to those problems and issues.

- Soliciting the public's involvement in identifying a full range of alternative approaches for addressing those problems and issues, facilitating the resolution of conflict, and working toward the development of broad-based consensus, both on EM's objectives and on how to achieve those objectives.

- Increasing public understanding of the complex environment in which DOE operates; the legal, regulatory, political, technical, funding, and resource constraints it faces; and the need to balance a variety of interest and considerations.

- Coordinating, integrating, and communicating information about EM public participation activities such that the public is not confronted with multiple, overlapping, disconnected participation opportunities.

- Providing a range of EM public participation opportunities tailored to meet the needs and interests of various segments of the public.

- Providing the public with timely feedback on how and why their input was or was not incorporated into decision making.

- Fulfilling the letter and the spirit of legal, regulatory, negotiated, and policy requirements of the National Environmental Policy Act, the Resources 
Conservation and Recovery Act, the Comprehensive Response, Liability and Compensation Act and the Federal Facility Compliance Act. 


\section{APPENDIX C: Field Visit Protocol}

\section{Protocol to Guide Public Participation Discussions}

\section{Participation Background}

[Show list of activities at the site]

1. Background information:

a. Participation activities in which participant has participated over the past year or two

b. Type of participation in those activities

[Probe: duration, frequency, intensity, role]

2. Of these activities ::

a. Which is he/she aware of

b. Which are viewed as important/helpful? Why?

c. Which are viewed as unimportant/unhelpful? Why?

\section{Participation at the Site}

3. Do all interested stakeholders have opportunities to participate? If not, who is being overlooked/left out? Why? What could be done about this?

4. What affects peoples' willingness to participate?

[Probe for possible causes/challenges to participation, e.g., time, technical complexity]

5. Has anything been done about this?

6. How does the technical nature of the issues affect the nature of public participation at the site?

\section{Cross-Site Participation}

7. Have you participated/discussed participation issues with members of the public at other DOE sites? How? Has this been helpful/not helpful? Why or why not?

\section{Acceptability Diamond Components Discussion}

[EXPLAIN THAT WE ARE GOING TO ASK THEM ABOUT FOUR DIMENSIONS THAT PREVIOUS RESEARCH HAS SHOWN AS BEING IMPORTANT TO AN EFFECTIVE PUBLIC PARTICIPATION PROGRAM]

\section{Substantive Issues}

8. How well does the respondent think DOE-EM is doing in addressing the site issues of greatest importance to him/her and the community [or other stakeholders]? 
a. Are the key issues being identified?

b. Are the issues being resolved in a way that is not harmful to the community?

c. How does the respondent think the public participation activities have affected 1) identifying and 2) resolving the important site issues in a way that is not harmful to the community? [Probe for how hard has it been to identify the key issues at the site and clarify stakeholder values and interests in them]

d. Which public participation activities (if any) have been particularly important/unimportant in helping identify and clarify key site issues? Why?

\section{Decision-Making Process:}

9. How well does the respondent think DOE-EM 's decision- making process is working? Why?

10. How does respondent think the public participation activities have (or are):

a. Clarified and explained the basis for site decisions?

b. Ensued that the public has a real opportunity to influence site decisions? [Probe for how hard it has been to obtain the opportunity for the public to influence site decisions]

c. Which public participation activities (if any) have been particularly important in helping clarify and explain the basis for site issues? Why?

d. Which [public participation activities] (if any) have been particularly important/unimportant in providing the public an opportunity to influence site decisions? Why?

[MAKE A TRANSITION EXPLAINING THAT THE FOLLOWING TWO ASPECTS HAVE NOT BEEN AS EXTENSIVELY ADDRESSED IN PREVIOUS RESEARCH]

\section{Relationships:}

11. How does respondent describe the nature of the current relationship between DOE and the community at this site?

12. Explore what respondent means by their answer (e.g., good, poor, etc) and how the current relationship compares to what they think a desirable relationship would be

13. How does respondent think the public participation activities have built (or are building) relationships between DOE-EM and the community at this site? [Probe for how hard it has been/would be to build the desirable relationships between DOE and the community]

14. Which public participation activities (if any) have been particularly important/unimportant in building relationships between DOE-EM and the community? Why? What about building relationships among the different stakeholders? 


\section{Accountability:}

15. How does respondent describe DOE's accountability for its actions and decisions at this site?

16. At this site, what mechanisms provide for accountability? [Probe for mechanisms, such as oversight by regulators, federal regulations, environmental activist groups, media, law suits]

17. How does respondent think public participation has affected/is affecting accountability?

18. Which public participation activities (if any) have been particularly important/unimportant for holding DOE accountable. Why?

\section{Role of Long-Term and Short-Term Public Participation Activities}

19. What does respondent see as the advantages of long-term public participation activities such as the $\mathrm{CAB}$ and Task Forces? What are disadvantages?

20. What about short term activities such as public meetings or workshops about a specific topic or decision? What are the advantages? What are disadvantages?

[Probe for the role of long and short-term activities in the overall program]

\section{Summary Assessment}

21. How does the respondent rate the overall public participation program at this site, in terms of
a. DOE-EM effort?
b. Public effort?
c. Results?
[Probe for underlying reasons]

22. If respondent were a manager with 100 units of public participation resources to allocate, how would he/she allocate them among the four dimensions:
a. Substantive issues - identifying and addressing key site issues
b. Decision making - designing and conducting an effective decision-making process
c. Relationships - building effective relationships
c. Accountability - holding DOE accountable?

23. Does respondent have any other points they would like to make? 